This document was prepared in conjunction with work accomplished under Contract No. DE-AC09-96SR18500 with the U. S. Department of Energy.

\title{
DISCLAIMER
}

This report was prepared as an account of work sponsored by an agency of the United States Government. Neither the United States Government nor any agency thereof, nor any of their employees, nor any of their contractors, subcontractors or their employees, makes any warranty, express or implied, or assumes any legal liability or responsibility for the accuracy, completeness, or any third party's use or the results of such use of any information, apparatus, product, or process disclosed, or represents that its use would not infringe privately owned rights. Reference herein to any specific commercial product, process, or service by trade name, trademark, manufacturer, or otherwise, does not necessarily constitute or imply its endorsement, recommendation, or favoring by the United States Government or any agency thereof or its contractors or subcontractors. The views and opinions of authors expressed herein do not necessarily state or reflect those of the United States Government or any agency thereof. 


\section{IMPACT OF SIMULANT PRODUCTION METHODS ON THE PHYSICAL PROPERTIES OF DWPF SLUDGE BATCH 3 SIMULANT}

Russell E. Eibling

January 2005

Immobilization Technology Section Savannah River National Laboratory Aiken, SC 29808 
WSRC-TR-2004-00578

Revision 0

Key Words:

Rheology, Particle Size, DWPF Sludge

Retention: Permanent

\section{IMPACT OF SIMULANT PRODUCTION METHODS ON THE PHYSICAL PROPERTIES OF DWPF SLUDGE BATCH 3 SIMULANT}

Russell E. Eibling

January 2005

Immobilization Technology Section Savannah River National Laboratory Aiken, SC 29808

Prepared for the U.S. Department of Energy Under Contract Number DEAC09-96SR18500

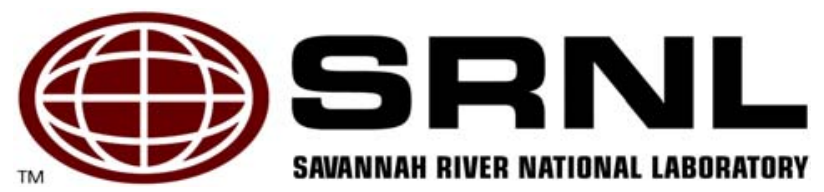


This page was intentionally left blank 


\section{EXECUTIVE SUMMARY}

The research and development programs in support of the Defense Waste Processing Facility (DWPF) and other high level waste vitrification processes require the use of both nonradioactive waste simulants and actual waste samples. The nonradioactive waste simulants have been used for laboratory testing, pilot-scale testing and full-scale integrated facility testing. These waste simulants were designed to reproduce the chemical and, if possible, the physical properties of the actual high level waste. This technical report documents a study of simulant production methods for high level waste simulated sludge and their impact on the physical properties of the waste simulant.

The limited testing performed as part of this program demonstrated that many factors influence the physical properties of a sludge simulant. Factors such as order of chemical addition, mixing (shear) rate and temperature have been shown to modify sludge batches that were compositionally the same. As a result of these tests, the following conclusions were made:

- Precipitating as many species as possible (Al, Fe, Ca, etc.) and heat treating the washed sludge produces a product which nearly matches actual waste yield stress but not consistency. This is the best method for producing a DWPF sludge simulant based upon current testing.

- Inclusion of metals in $\mathrm{MnO}_{2}$ production impacts rheology.

- Precipitation of $\mathrm{Al}$ with the other metals appears to dilute the simulant based on the change in simulant rheology.

- Heat treatment narrows the particle size distribution but has less impact on the rheology of the sludge simulant.

- Heat treatment after precipitation but before washing significantly alters the particle size distribution.

- Shear has a large impact on particle size, which has been shown to impact rheology.

- Compositional changes may have the strongest impact on sludge rheology.

- All eight simulants prepared in this study were rheologically conservative (yield stress and consistency greater than) compared to actual waste. Previous simulants were not necessarily conservative based upon rheology. ${ }^{14}$

The results of the current sludge preparation study indicate that there are many methods of modifying the physical properties of a DWPF sludge simulant. Additional studies are recommended to improve our understanding of the important properties (chemical and physical) of DWPF sludges.

- Measure the impact of solids concentration on actual DWPF sludge feed rheology to provide a better basis for comparison with potential simulants.

- Actual waste particle size information is needed to guide the application of heat treatment or of shear in preparing sludge simulants.

- Heat treatment time/temperature need to be studied since this study only examined one temperature and one time.

- Test all metals precipitated then heat treat followed by crossflow filter washing.

- Test all metals precipitated then crossflow filter washed followed by heat treatment.

- Vary levels of Fe, Al, Mn, Mg, Ni, etc. to study compositional impact on physical properties.

- Perform the DWPF Chemical Process Cell (CPC) process on the modified simulants to determine which property changes remain factors throughout DWPF processing.

- Irradiate sludge simulant to determine the impact of radiation on the physical properties of the simulant. 


\section{TABLE OF CONTENTS}

$\begin{array}{lr}\text { EXECUTIVE SUMMARY } & \text { iii } \\ \text { LIST OF FIGURES } & \text { v } \\ \text { LIST OF TABLES } & \text { vii } \\ \text { LIST OF ACRONYMS } & \text { viii } \\ \text { 1.0 INTRODUCTION AND BACKGROUND } & 1 \\ \text { 2.0 PHYSICAL PROPERTY METHODS } & 3 \\ \text { 2.1 Weight Percent Solids and Density Measurements } & 3 \\ \text { 2.2 Rheology Measurements } & 4 \\ \text { 2.3 Particle Size Measurements } & 5 \\ \text { 3.0 EXPERIMENTAL RESULTS } & 7 \\ \text { 3.1 Compositional Basis the Sludge Batch 3 Simulant } & 8 \\ \text { 3.2 Raw Material Properties } & 10 \\ \text { 3.3 Test 1 Baseline Method } & 10 \\ \text { 3.4 Test 2 High Shear Method } & 18 \\ \text { 3.5 Test 3 Crossflow Filtration Method } & 21 \\ \text { 3.6 Test 4 Heat Treatment before Washing Method } & 26 \\ \text { 3.7 Test 5 Heat Treatment after Washing Method } & 30 \\ \text { 3.8 Test 6 Modified MnO }{ }_{2} \text { Generation Method } & 35 \\ \text { 3.9 Test 7 Coprecipitation of Aluminum Method } & 38 \\ \text { 3.10 Test } 8 \text { Heat Treatment Combined with Coprecipitation of Aluminum Method } & 42 \\ \text { 3.11 Impact of the Sequence of Metal Species Addition } & 47 \\ \text { 3.12 Impact of the Heat Treatment } & 53 \\ \text { 3.13 The Impact of Shear } & 57 \\ \text { 4.0 CONCLUSIONS } & 61 \\ \text { 5.0 RECOMMENDATIONS/PATH FORWARD } & 63 \\ \text { 6.0 REFERENCES } & 65 \\ \text { 7.0 ACKNOWLEDGEMENTS } & 66 \\ \text { APPENDIX A. PARTICLE SIZE DATA FOR INSOLUBLE RAW MATERIALS } & 67\end{array}$




\section{LIST OF FIGURES}

Figure 3-1 Agitators used during Sludge Simulant Preparation ........................................................ 11

Figure 3-2 Particle Size Data for Test 1 Sludge Before Washing ..................................................... 12

Figure 3-3 Impact of Washing on Particle Size Distribution (Volume Basis) for Test 1 Sludge........ 13

Figure 3-4 Impact of Washing on the Particle Size Distribution (Number Basis) for Test 1 Sludge.. 14

Figure 3-5 Cone and Plate Flow Curves for Test 1 Highest Insoluble Solids Loading....................... 15

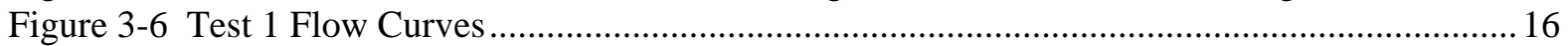

Figure 3-7 Test 1 Yield Stress Dependence on Insoluble Solids.................................................... 17

Figure 3-8 Test 1 Consistency as a Function of Insoluble Solids....................................................... 18

Figure 3-9 Test 2 Particle Size Distribution Based on Volume..................................................... 19

Figure 3-10 Test 2 Particle Size Distribution Based on Number .................................................. 19

Figure 3-11 Test 2 Yield Stress Dependence on Insoluble Solids................................................... 21

Figure 3-12 Test 2 Consistency as a Function of Insoluble Solids.............................................. 21

Figure 3-13 Crossflow Filter Apparatus......................................................................................... 22

Figure 3-14 Particle Size Distribution on a Volume Basis for Test 3 .............................................. 23

Figure 3-15 Particle Size Distribution on a Number Basis for Test 3 ............................................... 24

Figure 3-16 Test 3 Yield Stress versus Insoluble Solids ............................................................... 26

Figure 3-17 Test 3 Consistency as a Function of Insoluble Solids.................................................... 26

Figure 3-18 Test 4 Particle Size Distribution on a Volume Basis ...................................................... 27

Figure 3-19 Test 4 Particle Size Distribution on a Number Basis.......................................................28

Figure 3-20 Test 4 Yield Stress as a Function of Insoluble Solids................................................... 30

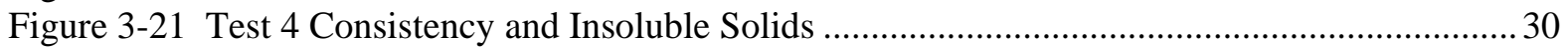

Figure 3-22 Test 5 Particle Size Distribution Volume Basis......................................................... 31

Figure 3-23 Test 5 Particle Size Distribution on a Number Basis.................................................. 32

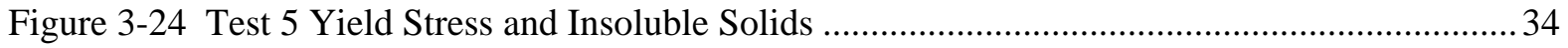

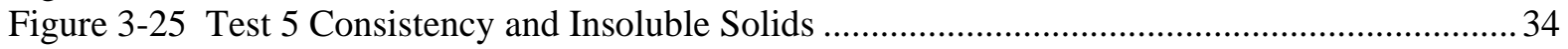

Figure 3-26 Test 6 Particle Size Distribution on a Volume Basis .......................................................36

Figure 3-27 Test 6 Particle Size Distribution on a Number Basis....................................................... 36

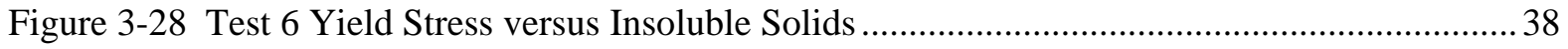

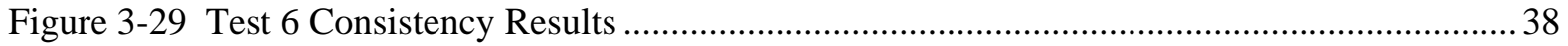

Figure 3-30 Test 7 Particle Size Distribution on a Volume Basis ..................................................... 39

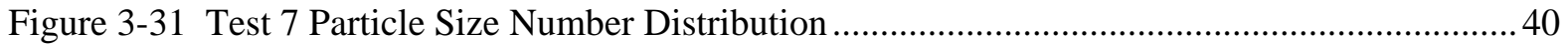

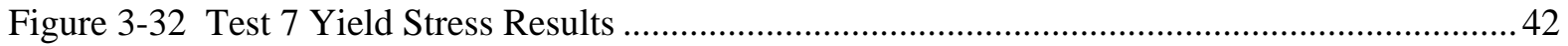

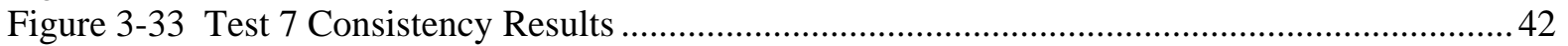

Figure 3-34 Test 8 Simulant Density as a Function of Insoluble Solids ............................................. 43

Figure 3-35 Test 8 Particle Size Volume Distribution ........................................................................ 44

Figure 3-36 Test 8 Particle Size Number Distribution ........................................................................ 44

Figure 3-37 Test 8 Yield Stress as a Function of Insoluble Solids.................................................... 46

Figure 3-38 Test 8 Consistency Results ......................................................................................... 46

Figure 3-39 Comparison of the Particle Size Distribution by Volume for the Modified $\mathrm{MnO}_{2}$ Method

(Test 6) to the Baseline Method (Test 1) ................................................................................... 47

Figure 3-40 Comparison of the Particle Size Distribution by Number for the Modified $\mathrm{MnO}_{2}$ Method

(Test 6) to the Baseline Method (Test 1) .................................................................................. 48

Figure 3-41 Comparison of Test 6 Yield Stress Result with the Baseline (Test 1) and Actual Sludge

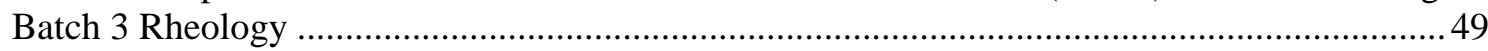

Figure 3-42 Comparison of Test 6 Consistency with Test 1 and Actual Sludge Batch 3 Consistency49

Figure 3-43 All Metals Precipitated Method Impact on Particle Size Volume Distribution................ 50 
Figure 3-44 All Metals Precipitated Method (Test 7) Impact on Particle Size Number Distribution.51 Figure 3-45 Impact of Precipitating All Metals on Yield Stress by Comparison of Test 1 and Test 7

Simulants .....

Figure 3-46 Impact of Precipitating All Metals on Consistency by Comparing Test 7 and Test 1

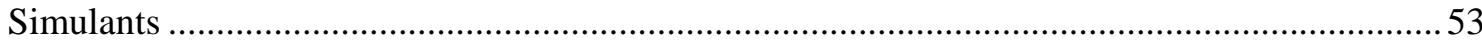

Figure 3-47 Heat Treatment (Before or After Washing) and Particle Size Volume Distribution ....... 54

Figure 3-48 Heat Treatment (Before or After Washing) and Particle Size Number Distribution....... 54

Figure 3-49 Heat Treatment and Yield Stress .................................................................................. 55

Figure 3-50 Consistency and Heat Treatment Methods ....................................................................56

Figure 3-51 Combining Heat Treatment and All Metals Precipitated Versus Yield Stress ................ 57

Figure 3-52 All Metals Precipitated Plus Heat Treated and Consistency .......................................... 57

Figure 3-53 Comparison of Shearing Method versus Particle Size Volume Distribution....................58

Figure 3-54 Comparison of Shear Method versus Particle Size Number Distribution ....................... 59

Figure 3-55 Impact of the Shearing Method on Yield Stress .......................................................59

Figure 3-56 Comparison of Shear Methods and Impact on Consistency …...................................... 60

Figure A- 1 Alumina Particle Size Distribution (Volume Basis) ....................................................68

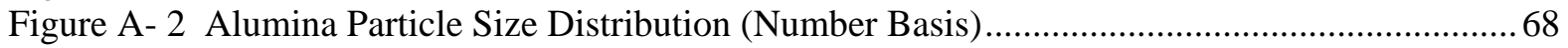

Figure A- 3 Silica Particle Size Distribution (Volume Basis) ............................................................69

Figure A- 4 Silica Particle Size Data (Number Basis) …....................................................................69

Figure A- 5 Tin Dioxide, $\mathrm{SnO}_{2}$, Particle Size Data (Volume Basis) ................................................. 70

Figure A- 6 Tin Dioxide, $\mathrm{SnO}_{2}$, Particle Size Data (Number Basis) ................................................. 70

Figure A- 7 Titanium Dioxide, $\mathrm{TiO}_{2}$, Particle Size Data (Volume Basis)......................................... 71

Figure A- 8 Titanium Dioxide, $\mathrm{TiO}_{2}$, Particle Size Data (Number Basis) ......................................... 71 


\section{LIST OF TABLES}

Table 2-1 Cylindrical Geometry Rheology Program ..................................................................... 4

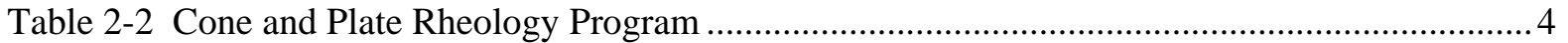

Table 3-1 Simulated Sludge Preparation Methods ..................................................................... 7

Table 3-2 Selected Physical Property Results for the Tank 40 Dip Sample ${ }^{3}$................................... 8

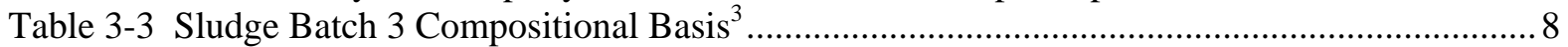

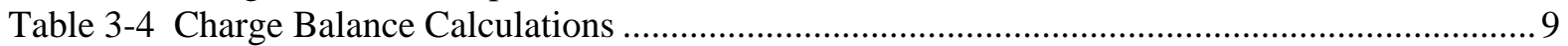

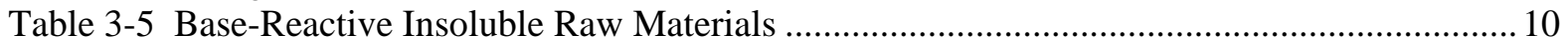

Table 3-6 Particle Size Data Summary for Insoluble Raw Materials................................................. 10

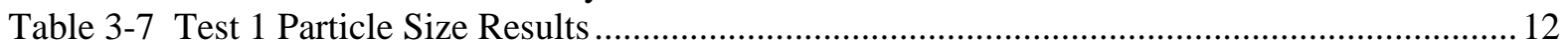

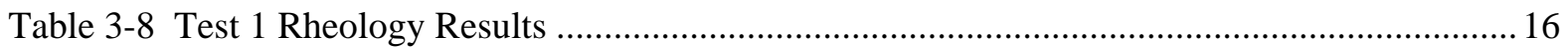

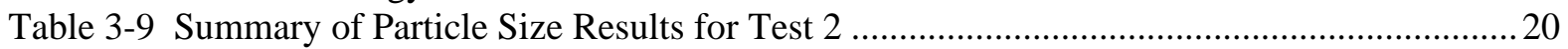

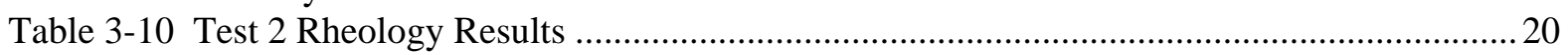

Table 3-11 Summary of Particle Size Results for Test 3 ................................................................ 24

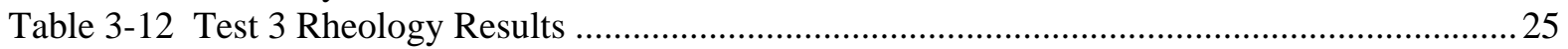

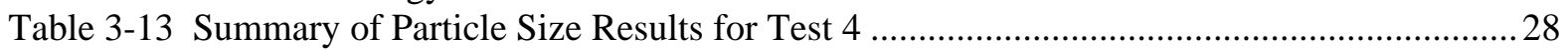

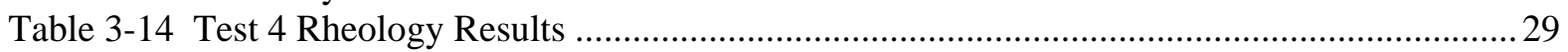

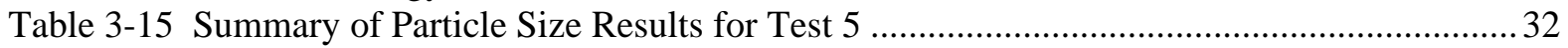

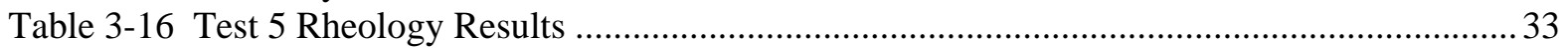

Table 3-17 Summary of Particle Size Results for Test 6 .................................................................. 37

Table 3-18 Test 6 Rheology Results ............................................................................................. 37

Table 3-19 Summary of Particle Size Results for Test 7 .............................................................. 40

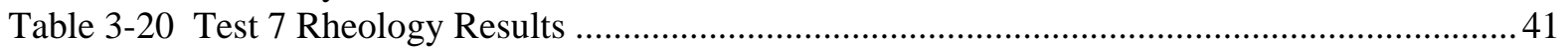

Table 3-21 Summary of Particle Size Results for Test 8 ............................................................... 45

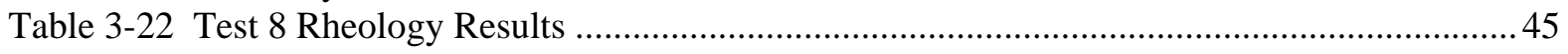

Table 3-23 Particle Size Comparisons …...................................................................................... 50

Table 3-24 Comparison of Average Particle Size Data for the Tests that Examined Shear................ 58 


\section{LIST OF ACRONYMS}

$\begin{array}{ll}\text { cP } & \text { Centipoise } \\ \text { CPC } & \text { Chemical Process Cell } \\ \text { CSSA } & \text { Calculated Specific Surface Area } \\ \text { DS } & \text { Dissolved Solids in supernate } \\ \text { DWPF } & \text { Defense Waste Processing Facility } \\ \text { IC } & \text { Ion Chromatography } \\ \text { ICP-ES } & \text { Inductively Coupled Plasma - Emission Spectrophotometer } \\ \text { IS } & \text { Insoluble Solids } \\ \text { mPa.s } & \text { milliPascal.Seconds } \\ \text { psi } & \text { pounds per square inch } \\ \text { Pa } & \text { Pascal } \\ \text { SME } & \text { Slurry Mix Evaporator } \\ \text { SRAT } & \text { Sludge Receipt and Adjustment Tank } \\ \text { SS } & \text { Soluble Solids } \\ \text { TIC } & \text { Total Inorganic Carbon } \\ \text { TS } & \text { Total Solids }\end{array}$




\subsection{INTRODUCTION AND BACKGROUND}

The research and development programs in support of the Defense Waste Processing Facility (DWPF) and other high level waste vitrification processes require the use of both nonradioactive waste simulants and actual waste samples. The nonradioactive waste simulants have been used for laboratory testing, pilot-scale testing and full-scale integrated facility testing. These waste simulants were designed to reproduce the chemical and, if possible, the physical properties of the actual high level waste. This technical report documents a study of simulant production methods for high level waste simulated sludge and their impact on the physical properties of the waste simulant.

The sludge simulants used in support of DWPF have been based on average waste compositions and on expected or actual batch compositions. These sludge simulants were created to primarily match the chemical properties of the actual waste. These sludges were produced by generating $\mathrm{MnO}_{2}$ from $\mathrm{MnO}_{4}{ }^{-}$ and manganous nitrate, precipitating ferric nitrate and nickel nitrate with sodium hydroxide, washing with inhibited water and then addition of other waste species. ${ }^{1}$ While these simulated sludges provided a good match for chemical reaction studies, they did not adequately match the physical properties (primarily rheology) that had been measured on the actual waste.

The objective of the project documented in this report was to determine the best method for producing a DWPF simulated sludge based on the physical properties of the sludge. Based on the composition of DWPF Sludge Batch 3 sample, the prepared sludge simulant should have physical and chemical properties that more closely match those measured for actual radioactive Sludge Batch 3 waste samples. In order to determine the best processing method, it was necessary to develop an improved understanding of the impact of various methods of simulated sludge production on the physical properties of simulated sludge. 
WSRC-TR-2004-00578

Revision 0

This page intentionally left blank. 


\subsection{PHYSICAL PROPERTY METHODS}

The physical properties measured during this project include weight percent solids (total solids and total dissolved solids in the supernate), sludge density, sludge rheology and particle size distribution. The methods used to measure each of these properties are described below.

\subsection{Weight Percent Solids and Density Measurements}

The weight percent solids were determined using a Mettler Toledo HR73P Halogen Moisture Analyzer. The HR73P is programmed to heat the sample to $105{ }^{\circ} \mathrm{C}$ and monitor the mass of the sample until the change in mass is less than or equal to $1 \mathrm{mg}$ over a period of 130 seconds. The advantage of this method is that a weight percent solids analysis can be performed in less than 20 minutes while a complete analysis of total solids in the sludge and dissolved solids in the supernate can take less than an hour. The homogenous sample (slurry or liquid) is placed on a glass fiber pad and the pad placed in the HR73P. The HR73P weighs the sample. The initial mass of the sample is the total mass $\left(\mathrm{m}_{\mathrm{tt}}\right)$. The sample is then heated by the infrared radiation from a Halogen lamp to $105^{\circ} \mathrm{C}$ (controlled by a thermocouple) to drive off all the water (assuming mass loss is only from water) and the resulting remaining mass is the total solids $\left(\mathrm{m}_{\mathrm{ts}}\right)$ in the sample. The weight percent (wt \%) total solids (TS) of the sludge was determined using equation [1].

$$
w t \%_{t s}=\frac{m_{t s}}{m_{t t}} \times 100 \%
$$

A sample of the slurry is centrifuged (at 4332 gravities) to obtain the supernate. The resulting supernate is then processed through a $0.45 \mu \mathrm{m}$ filter. A sample of the filtered supernate is then placed on a glass fiber pad, placed in the HR73P, and weighed. The mass of sample used is considered as the total mass of the supernate $\left(\mathrm{m}_{\mathrm{st}}\right)$. The sample is then heated by the Halogen lamp to $105^{\circ} \mathrm{C}$ to drive off all the water and the resulting remaining mass is the total dissolved solids $\left(\mathrm{m}_{\mathrm{ds}}\right)$ in the supernate. The weight percent of total dissolved solids (DS) in the supernate is determined using equation [2]. This analysis assumes that all the solids in the resulting supernate are dissolved.

$$
w t \%_{d s}=\frac{m_{d s}}{m_{s t}} \times 100 \%
$$

The weight percent of insoluble solids (IS) and soluble solids (SS) of the slurry are then calculated by the following conservation of mass relationships, equations [3] and [4] respectively.

$$
\begin{gathered}
w t \%_{i s}=\frac{w t \%_{t s}-w t \%_{d s}}{100 \%-w t \%_{d s}} \times 100 \% \\
w t \%_{s s}=w t \%_{t s}-w t \%_{i s}
\end{gathered}
$$

Density was determined using an Anton Paar DMA 4500 density meter. The density meter determines the density of a sample by measuring the resonant frequency of a sample-filled $U$ tube at a specified temperature. 


\subsection{Rheology Measurements}

Slurry rheology measurements were performed using a Haake RS600 rheometer at $25{ }^{\circ} \mathrm{C}$. The rheometer uses a Searle type measuring system, where both speed and torque are measured at the rotating shaft. The rheometer was operated in the controlled rate mode for all of the data reported in this report. A few measurements were also made in the controlled stress mode when additional clarification of a rheology result was needed. The measuring geometries used were the cylindrical sensor and cup ( $\mathrm{Z} 41 \mathrm{Ti}$ ) for the less viscous slurries and the cone and plate (35 mm Ti/4 degree) for the slurries that were too thick for loading into the cylindrical geometry.

Flow curves were obtained by linearly varying the shear rate from 0 to 500 seconds $^{-1}$ over a given time period. The program details for the flow curves are listed in Table 2-1 and Table 2-2 for the cylindrical and cone geometries respectively. The measured shear stresses for the down flow curves were fitted to the Bingham Plastic rheology model (equation 5) over the shear rate range of 50 to 500 seconds $^{-1}$.

$$
\tau=\tau_{0}+\eta_{0} \dot{\gamma}
$$

$$
\begin{aligned}
& \tau=\text { shear stress, } \mathrm{Pa} \\
& \tau_{0}=\text { Bingham Yield Stress, } \mathrm{Pa} \\
& \dot{\gamma}=\text { Shear rate, } 1 \text { /seconds } \\
& \eta_{0}=\text { Bingham consistency, mPa.sec (or cP) }
\end{aligned}
$$

The upper limit for the fitted shear rate region was adjusted to a lower value of shear rate when necessary to avoid nonlaminar flow conditions.

Table 2-1 Cylindrical Geometry Rheology Program

\begin{tabular}{|c|c|c|}
\hline $\begin{array}{c}\text { Program } \\
\text { Section }\end{array}$ & $\begin{array}{c}\text { Shear rate, } \\
\text { seconds }^{-1}\end{array}$ & $\begin{array}{c}\text { Time, } \\
\text { minutes }\end{array}$ \\
\hline Up Curve & 0 to 500 & 5 \\
\hline Hold Period & 500 & 2 \\
\hline Down Curve & 500 to 0 & 5 \\
\hline
\end{tabular}

Table 2-2 Cone and Plate Rheology Program

\begin{tabular}{|c|c|c|}
\hline Program Section & Shear rate, seconds ${ }^{-1}$ & Time, minutes \\
\hline Initial Hold & 0 & 2 \\
\hline 1st Up Curve & 0 to 500 & 5 \\
\hline 1st Hold & 500 & 2 \\
\hline 1st Down Curve & 500 to 0 & 5 \\
\hline Hold & 0 & 2 \\
\hline 2nd Up Curve & 0 to 500 & 5 \\
\hline 2nd Hold & 500 & 2 \\
\hline 2nd Down Curve & 500 to 0 & 5 \\
\hline
\end{tabular}




\subsection{Particle Size Measurements}

Particle size analysis was obtained by submitting samples to the Analytical Development Section for analysis. Samples were analyzed with a Microtrac S3000 Tri-laser Particle Size Analyzer. This instrument uses angular light scattering techniques to measure the particle size distribution. Preparation of the samples for analysis by the Microtrac consists of dilution of the slurry with water. The particle size distribution can be expressed in terms of a volume distribution, number distribution or area distribution. In this report, the graphical display of particle size data will use the volume and number distributions. The calculated mean of the volume, number and area distributions will also be reported. It should be noted that the mean for a volume distribution is weighted toward the larger particles while the mean for the number distribution is weighted toward the smallest particles. ${ }^{2}$ The calculated specific surface area in meters ${ }^{2} / \mathrm{cm}^{3}$ is based on an assumption of smooth, solid spherical particles and does not reflect porosity or topology of the particles. 
WSRC-TR-2004-00578

Revision 0

This page intentionally left blank. 


\subsection{EXPERIMENTAL RESULTS}

The goal of the project was to determine how the physical properties of a DWPF sludge simulant are impacted by using different preparation methods for producing the simulant. The physical properties that were measured and compared are the sludge rheology and particle size distribution. The different preparation methods being tested included:

- Transition Metal salts inclusion in the manganese dioxide precipitation.

- Precipitation of Aluminum instead of direct addition of aluminum hydroxide

- Thermal treatment (and when to do the treatment).

- Crossflow filtration versus gravity washing and decanting.

- Agitation rate during precipitation.

These tests used only one elemental composition of sludge for the various preparation methods. The composition used is based on DWPF Sludge Batch 3. The tests did not explore the impact of varying the elemental composition on sludge physical properties. Later tests could performed using the optimum conditions chosen from these preparation study tests to examine compositional impact.

The sludge preparation methods to be explored are shown in Table 3-1:

Table 3-1 Simulated Sludge Preparation Methods

\begin{tabular}{|c|l|c|}
\hline $\begin{array}{c}\text { Test } \\
\text { n }\end{array}$ & \multicolumn{1}{|c|}{ Preparation Method } & $\begin{array}{c}\text { Document } \\
\text { Section }\end{array}$ \\
\hline 1 & $\begin{array}{l}\text { Current preparation method - normal agitation without a thermal treatment step } \\
\text { (Baseline case) }\end{array}$ & 3.3 \\
\hline 2 & Current preparation method - with high agitation - no thermal treatment & 3.4 \\
\hline 3 & $\begin{array}{l}\text { Current preparation method - washing using crossflow filtration - no thermal } \\
\text { treatment }\end{array}$ & 3.6 \\
\hline 4 & $\begin{array}{l}\text { Current preparation method - normal agitation with thermal treatment before } \\
\text { washing }\end{array}$ & 3.7 \\
\hline 5 & $\begin{array}{l}\text { Current preparation method - normal agitation with thermal treatment after washing } \\
\text { Preparation including all metals except } \mathrm{Al} \text { and base-reactive solids in the } \mathrm{MnO}_{2} \\
\text { generation step followed by caustic precipitation }\end{array}$ & 3.8 \\
\hline 7 & $\begin{array}{l}\text { Preparation including all metals in the } \mathrm{MnO}_{2} \text { generation step followed by caustic } \\
\text { precipitation at } \mathrm{pH}<10 \text { without a thermal treatment }\end{array}$ & $\begin{array}{l}\text { Preparation including all metals in the } \mathrm{MnO}_{2} \text { generation step followed by caustic } \\
\text { precipitation at } \mathrm{pH}<10 \text { with a thermal treatment step after sludge washing. }\end{array}$ \\
\hline
\end{tabular}


The elemental compositional basis for the sludge (section 3.1) will be described first followed by information on the raw materials (section 3.2) used to make the sludge simulant. Then each test will be described along with the results of comparisons between the tests.

\subsection{Compositional Basis the Sludge Batch 3 Simulant}

The compositional basis for the Sludge Batch 3 simulant used in this study is derived from the composition of two dip samples collected from Tank 40H in March 2004. ${ }^{3}$ The physical properties of the Tank 40H sample are shown in Table 3-2 and the elemental and anion composition of the sample are shown in Table 3-3.

Table 3-2 Selected Physical Property Results for the Tank 40 Dip Sample ${ }^{3}$

\begin{tabular}{|c|c|c|}
\hline Physical Property & Value & Units \\
\hline Density & 1.19 & $\mathrm{~g} / \mathrm{mL}$ \\
\hline Weight \% Total Solids & 20.0 & $\%$ \\
\hline Weight \% Insoluble Solids & 14.8 & $\%$ \\
\hline Weight \% Soluble Solids & 5.2 & $\%$ \\
\hline Bingham Yield Stress & 33 & dynes $/ \mathrm{cm}^{2}$ \\
\hline Bingham Consistency & 5.6 & $\mathrm{cP}$ \\
\hline
\end{tabular}

Table 3-3 Sludge Batch 3 Compositional Basis ${ }^{3}$

\begin{tabular}{|c|c|c|c|c|}
\hline Basis & Measured Solids & Measured Slurry & Slurry & Concentration \\
\hline Analyte & microgram/gram & microgram/gram & g/L slurry & moles/Liter \\
\hline $\mathrm{Ag}$ & 300 & & 0.0714 & $6.62 \mathrm{E}-04$ \\
\hline $\mathrm{Al}$ & 60400 & & 14.3752 & 5.33E-01 \\
\hline $\mathrm{B}$ & 100 & & 0.0238 & $2.20 \mathrm{E}-03$ \\
\hline $\mathrm{Ba}$ & 500 & & 0.1190 & 8.67E-04 \\
\hline $\mathrm{C}_{2} \mathrm{O}_{4}^{-2}$ & & 1033 & 1.2293 & $1.40 \mathrm{E}-02$ \\
\hline $\mathrm{Ca}$ & 16600 & & 3.9508 & $9.86 \mathrm{E}-02$ \\
\hline $\mathrm{Cd}$ & 1900 & & 0.4522 & 4.02E-03 \\
\hline $\mathrm{Ce}$ & 1100 & & 0.2618 & $1.87 \mathrm{E}-03$ \\
\hline $\mathrm{Cl}$ & & 200 & 0.2380 & $6.71 \mathrm{E}-03$ \\
\hline Cr(TOTAL) & 2500 & & 0.5950 & $1.14 \mathrm{E}-02$ \\
\hline $\mathrm{Cu}$ & 300 & & 0.0714 & $1.12 \mathrm{E}-03$ \\
\hline $\mathrm{F}$ & 235 & 235 & 0.2797 & $1.47 \mathrm{E}-02$ \\
\hline $\mathrm{Fe}$ & 194400 & & 46.2672 & $8.28 \mathrm{E}-01$ \\
\hline Gd & 500 & & 0.1190 & 7.57E-04 \\
\hline $\mathrm{K}$ & 3300 & & 0.7854 & $2.01 \mathrm{E}-02$ \\
\hline $\mathrm{La}$ & 400 & & 0.0952 & $6.85 \mathrm{E}-04$ \\
\hline $\mathrm{Li}$ & 400 & & 0.0952 & $1.37 \mathrm{E}-02$ \\
\hline $\mathrm{Mg}$ & 16700 & & 3.9746 & $1.64 \mathrm{E}-01$ \\
\hline Mn & 39500 & & 9.4010 & $1.71 \mathrm{E}-01$ \\
\hline Mo & 500 & & 0.1190 & $1.24 \mathrm{E}-03$ \\
\hline $\mathrm{Na}$ & 120600 & & 28.7028 & $1.25 \mathrm{E}+00$ \\
\hline $\mathrm{Ni}$ & 10900 & & 2.5942 & 4.42E-02 \\
\hline $\mathrm{NO}_{2}^{-}$ & & 15462 & 18.3998 & $4.00 \mathrm{E}-01$ \\
\hline $\mathrm{NO}_{3}^{-}$ & & 10536 & 12.5378 & 2.02E-01 \\
\hline $\mathrm{OH}^{-}$ & & & 7.3132 & $4.30 \mathrm{E}-01$ \\
\hline P (by ICP-ES) & 4300 & & 1.0234 & $3.30 \mathrm{E}-02$ \\
\hline $\mathrm{Pb}$ & 600 & & 0.1428 & $6.89 \mathrm{E}-04$ \\
\hline
\end{tabular}


WSRC-TR-2004-00578

Revision 0

\begin{tabular}{|c|c|c|c|c|}
\hline Basis & Measured Solids & Measured Slurry & Slurry & Concentration \\
\hline Analyte & microgram/gram & microgram/gram & g/L slurry & moles/Liter \\
\hline $\mathrm{PO}_{4}^{-3}$ (by IC) & & 940 & 1.1186 & $1.18 \mathrm{E}-02$ \\
\hline $\mathrm{S}$ & 2900 & & 0.6902 & $2.15 \mathrm{E}-02$ \\
\hline $\mathrm{Sb}$ & 600 & & 0.1428 & $1.17 \mathrm{E}-03$ \\
\hline $\mathrm{Si}$ & 4000 & & 0.9520 & 3.39E-02 \\
\hline Sn & 500 & & 0.1190 & $1.00 \mathrm{E}-03$ \\
\hline $\mathrm{SO}_{4}^{-2}$ & & 1689 & 2.0099 & $2.09 \mathrm{E}-02$ \\
\hline $\mathrm{Sr}$ & 4200 & & 0.9996 & $1.14 \mathrm{E}-02$ \\
\hline $\mathrm{Ti}$ & 200 & & 0.0476 & 9.94E-04 \\
\hline $\mathrm{U}$ & 69900 & & 16.6362 & 6.99E-02 \\
\hline $\mathrm{V}$ & 100 & & 0.0238 & $4.67 \mathrm{E}-04$ \\
\hline $\mathrm{Zn}$ & 300 & & 0.0714 & 1.09E-03 \\
\hline $\mathrm{Zr}$ & 100 & & 0.0238 & 2.61E-04 \\
\hline
\end{tabular}

The elemental composition was based upon inductively coupled plasma emission spectrophotometry (ICP-ES) and the anions were based upon ion chromatography (IC). The hydroxide value was based upon an acid-base titration. The following species were assumed to be present as soluble components only for the purposes of calculating a supernate composition: $\mathrm{Na}, \mathrm{Li}, \mathrm{K}, \mathrm{B}$ (as borate, $\mathrm{BO}_{3}^{-3}$ ), oxalate, chloride, fluoride, hydroxide, nitrite, nitrate, phosphate, and sulfate. Carbonate was expected to be present but not analyzed on the Tank 40 dip samples. Therefore, the concentration of carbonate in the supernate (0.122 moles/liter) was based on DWPF batch 275 Sludge Receipt and Adjustment Tank (SRAT) receipt value of $870 \mathrm{mg} / \mathrm{kg}$ total inorganic carbon (TIC). This value was corrected for a SRAT heel volume of 1500 gallons, transfer line flush water volume of 1000 gallons and sludge batch volume of 6000 gallons and then converted from a Carbon basis to a carbonate basis (60/12). Calculating a charge balance between the anions and cations shows an imbalance of 0.185 moles of excess negative charge.

To correct this imbalance, an additional 0.185 moles of sodium ion was added to the simulant composition. Table 3-4 shows the resulting charge balance results based on the above information.

Table 3-4 Charge Balance Calculations

\begin{tabular}{|c|c|c|c|c|c|c|c|}
\hline \multicolumn{4}{|c|}{ Cations } & \multicolumn{4}{|c|}{ Anions } \\
\hline Species & Charge & Moles/Liter & $\begin{array}{l}\text { Charge, } \\
\text { moles/Liter }\end{array}$ & Species & Charge & Moles/Liter & $\begin{array}{l}\text { Charge, } \\
\text { moles/Liter }\end{array}$ \\
\hline Lithium & 1 & 0.0137 & 0.0137 & Borate & -3 & 0.0022 & 0.0066 \\
\hline Sodium & 1 & 1.43 & 1.43 & Oxalate & -2 & 0.014 & 0.028 \\
\hline \multirow[t]{8}{*}{ Potassium } & 1 & 0.0201 & 0.0201 & Chloride & -1 & 0.0067 & 0.0067 \\
\hline & & & & Carbonate & -2 & 0.122 & 0.244 \\
\hline & & & & Fluoride & -1 & 0.0147 & 0.0147 \\
\hline & & & & Hydroxide & -1 & 0.43 & 0.43 \\
\hline & & & & Nitrite & -1 & 0.4 & 0.4 \\
\hline & & & & Nitrate & -1 & 0.2 & 0.2 \\
\hline & & & & Phosphate & -3 & 0.033 & 0.099 \\
\hline & & & & Sulfate & -2 & 0.0209 & 0.0418 \\
\hline \multicolumn{2}{|c|}{ Total Plus Charge } & & 1.47 & \multicolumn{2}{|c|}{$\begin{array}{c}\text { Total Minus } \\
\text { Charge }\end{array}$} & & 1.47 \\
\hline
\end{tabular}


The only other modification to the composition given in Table 3-3 was to remove the uranium from the composition without adding a chemical substitute. Since this program was based on examining the physical properties of the sludge simulants and all of the simulants were prepared based on the same compositional recipe, the composition of each test batch was not chemically determined as part of the tests.

\subsection{Raw Material Properties}

The raw materials used for the production of the waste sludge were obtained as reagent grade chemicals. In several of the tests, base-reactive insoluble solids were added near the end of sludge preparation.

These compounds were added after caustic precipitation was complete and removal of the excess nitrate anions by sludge washing was also complete. Table 3-5 lists the raw materials used in some of the sludge preparation tests. Since these solids were assumed to remain insoluble (though some dissolution is possible), the initial particle size data is summarized in Table 3-6. The measured particle size distributions for these materials are shown in Appendix A as Figure A- 1 to Figure A- 8.

Table 3-5 Base-Reactive Insoluble Raw Materials

\begin{tabular}{|c|c|c|}
\hline Material & Product Name & Material Supplier \\
\hline Aluminum Oxide, 99.5\% & $\begin{array}{c}\text { Fine Powder, } \\
\text { Cat \#12553 }\end{array}$ & Alfa Aesar \\
\hline Silica, $\mathrm{SiO}_{2}$ & $\begin{array}{c}\text { Silicon(IV) Oxide, 99.5\% } \\
-400 \text { mesh, Cat \#13024 }\end{array}$ & Alfa Aesar \\
\hline Tin (IV) Oxide, $\mathrm{SnO}_{2}$ & $\begin{array}{c}\text { Tin (IV) Oxide,-325 Mesh, } \\
99.9 \%, \text { Cat \#24465-1 }\end{array}$ & Sigma-Aldrich \\
\hline Titanium Dioxide, $\mathrm{TiO}_{2}$ & $\begin{array}{c}\text { Titanium(IV) Oxide, } \\
\text { powder, }<5 \text { micron, 99.9+\%, } \\
\text { Cat \#22422-7 }\end{array}$ & Sigma-Aldrich \\
\hline
\end{tabular}

Table 3-6 Particle Size Data Summary for Insoluble Raw Materials

\begin{tabular}{|c|c|c|c|c|}
\hline $\begin{array}{c}\mathrm{Raw} \\
\mathrm{Material}\end{array}$ & $\begin{array}{c}\text { Volume, } \\
\text { microns }\end{array}$ & $\begin{array}{c}\text { Mean - } \\
\text { Number, } \\
\text { microns }\end{array}$ & $\begin{array}{c}\text { Mean - } \\
\text { Area, } \\
\text { microns }\end{array}$ & $\begin{array}{c}\text { Calculated } \\
\text { Specific } \\
\text { Surface } \\
\text { Area, } \mathrm{m}^{2} / \mathrm{cm}^{3}\end{array}$ \\
\hline $\mathrm{Al}_{2} \mathrm{O}_{3}$ & 104.9 & 23.6 & 85.72 & 0.07 \\
\hline $\mathrm{SiO}_{2}$ & 3.45 & 0.78 & 1.8 & 3.33 \\
\hline $\mathrm{SnO}_{2}$ & 1.31 & 0.45 & 0.84 & 7.12 \\
\hline $\mathrm{TiO}_{2}$ & 3.95 & 0.16 & 0.68 & 8.85 \\
\hline
\end{tabular}

\subsection{Test 1 Baseline Method}

Test 1 served as the baseline method since it approximates the current methods used to generate simulated DWPF sludge feeds. The steps in making the sludge simulant are described below: 
A. Precipitate hydrated manganese dioxide, $\mathrm{MnO}_{2}$, by reacting potassium permanganate and manganous nitrate solution.

B. Dissolve the following metal nitrates in the precipitated $\mathrm{MnO}_{2}$ slurry: $\mathrm{Fe}, \mathrm{Ni}, \mathrm{Zr}, \mathrm{Ce}, \mathrm{Gd}, \mathrm{La}, \mathrm{Ba}$, $\mathrm{Ca}, \mathrm{Cd}, \mathrm{Cr}, \mathrm{Cu}, \mathrm{Mg}, \mathrm{Pb}, \mathrm{Sr}, \mathrm{Zn}$ and $\mathrm{Ag}$

C. Precipitate the metals by the addition of an 8 molar or greater $\mathrm{NaOH}$ solution while maintaining good mixing. The $\mathrm{pH}$ target of the sludge for this addition is between $\mathrm{pH} 10$ and $\mathrm{pH} 11$.

D. Add 0.4 liters of a 0.6 molar sodium carbonate solution per liter of precipitated sludge to convert moderately-soluble hydroxides into less soluble carbonates.

E. Stop mixing and allow the sludge to settle for 24 to 48 hours before decanting and disposing of the clear supernate (high in sodium nitrate solution).

F. Wash the settled sludge by adding 3 volumes of $\mathrm{pH} 11$ inhibited water $(0.001$ molar NaNO2 and $0.001 \mathrm{molar} \mathrm{NaOH}$ ) per volume of settled sludge and thoroughly mixing. Settle overnight and decant the clear spent wash water.

G. Repeat step F two more times.

H. Confirm that the nitrate anion concentration in the supernate is $1000 \mathrm{mg} / \mathrm{L}$ or less. If not add an additional wash water batch and reanalyze.

I. Add the following base-reactive insoluble solids: $\mathrm{Al}_{2} \mathrm{O}_{3}, \mathrm{SiO}_{2}, \mathrm{SnO}_{2}$ and $\mathrm{TiO}_{2}$.

J. Measure the volume of sludge produced. This can be done by measuring the sludge mass and the density of the sludge and calculating the volume.

K. Add the salts necessary to match the supernate concentrations for the soluble species.

The only differences between the baseline method described above and the methods used for previous DWPF sludge simulants are that the earlier sludges only coprecipitated iron and nickel to minimize the potential for loss of metals during the washing steps. The method used in Test 1 increased the number of coprecipitated species, which is expected to be more realistic and included step D to convert species such as $\mathrm{Ca}, \mathrm{Sr}, \mathrm{Mg}$ and $\mathrm{Pb}$ to more insoluble carbonates.

A 2 liter batch of sludge was the targeted test batch and the precipitation was performed in a 4 liter glass reaction kettle (5 inch diameter by 13 inch tall). Temperature was monitored during the precipitation but did not require cooling to maintain the sludge below $50{ }^{\circ} \mathrm{C}$. Agitation was provided by a high shear, Rushton radial flow impeller (3.5 inch diameter) with a 4 blade, 45 degree turbine impeller (3.5 inch diameter) mounted above. Agitation speed was 300 revolutions per minute (rpm). Figure 3-1 shows the agitators used to prepare the sludge simulants in all of the tests.

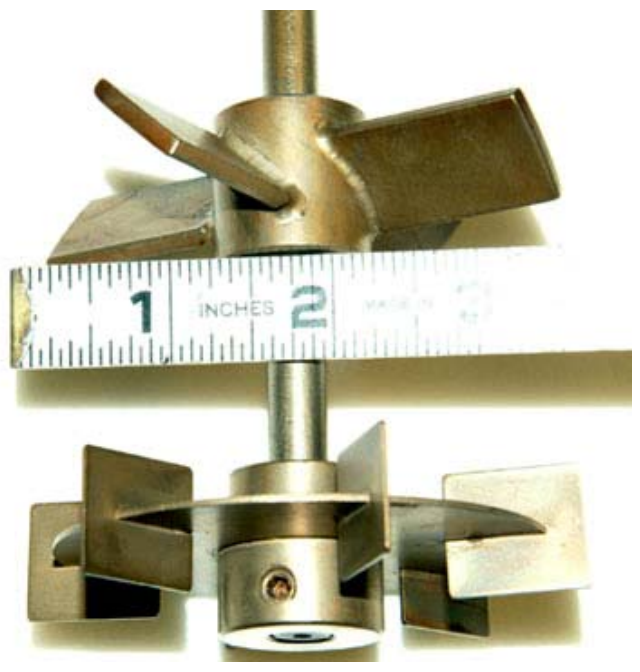

Figure 3-1 Agitators used during Sludge Simulant Preparation 
Samples were collected for rheology and particle size distribution after steps E, F, H and K. Samples with higher insoluble solids loadings were prepared by centrifuging 500 to 600 gram quantities of the sludge simulant using a IEC Centra GP8 centrifuge at $1500 \mathrm{rpm}$ for 40 minutes. Different quantities of supernate were removed to increase the quantity of insoluble solids relative to the soluble solids. The centrifuged materials were then mixed vigorously for 60 seconds to resuspend the insoluble solids and to homogenize the sample. The homogenized sample was then analyzed for $t$ weight $\%$ solids and the rheology measured.

The initial sample of Test 1 sludge before washing (process step E) showed a slight bimodal distribution of particle sizes based on a volume distribution. Figure 3-2 shows that the primary mode for the volume distribution is centered at about 20 to 25 microns and the secondary mode is around 250 microns. The number distribution shows the distribution is skewed towards the smallest particles as expected.

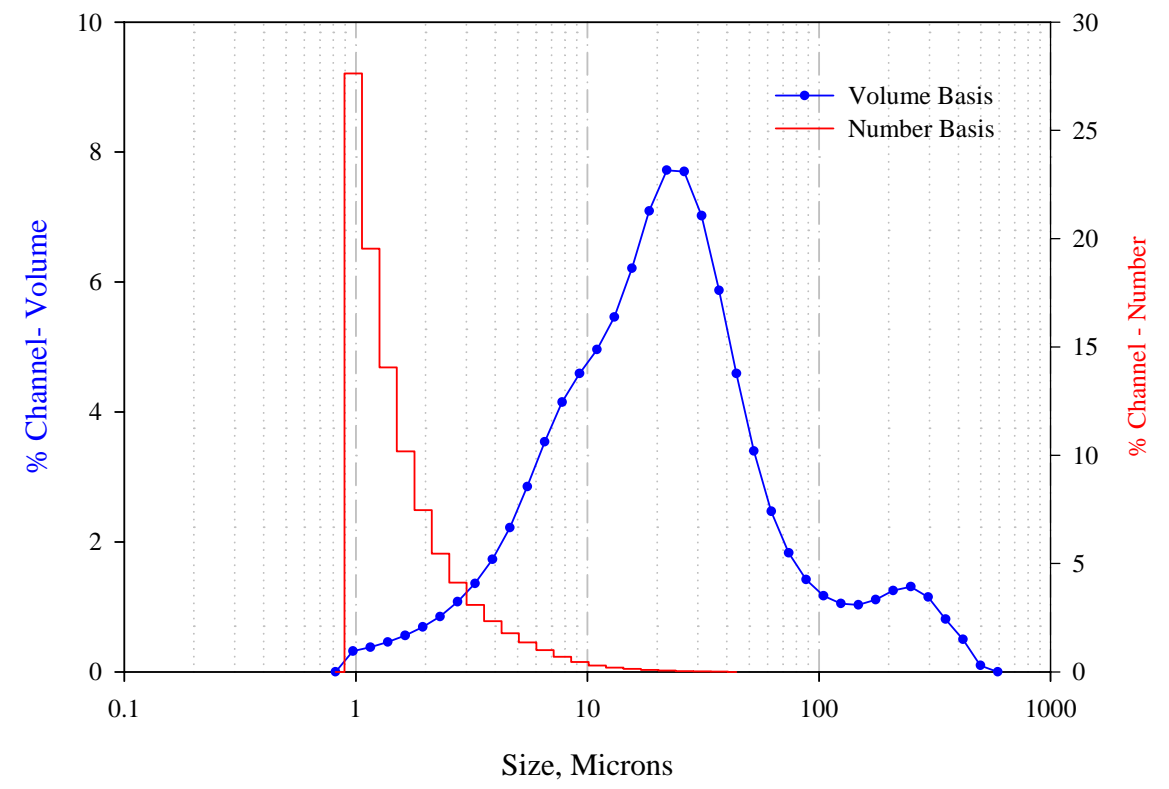

Figure 3-2 Particle Size Data for Test 1 Sludge Before Washing

The calculated mean particle sizes based on the various types of distribution are listed in Table 3-7.

Table 3-7 Test 1 Particle Size Results

\begin{tabular}{|c|c|c|c|}
\hline Measurement & Units & $\begin{array}{c}\text { Process } \\
\text { Step E }\end{array}$ & $\begin{array}{c}\text { Process } \\
\text { Step K }\end{array}$ \\
\hline $\begin{array}{c}\text { Mean, Volume } \\
\text { Basis }\end{array}$ & microns & 38.2 & 33.8 \\
\hline $\begin{array}{c}\text { Mean, } \\
\text { Number Basis }\end{array}$ & microns & 1.7 & 0.75 \\
\hline $\begin{array}{c}\text { Mean, Area } \\
\text { Basis }\end{array}$ & microns & 10.4 & 5 \\
\hline CSSA & $\mathrm{m}^{2} / \mathrm{cm}^{3}$ & 0.58 & 1.2 \\
\hline
\end{tabular}

CSSA is the Calculated Specific Surface Area 
The impact of washing the sludge was a reduction in particle size as seen in the mean values in Table 3-7. The Calculated Specific Surface Are (CSSA) increased because of the increase in the number of smaller particles. Figure 3-3 and Figure 3-4 shows the particle size distribution shifts to smaller particles due to washing the sludge. Unless otherwise specified, "Initial" is the result of a measurement on the freshly precipitated sludge solids (sampled after step E in section 3.3) and "Final" is the final product simulant after all processing steps are complete (sampled after step $\mathrm{K}$ in section 3.3). The bimodal volume distribution remains, however, the primary mode shifts from about 20 microns down to about 12 microns. The lesser mode (largest particles) did not show a significant change due to washing. The number distribution (Figure 3-4) shows a definite shift to smaller particle sizes.

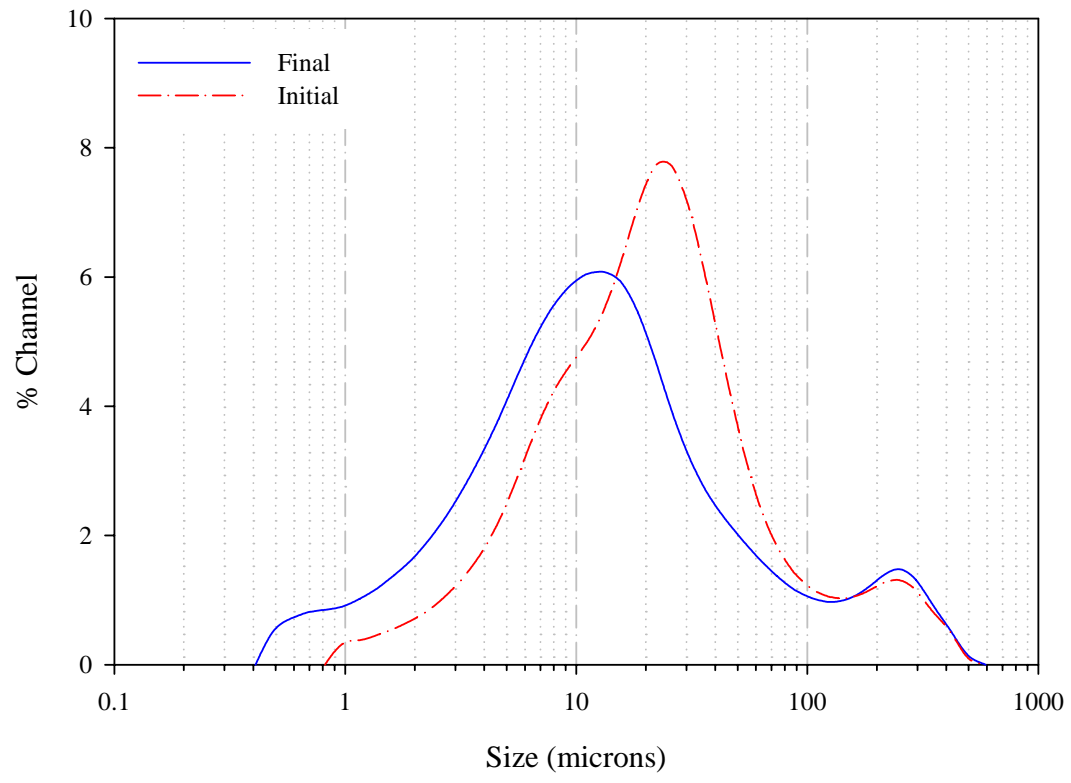

Figure 3-3 Impact of Washing on Particle Size Distribution (Volume Basis) for Test 1 Sludge 
WSRC-TR-2004-00578

Revision 0

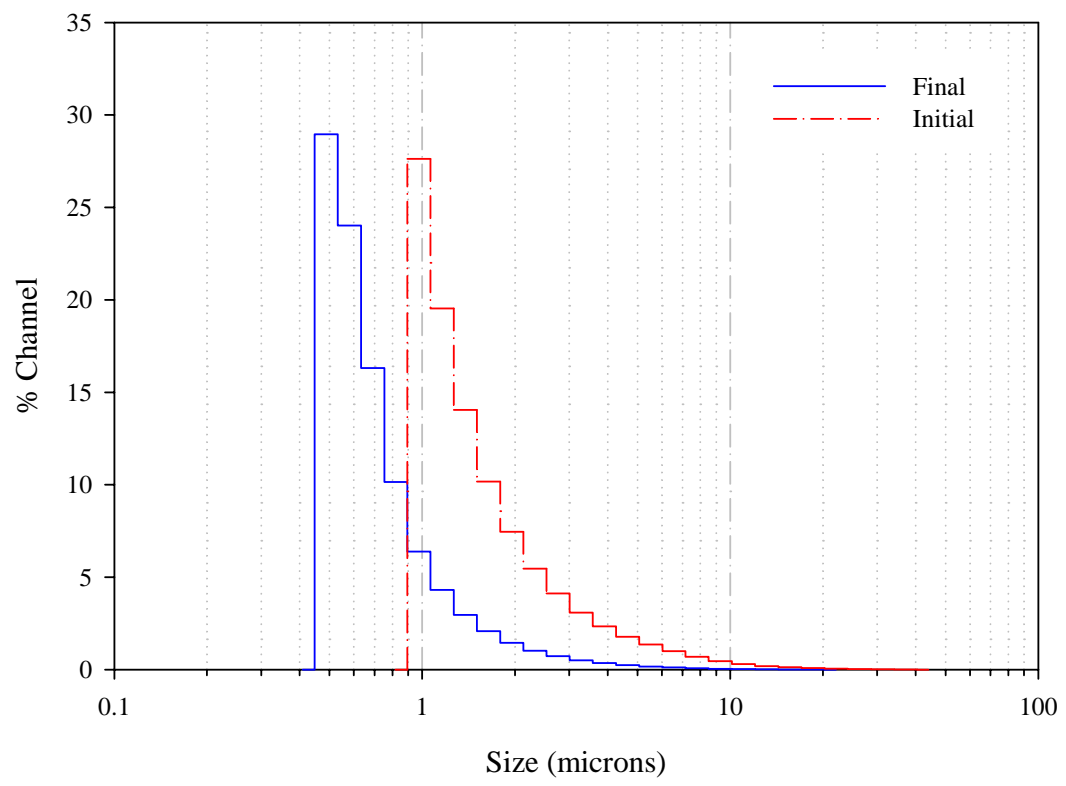

Figure 3-4 Impact of Washing on the Particle Size Distribution (Number Basis) for Test 1 Sludge

The rheology of a suspension such as DWPF sludge is a function of the solids content (insoluble and soluble) of the slurry, the fluid properties of the mobile phase (water plus the soluble solids in the liquid) and the morphology of the particles (soluble and insoluble). To understand the rheological impact of a preparation method, the dependence of the slurry rheology on the solids content of the samples was determined by preparing different insoluble solids loadings as previously described. Flow curves were obtained for each of the solids loadings using the cylindrical geometry method (see Table 2-1 for details) for the less viscous samples and the cone and plate geometry for the most viscous samples (see Table 2-2 for details). The most viscous samples generally produced a time dependent up curve (thixotropic behavior), which seems to indicate the presence of structure that was destroyed or the alignment of the particles modified during the initial periods of increasing shear. Figure 3-5 shows that the subsequent up and down curves essentially overlaid each other, indicating that any thixotropic behavior had been removed. Therefore, all of the thickest samples were run through two successive flow curves with the second down curve used as the basis for the flow properties of the sheared sludge simulant. This should be consistent with the actual DWPF sludge since the actual waste also experiences a high level of shear from the slurry pumps and from the transfer pumps prior to reaching the DWPF process, where all thixotropic behavior have been removed due to this shearing. If the yield strength of the structured material is of interest then much higher values for the yield stress would be determined from the maxima in the initial up flow curve. 


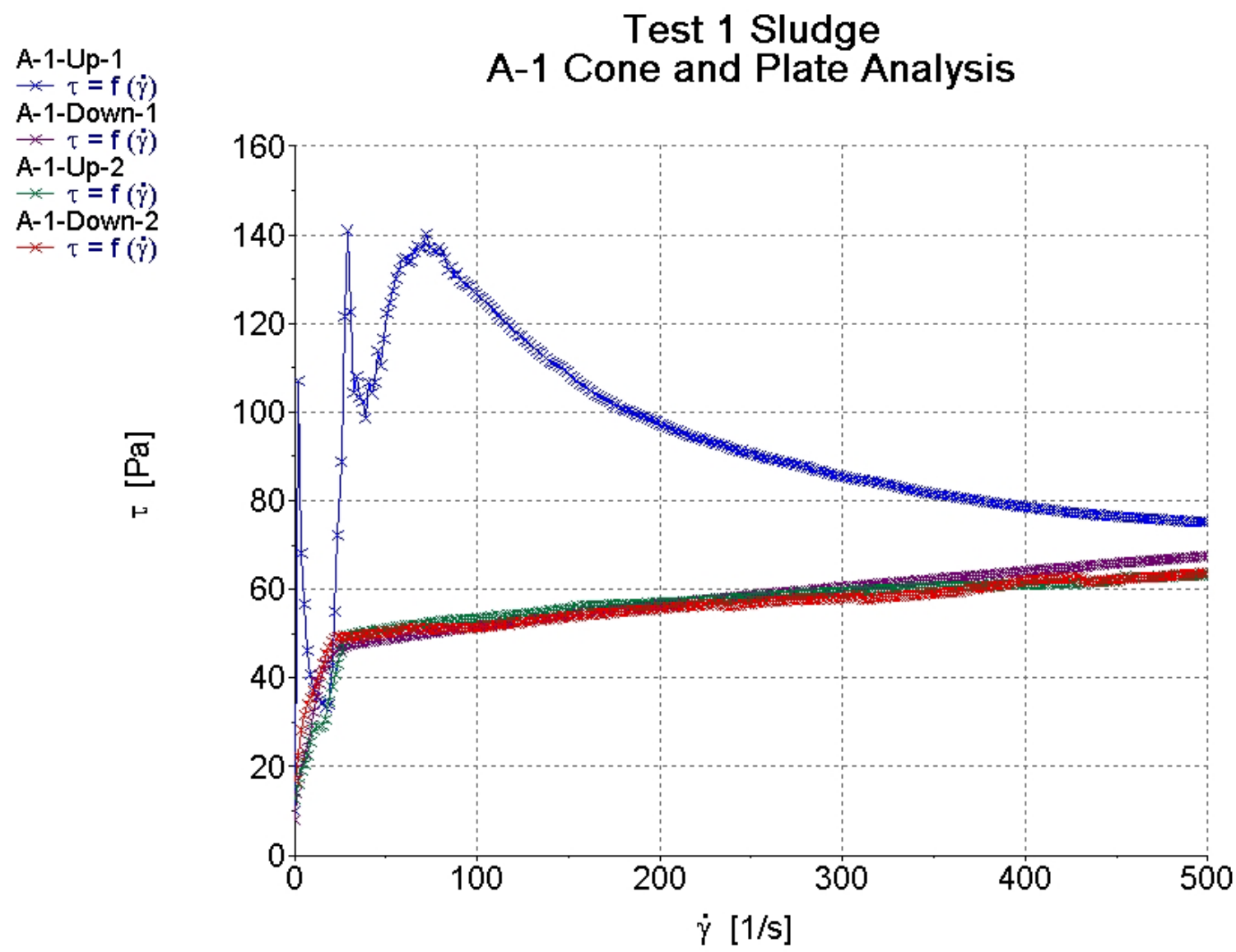

Figure 3-5 Cone and Plate Flow Curves for Test 1 Highest Insoluble Solids Loading

The samples that were less viscous had their rheology measured twice. The high-solids samples that were not fluid were generally measured only once. Five different wt \% solids loadings were rheologically characterized for Test 1 and the down flow curves are shown in Figure 3-6. Similar families of curves were obtained for each test method but only the curves for Test 1 are included as an example.

Each down curve was fit from $50 \mathrm{sec}^{-1}$ to $500 \mathrm{sec}^{-1}$ shear rate to a Bingham Plastic rheological model to determine the y-intercept (Bingham Yield Stress) in Pascals and the slope (Bingham consistency) in milliPascal.seconds (mPa.s) or centipoise (cP) (see equation (5) on page 4). The Bingham Plastic results for the 5 curves are tabulated in Table 3-8. Also included in Table 3-8 are the calculated weight \% insoluble and measured total solids results for these test mixtures. 
WSRC-TR-2004-00578

Revision 0

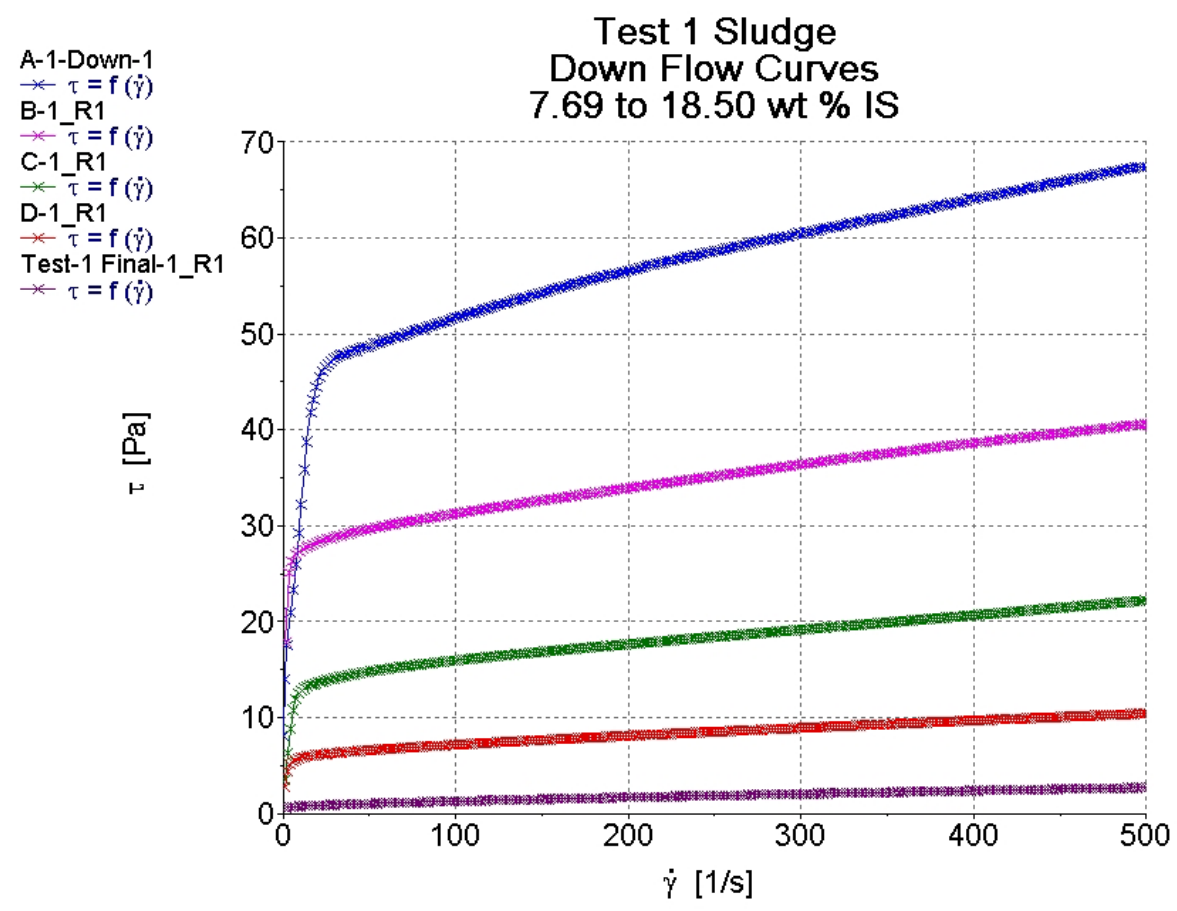

Figure 3-6 Test 1 Flow Curves

Table 3-8 Test 1 Rheology Results

\begin{tabular}{|c|c|c|c|}
\hline $\begin{array}{c}\text { Insoluble } \\
\text { Solids } \\
\text { (wt \%) }\end{array}$ & $\begin{array}{c}\text { Total } \\
\text { Solids } \\
\text { (wt \%) }\end{array}$ & $\begin{array}{c}\text { Bingham Yield Stress } \\
\text { (Pascal) }\end{array}$ & $\begin{array}{c}\text { Bingham Consistency } \\
\text { (cP) }\end{array}$ \\
\hline 7.69 & 15.22 & 1.0 & 3.4 \\
\hline 7.69 & 15.22 & 1.7 & 3.9 \\
\hline 10.29 & 17.53 & 6.4 & 8.3 \\
\hline 10.29 & 17.53 & 6.4 & 8.3 \\
\hline 12.90 & 19.97 & 14.3 & 15.6 \\
\hline 12.90 & 19.97 & 14.4 & 15.7 \\
\hline 15.10 & 21.96 & 30.3 & 34.8 \\
\hline 18.50 & 25.06 & 48.0 & 40.3 \\
\hline 18.50 & 25.06 & 49.2 & 29.8 \\
\hline
\end{tabular}

The rapid increase in both yield stress and consistency observed in Test 1 samples is typical of the rheological response of slurries to the increase of solids within those slurries. ${ }^{4}$ This rapid rise can be expressed as an exponential function of the form: ${ }^{5,6}$

$$
Y=\frac{e^{A X}}{(1-X / B)}
$$


where $\mathrm{A}$ and $\mathrm{B}$ are independent parameters, $\mathrm{Y}$ is the viscosity and $\mathrm{X}$ is the volume fraction of the solids in the slurry. Parameter B represents the limiting amount of solids that yields a solid material instead of a fluid. Equation (6) has been extended successfully to yield stress and consistency in previous rheology studies of DPWF simulants. ${ }^{7,8}$ Instead of the solids volume fraction, $\mathrm{X}$ would be the weight \% insoluble solids. Note that the yield stress and consistency could also be fitted to similar equations expressed in terms of weight \% total solids. The curve fitted equation is only applicable in the range in which the data was obtained. Using the nonlinear equation (6) as the model, the data in Table 3-8 was fit to the model using TableCurve ${ }^{\circledR} 2 \mathrm{D}$ software to generate the following results for yield stress $(\tau)$ and for consistency $(\eta)$ :

$$
\begin{array}{ll}
\tau=\frac{e^{0.195 X}}{1-X / 71.77} & \mathrm{r}^{2}=0.975 \\
\eta=\frac{e^{0.187 X}}{1-X / 99.9} & \mathrm{r}^{2}=0.818
\end{array}
$$

The fit for yield stress is good but not for consistency, because the last data point listed in Table 3-8 has a much lower consistency compared to the prior two measurements. The large difference in the B value indicates that the simulant will become a solid due to yield stress before consistency. Figure 3-7 and Figure 3-8 show the equations (7) and (8) plotted with the data and include lines indicating the expected range for receipt of DWPF sludge. Also plotted are the values for yield stress and consistency reported for actual radioactive samples from Sludge Batch 3., The lines defining the lower limit and upper limit for yield stress and consistency are based on the lower solids limit and upper solids limit of 13 and 19 wt $\%$ total solids (well washed basis) for incoming feed to the DWPF.,13 These limits will be shown on all of the rheology plots to indicate the normal DWPF operating region.

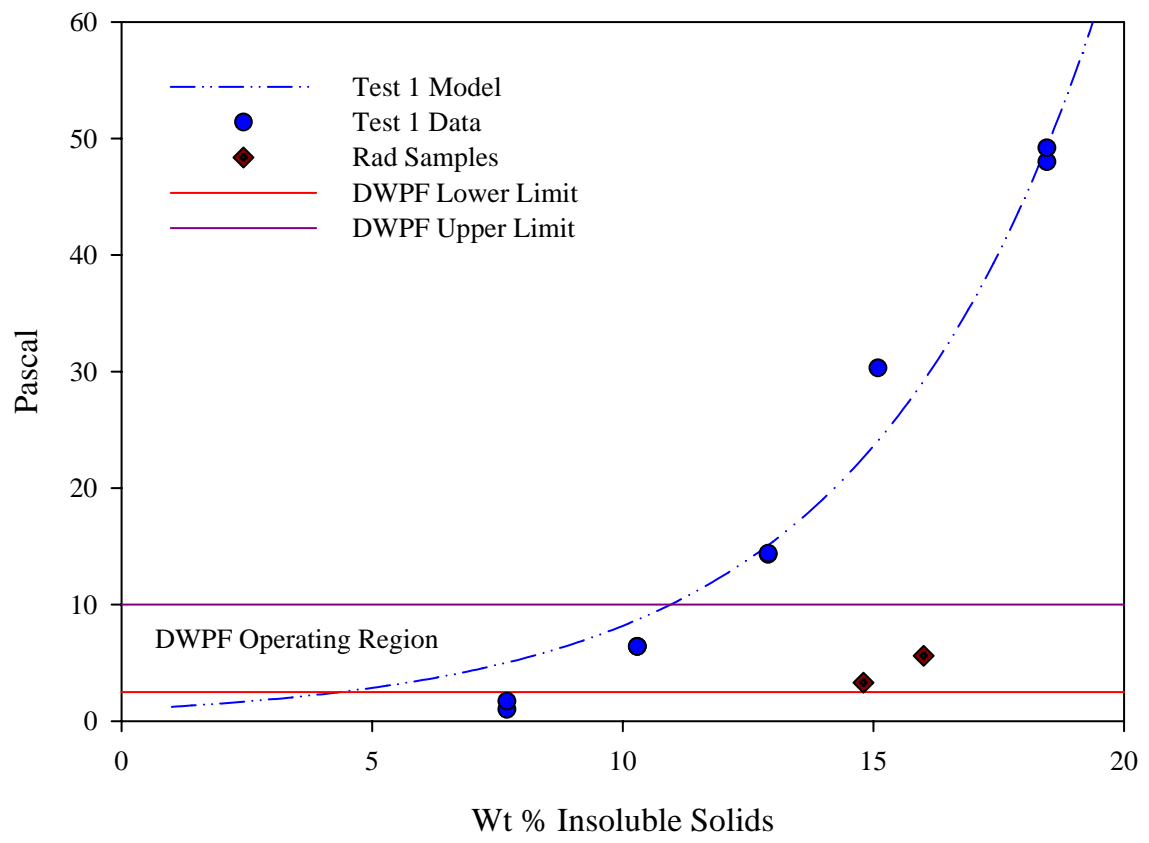

Figure 3-7 Test 1 Yield Stress Dependence on Insoluble Solids 


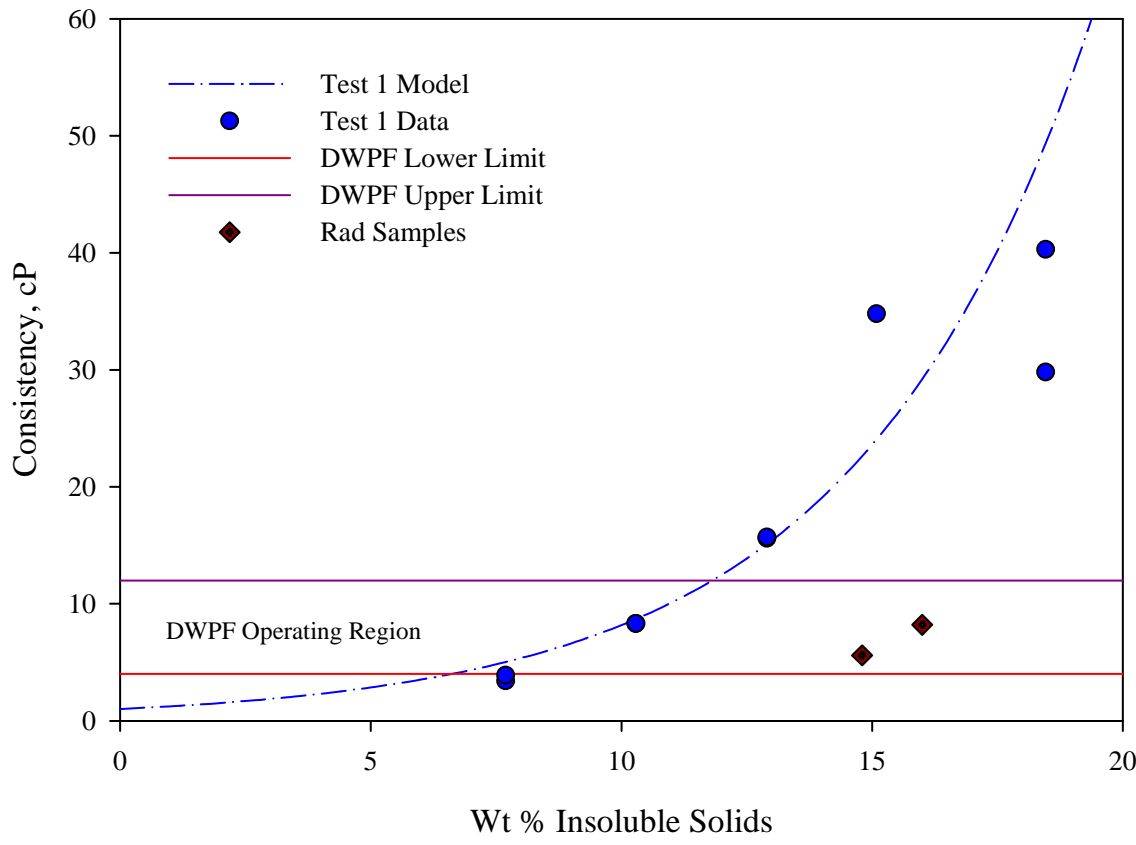

Figure 3-8 Test 1 Consistency as a Function of Insoluble Solids

From the plotted results, it is clear that the normal method of making a sludge simulant does not reproduce the actual rheology values well.

\subsection{Test 2 High Shear Method}

Test 2 was designed to determine if very high levels of shear would reduce the particle size of the simulated sludge and modify the sludge rheology. The Test 2 simulant was prepared in an identical manner as Test 1 simulant with the addition of one hour of a high level of shearing between steps $C$ and $D$ (see section 3.3). All other process steps were the same as Test 1. The Test 2 simulant was sheared at $5000 \mathrm{rpm}$ for one hour in a Silverson L4RT-A mixer using the square hole high shear screen. Mixing of the Test 2 simulant batch became difficult within ten minutes of beginning the high shear period due to the change in the rheological properties of the simulant. An effort was made to insure that all of the simulant was processed through the high shear region of the mixer equally. However, it cannot be proven that all of the simulant experienced an equal amount of shear. If this test were to be repeated, the mixer would be modified using a flow-through stator with a recirculating pump to insure that all portions of the simulant received an equivalent amount of shear.

The change in physical properties due to the period of high shear was apparent during batch washing since the gravity-settled sludge layer was of considerably larger volume (i. e. hindered settling began at a lower wt \% insoluble solids) as compared to the Test 1 batch of simulant. This was confirmed by the final weight \% solids measurements that showed the settled sludge was $5.5 \mathrm{wt} \%$ insoluble solids compared to $7.7 \mathrm{wt} \%$ IS in Test 1 simulant.

The particle size analyses of Test 2 simulant dramatically demonstrate the effect of shear on the sludge particles. Figure 3-9 and Figure 3-10 show that the sludge particles shifted to much smaller particles with an average reduction in size of a factor of two on a volume basis and a factor of five on a number basis. The particle size number distribution indicates that the vast majority of particles were much smaller after 
shearing. The high shearing also reduced the largest particle size from 400 to 200 microns. Table 3-9 summarizes the measured average particle sizes through the different steps of simulant production for Test 2. Washing did not produce much of a change in the average size after the high shear period was complete.

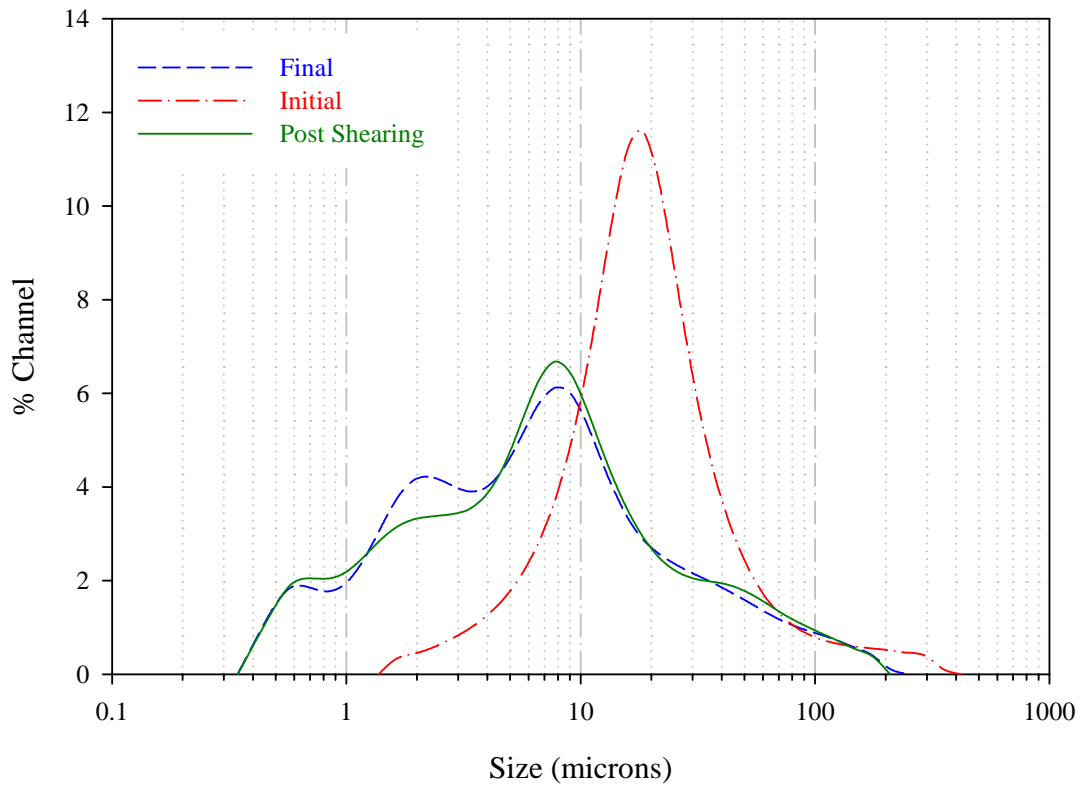

Figure 3-9 Test 2 Particle Size Distribution Based on Volume

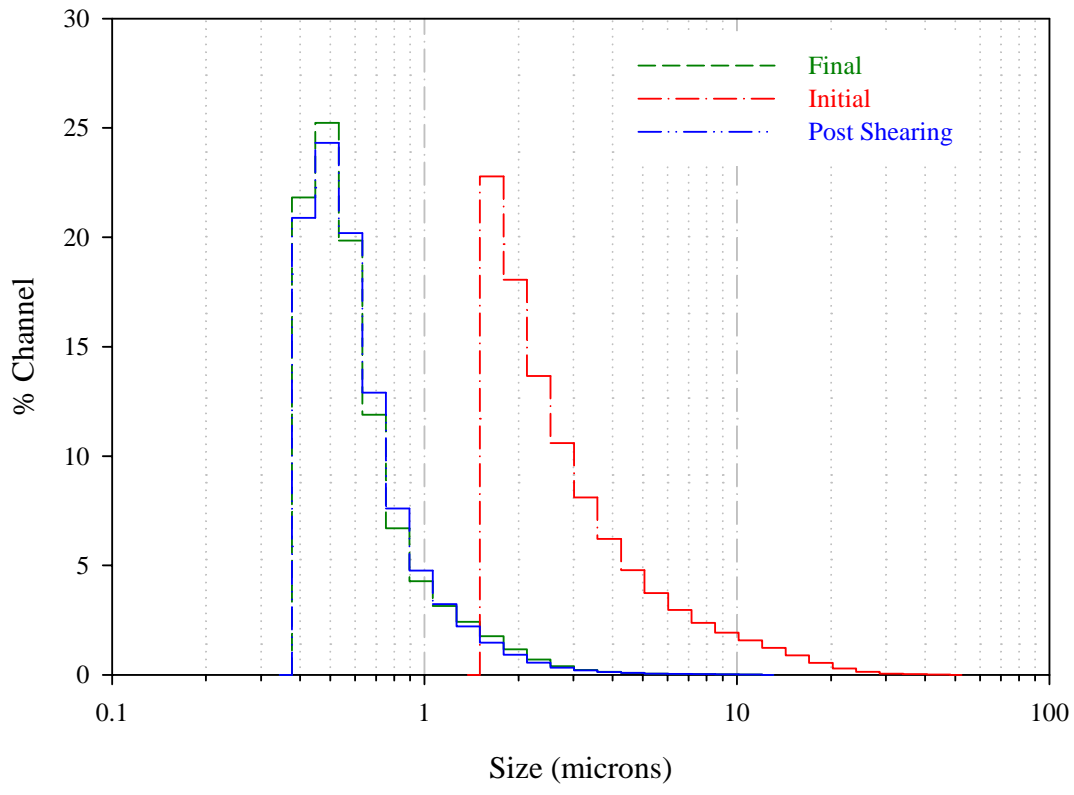

Figure 3-10 Test 2 Particle Size Distribution Based on Number 
WSRC-TR-2004-00578

Revision 0

Table 3-9 Summary of Particle Size Results for Test 2

\begin{tabular}{|c|l|c|c|c|c|c|}
\hline Measurement & Units & Initial & $\begin{array}{c}\text { After } \\
\text { Shearing }\end{array}$ & $\begin{array}{c}\text { After 1st } \\
\text { Wash }\end{array}$ & $\begin{array}{c}\text { After 2nd } \\
\text { Wash }\end{array}$ & Final \\
\hline $\begin{array}{c}\text { Mean, Volume } \\
\text { Basis }\end{array}$ & microns & 25.1 & 14.0 & 10.6 & 10.0 & 13.7 \\
\hline $\begin{array}{c}\text { Mean, } \\
\text { Number Basis }\end{array}$ & microns & 3.2 & 0.6 & 0.6 & 0.6 & 0.6 \\
\hline $\begin{array}{c}\text { Mean, Area } \\
\text { Basis }\end{array}$ & microns & 12.0 & 2.7 & 2.7 & 2.7 & 2.7 \\
\hline CSSA & $\mathrm{m}^{2} / \mathrm{cm}^{3}$ & 0.5 & 2.2 & 2.2 & 2.2 & 2.3 \\
\hline
\end{tabular}

The rheology for the Test 2 simulant measured immediately after shearing were consistent with a material that had mixing problems while being sheared (i.e. high yield stress). The summary of the rheology results for Test 2 simulant is listed in Table 3-10.

Table 3-10 Test 2 Rheology Results

\begin{tabular}{|c|c|c|c|}
\hline $\begin{array}{c}\text { Insoluble } \\
\text { Solids } \\
\text { (wt \%) }\end{array}$ & $\begin{array}{c}\text { Total } \\
\text { Solids } \\
\text { (wt \%) }\end{array}$ & $\begin{array}{c}\text { Bingham Yield Stress } \\
\text { (Pascal) }\end{array}$ & $\begin{array}{c}\text { Bingham Consistency } \\
\text { (cP) }\end{array}$ \\
\hline 5.47 & 13.39 & 0.9 & 3.7 \\
\hline 5.47 & 13.39 & 0.9 & 3.8 \\
\hline 10.43 & 17.78 & 15.0 & 9.2 \\
\hline 10.43 & 17.78 & 15.2 & 9.3 \\
\hline 13.21 & 20.34 & 38.0 & 22.3 \\
\hline 13.21 & 20.34 & 40.5 & 34.4 \\
\hline 14.69 & 21.69 & 70.1 & 55.7 \\
\hline 16.59 & 23.44 & 104.1 & \\
\hline
\end{tabular}

The rise in both yield stress and consistency as a function of wt \% IS again matches an exponential function. Applying equation (6) to the rheology results gave the following Test 2 model equations:

$$
\begin{array}{cc}
\tau=\frac{e^{0.26 X}}{1-X / 55.73} & \mathrm{r}^{2}=0.987 \\
\eta=\frac{e^{0.179 X}}{1-X / 25.49} & \mathrm{r}^{2}=0.997
\end{array}
$$

The fit for consistency was much better in the Test 2 data set than in the Test 1 data. The maximum IS for fluid properties for the Test 2 simulant is $25.49 \mathrm{wt} \%$ based on the consistency fit. Figure 3-11 and Figure 3-11 compare the model curve to the simulant data and also to the actual radioactive sample data. Test 2 simulant does not appear to be an appropriate physical simulant based on the limited actual waste data available. 


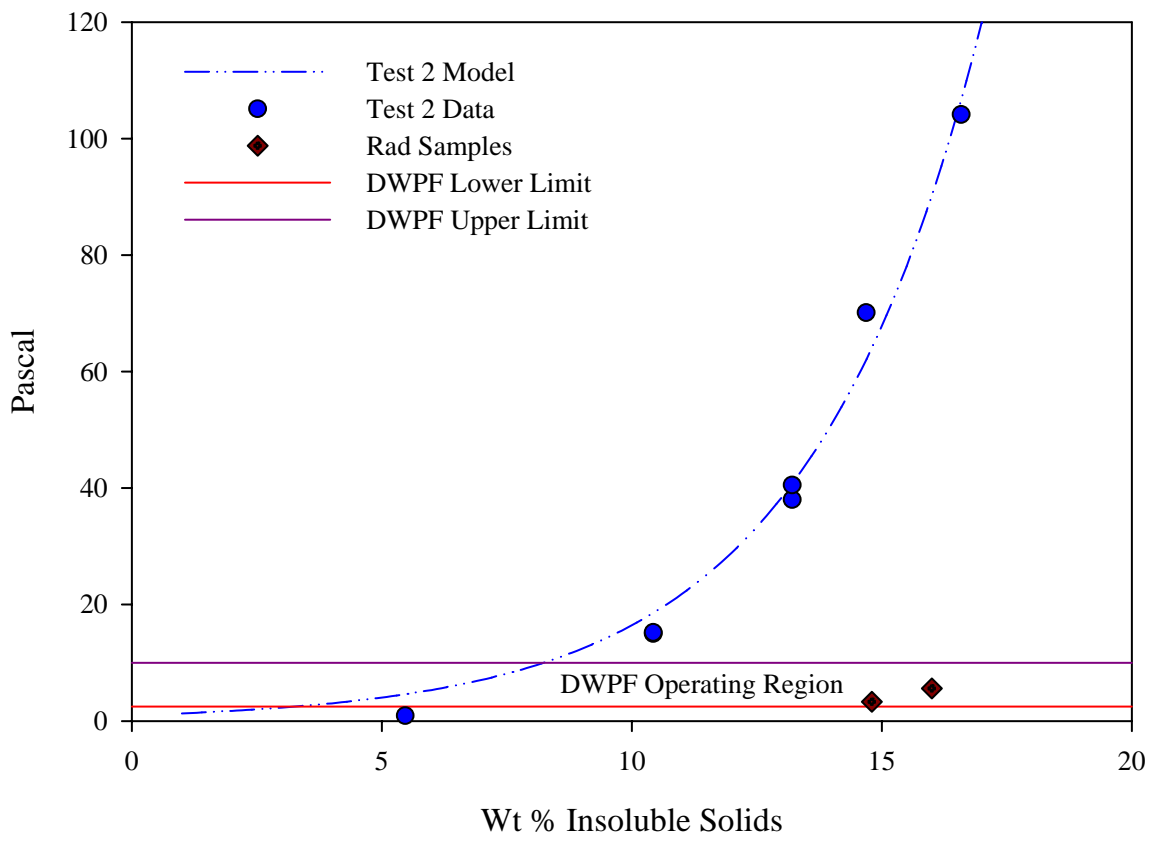

Figure 3-11 Test 2 Yield Stress Dependence on Insoluble Solids

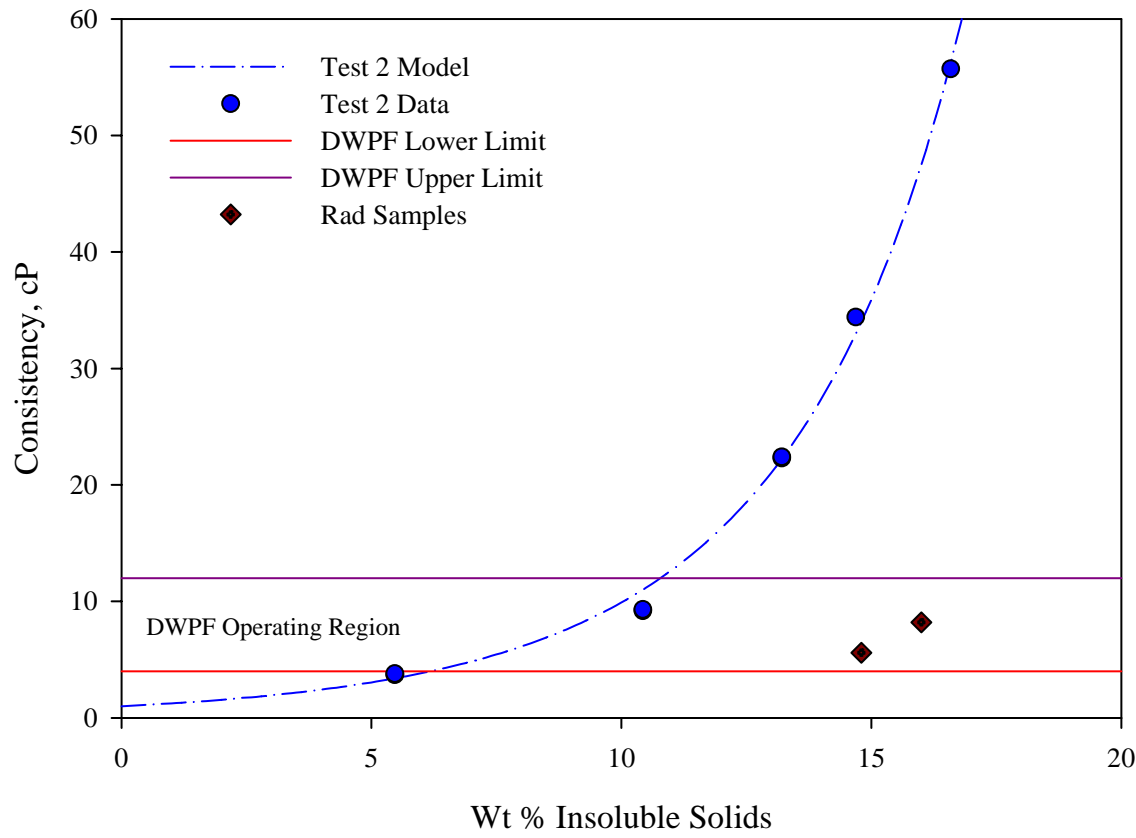

Figure 3-12 Test 2 Consistency as a Function of Insoluble Solids

\subsection{Test 3 Crossflow Filtration Method}

The Test 3 simulated sludge was prepared using a batch size five times larger than any of the other tests due to the volume of the crossflow filtration system. The sludge preparation method was based on the process used in Test 1 except for the washing method. The sludge simulant was washed continuously by 
the use of a crossflow filter instead of a batch washing process that relied upon gravity settling for separation of the wash water from the insoluble solids. Test 3 followed steps A through E (section 3.3) followed by crossflow filtration washing, and then the remaining steps ( $\mathrm{H}$ through $\mathrm{K}$, section 3.3 ) were completed. The crossflow filter system used is shown in Figure 3-13.

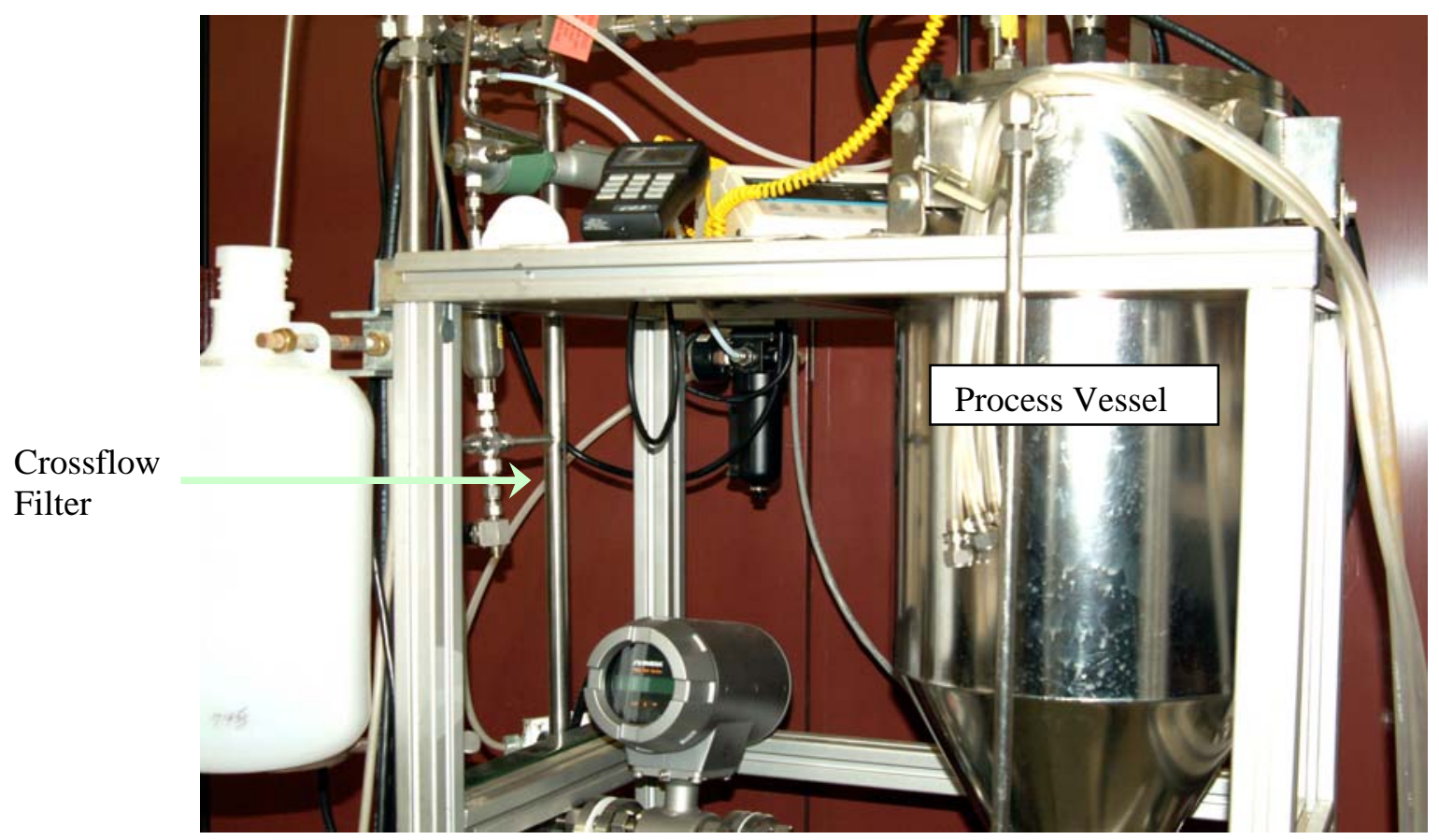

Figure 3-13 Crossflow Filter Apparatus

The crossflow filter system consisted of two parallel two feet long, 0.5 inch ID Mott sintered metal tubes rated at 0.1 micron pore size. The sludge was pumped through the tube bundle at 4.5 gallons/minute at 710 psi using a Moyno Model 33304 progressive cavity pump. Washing was accomplished by adding wash water $\left(0.001\right.$ molar $\mathrm{NaOH}$ and 0.001 molar $\left.\mathrm{NaNO}_{2}\right)$ at the same rate that permeate is removed $(\sim 25$ $\mathrm{mL} / \mathrm{minute}$ ). The total wash water volume used was 46 liters for a nominal 10 liter batch size of sludge. The washing time was approximately 30.5 hours. Agitation in the feed vessel was provided by two turbine impellers and was maintained at $750 \mathrm{rpm}$ for the duration of the washing process.

Unlike the other simulant production methods, Test 3 sludge was prepared at a higher insoluble solids loading (11.4 wt \% compared to $7.7 \mathrm{wt} \%$ ) due to the concentrating effect of filtration compared to the diluting effect of bulk dilution/gravity settling. Therefore, only two of the higher solids-loading samples were prepared by the use of the centrifuge for rheology measurements. The two lowest solids loading samples were prepared by adding additional supernate to dilute the insoluble solids level. The added supernate was obtained from the decanted supernate from samples whose insoluble solids were concentrated by the centrifuge. The decanted supernate was used to maintain the supernate at the appropriate soluble species concentration.

The crossflow filtration process adds a high amount of shear to the processed sludge due to the large number of volume turnovers ( 3000$)$ of the sludge through the pump and various orifices. The agitator provided additional shearing. This shear was reflected in the reduction in particle size measured for the Test 3 simulant. Figure 3-14 and Figure 3-15 show the shift in particle size distribution as result of the 
crossflow washing process. Table 3-11 lists the average particle size results for the Test 3 simulant. In general, there is nearly an order of magnitude reduction in average particle size as a result of the shearing during washing compared to the initially precipitated sludge or compared to the final test 1 sludge. In fact, the average particle size for Test 3 simulant is smaller than that of the high sheared Test 2 simulant. The volume and number means values for the Test 3 sludge are much closer to each other than for the Test 1 and Test 2 values.

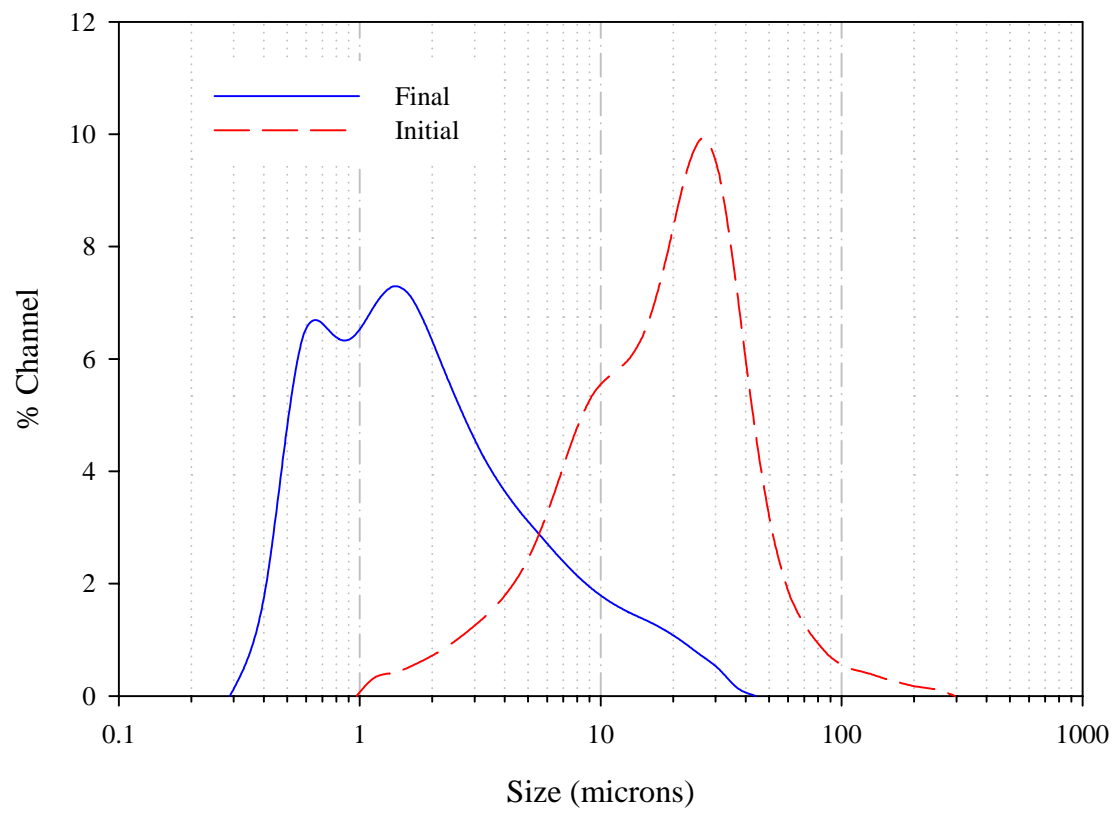

Figure 3-14 Particle Size Distribution on a Volume Basis for Test 3 
WSRC-TR-2004-00578

Revision 0

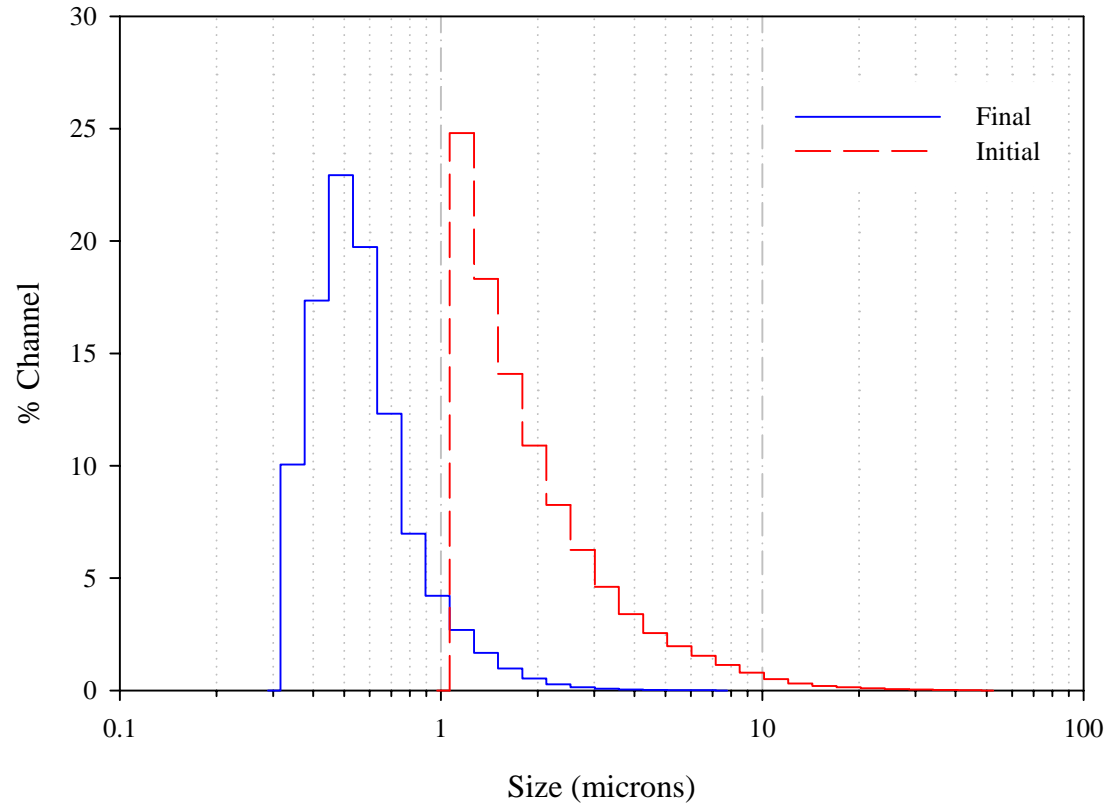

Figure 3-15 Particle Size Distribution on a Number Basis for Test 3

Table 3-11 Summary of Particle Size Results for Test 3

\begin{tabular}{|c|c|c|c|c|}
\hline Measurement & Units & $\begin{array}{c}\text { Initial (After } \\
\text { Precipitation) }\end{array}$ & $\begin{array}{c}\text { After Crossflow } \\
\text { Filtration/Washing }\end{array}$ & $\begin{array}{c}\text { Final } \\
\text { Simulant }\end{array}$ \\
\hline $\begin{array}{c}\text { Mean - } \\
\text { Volume }\end{array}$ & microns & 22.1 & 4.2 & 3.1 \\
\hline $\begin{array}{c}\text { Mean - } \\
\text { Number }\end{array}$ & microns & 2.1 & 0.6 & 0.6 \\
\hline Mean - Area & microns & 10.2 & 1.2 & 1.2 \\
\hline CSSA & $\mathrm{m}^{2} / \mathrm{cm}^{3}$ & 0.6 & 4.9 & 5.2 \\
\hline
\end{tabular}

The rheology results for the Test 3 simulant shows a very rapid rise in both yield stress and in consistency as the insoluble solids increase above $12 \mathrm{wt} \%$ similar to that observed with the Test 2 high shear simulant. Table 3-12 summarizes the rheology data as a function of weight percent insoluble and total solids. 
WSRC-TR-2004-00578

Revision 0

Table 3-12 Test 3 Rheology Results

\begin{tabular}{|c|c|c|c|}
\hline $\begin{array}{c}\text { Insoluble } \\
\text { Solids } \\
\text { (wt \%) }\end{array}$ & $\begin{array}{c}\text { Total } \\
\text { Solids } \\
\text { (wt \%) }\end{array}$ & $\begin{array}{c}\text { Bingham Yield Stress } \\
\text { (Pascal) }\end{array}$ & $\begin{array}{c}\text { Bingham Consistency } \\
\text { (cP) }\end{array}$ \\
\hline 7.41 & 14.88 & 2.5 & 5.6 \\
\hline 7.41 & 14.88 & 2.5 & 5.7 \\
\hline 10.09 & 17.33 & 5.0 & 7.6 \\
\hline 10.09 & 17.33 & 5.1 & 7.7 \\
\hline 11.41 & 18.70 & 7.3 & 8.0 \\
\hline 11.41 & 18.70 & 7.4 & 8.1 \\
\hline 12.71 & 19.75 & 13.4 & 15.7 \\
\hline 12.71 & 19.75 & 15.7 & 14.8 \\
\hline 15.09 & 21.93 & 31.1 & 27.2 \\
\hline
\end{tabular}

The rise in both yield stress and consistency as a function of either IS or TS again matches an exponential function. Applying equation (6) to the rheology results using the insoluble solids data gave the following Test 3 model equations:

$$
\begin{array}{ll}
\tau=\frac{e^{0.0974 X}}{1-X / 17.51} & \mathrm{r}^{2}=0.97 \\
\eta=\frac{e^{0.133 X}}{1-X / 20.78} & \mathrm{r}^{2}=0.966
\end{array}
$$

The limiting wt \% IS parameter for both fits are very close to each other, unlike the Test 1 and Test 2 results. . Figure 3-16 and Figure 3-17 compare equations (11) and (12) to the simulant data and also to the actual radioactive sample data. Additional data in the region of rapid increase in both yield stress and in consistency would be useful to better confirm the depicted curves. Test 3 does not appear to be an appropriate physical simulant based on the limited actual waste data available. As stated previously, the fitted equation is only good in the region in which the data is fitted. 
WSRC-TR-2004-00578

Revision 0

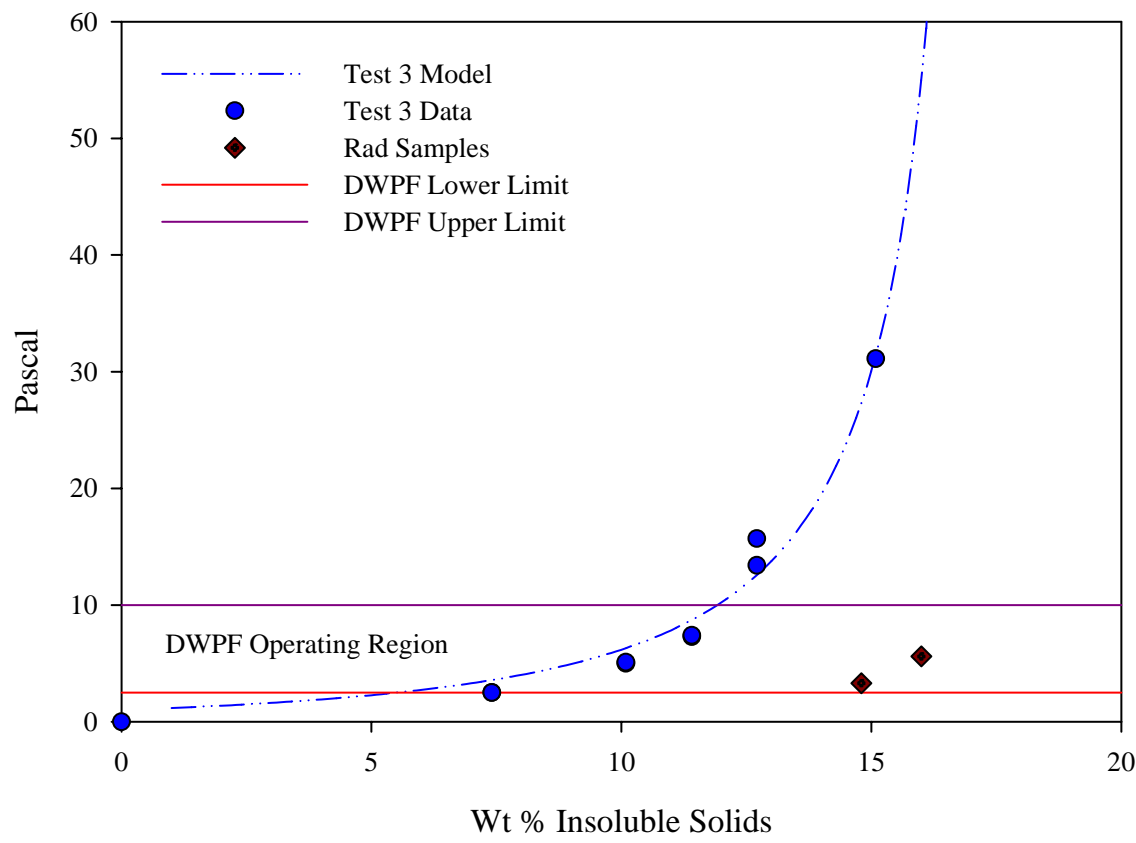

Figure 3-16 Test 3 Yield Stress versus Insoluble Solids

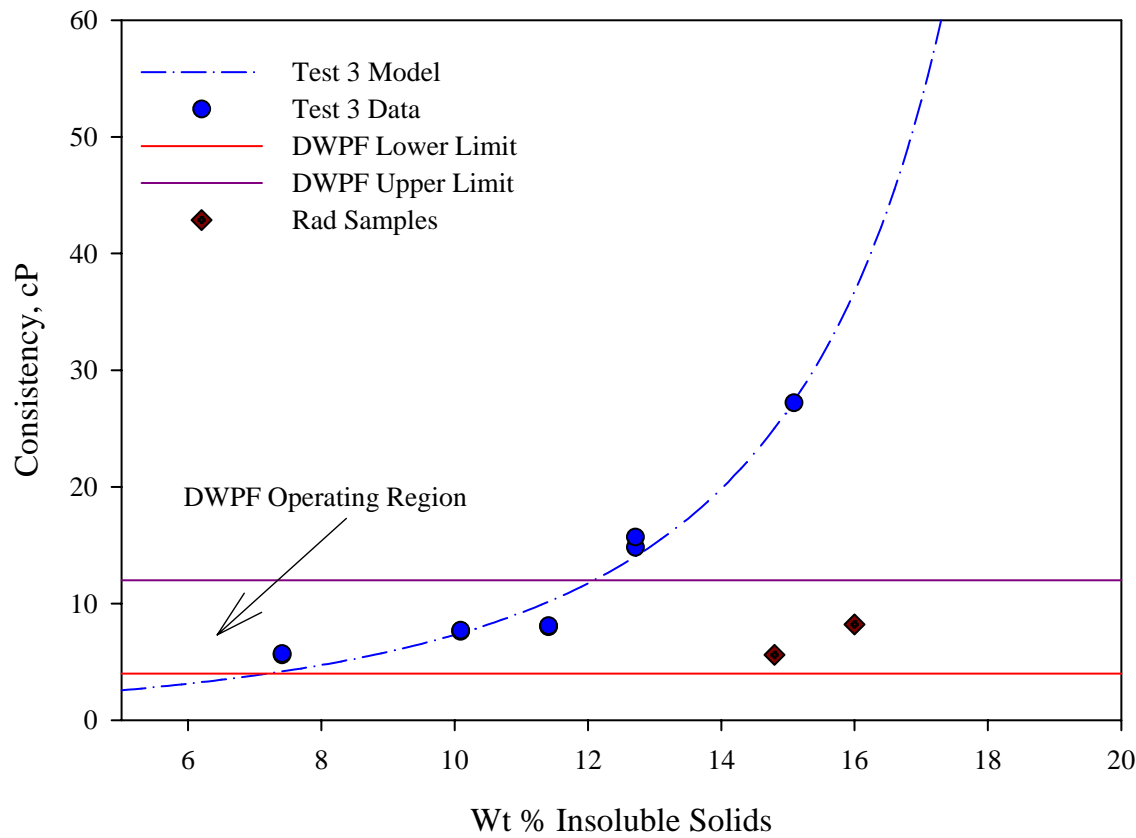

Figure 3-17 Test 3 Consistency as a Function of Insoluble Solids

\subsection{Test 4 Heat Treatment before Washing Method}

Test 4 simulant was prepared by the same process as Test 1 simulant with the only change being the addition of a heat treatment step between steps E and F (described in section 3.3). The heat treatment step was added to represent the thermal history of the radioactive waste. The radioactive waste in the Tank 
Farm experiences an extensive period of elevated temperatures due to the high level of radioactive decay in the sludge. For this testing, the heat treatment consisted of heating the sludge simulant to $98{ }^{\circ} \mathrm{C}$ for 8 hours while agitating at $300 \mathrm{rpm}$ with the agitator shown in Figure 3-1. After cooling, the simulant preparation was completed in the same series of steps as the Test 1 sludge.

The particle size measurements for the Test 4 simulant showed a shift in the size based on volume as seen in particle size distribution shown in Figure 3-18. Most of the shift is due to the heat treatment and results in an average particle size based on volume of about 10 microns compared to an initial size greater than 20 microns.

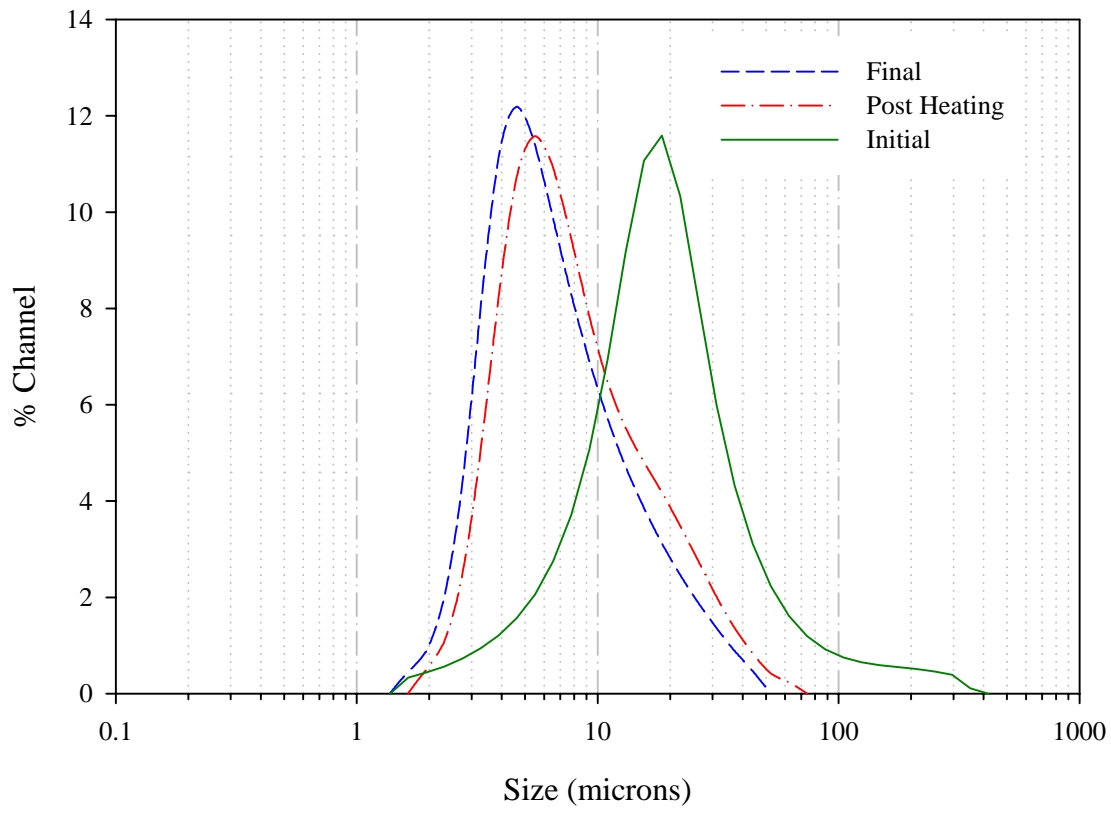

Figure 3-18 Test 4 Particle Size Distribution on a Volume Basis

The particle size distribution based on number shown in Figure 3-19 shows that the shift is not a shift to smaller particle sizes. Instead, the distribution indicates a narrowing of the distribution to center on particles of about 3 to 4 microns in diameter. This redistribution of particle sizes suggests the dissolution of the larger particles and consolidation ( or reprecipitation) of the smallest particles to produce larger particles. Either mechanism seems plausible since the ionic strength of the sludge supernate at this point in its production is quite high due to high levels of nitrate anions and of sodium cations.

Table 3-13 summarizes the calculated average particle size data for the Test 4 simulant. 
WSRC-TR-2004-00578

Revision 0

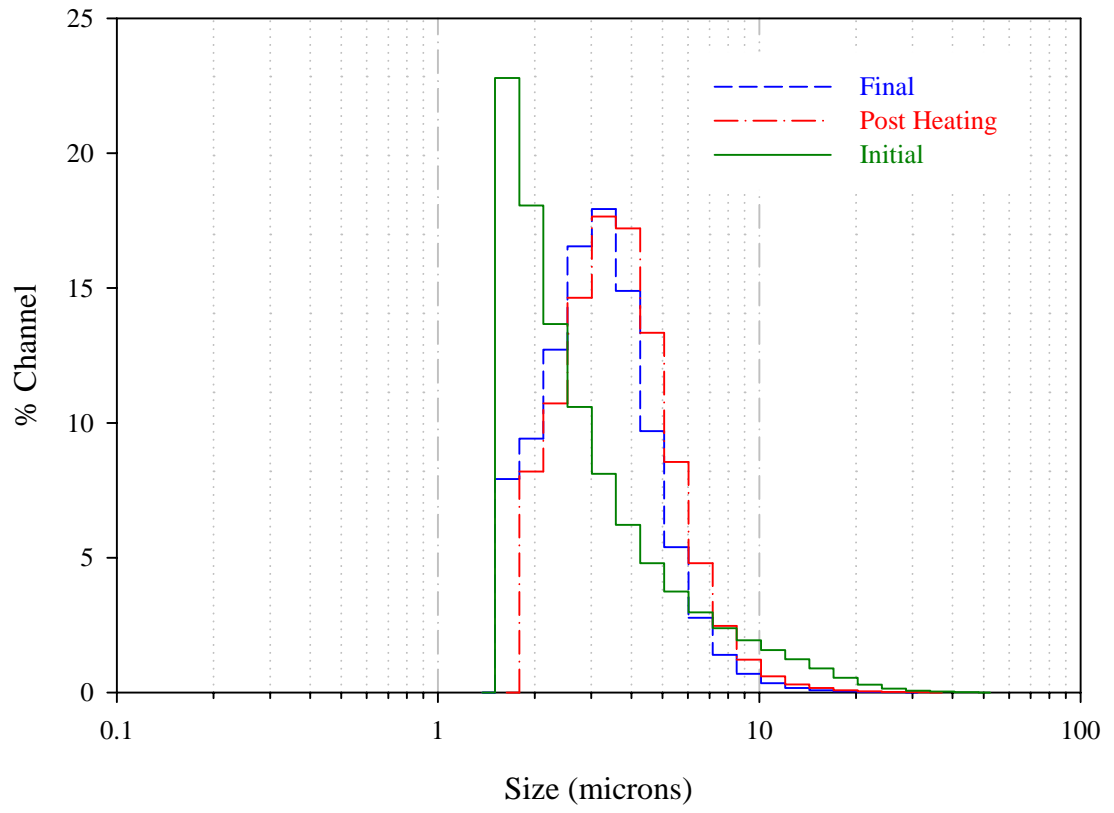

Figure 3-19 Test 4 Particle Size Distribution on a Number Basis

Table 3-13 Summary of Particle Size Results for Test 4

\begin{tabular}{|c|c|c|c|c|c|}
\hline Measurement & Units & $\begin{array}{c}\text { After Heat } \\
\text { Treatment }\end{array}$ & $\begin{array}{c}\text { After First } \\
\text { Wash }\end{array}$ & $\begin{array}{c}\text { After Second } \\
\text { Wash }\end{array}$ & Final \\
\hline Mean - Volume & microns & 9.4 & 9.1 & 8.9 & 7.7 \\
\hline Mean - Number & microns & 3.6 & 3.2 & 3.2 & 3.1 \\
\hline Mean - Area & microns & 6.0 & 5.4 & 5.3 & 5.1 \\
\hline CSSA & $\mathrm{m}^{2} / \mathrm{cm}^{3}$ & 1.0 & 1.1 & 1.1 & 1.2 \\
\hline
\end{tabular}

The rheology results for the Test 4 simulant at different solids loadings are shown in Table 3-14. Again, a rapid rise in yield stress and consistency is observed at the higher wt\% insoluble solids levels. A comparison of the values in Table 3-14 with those of the Test 1 simulant in Table 3-8 shows close match in viscosity. This contrasts with slurry studies described in the technical literature, which show that a narrower particle size distribution gives a higher viscosity than a broad particles size distribution. ${ }^{10}$ 
WSRC-TR-2004-00578

Revision 0

Table 3-14 Test 4 Rheology Results

\begin{tabular}{|c|c|c|c|}
\hline $\begin{array}{c}\text { Insoluble } \\
\text { Solids } \\
\text { (wt \%) }\end{array}$ & $\begin{array}{c}\text { Total } \\
\text { Solids } \\
\text { (wt \%) }\end{array}$ & $\begin{array}{c}\text { Bingham Yield Stress } \\
\text { (Pascal) }\end{array}$ & $\begin{array}{c}\text { Bingham Consistency } \\
\text { (cP) }\end{array}$ \\
\hline 8.48 & 16.01 & 1.7 & 5.3 \\
\hline 8.48 & 16.01 & 1.7 & 5.2 \\
\hline 10.28 & 17.58 & 3.8 & 7.7 \\
\hline 10.28 & 17.58 & 3.8 & 7.7 \\
\hline 12.83 & 19.86 & 10.5 & 14.3 \\
\hline 12.83 & 19.86 & 10.5 & 22.4 \\
\hline 15.38 & 22.23 & 20.7 & 32.7 \\
\hline 16.84 & 23.57 & 35.3 & \\
\hline
\end{tabular}

The rise in both yield stress and consistency as a function of either IS or TS again matches an exponential function. Applying equation (6) to the rheology results using wt \% IS, yields the following Test 4 equations:

$$
\begin{array}{ll}
\tau=\frac{e^{0.0915 X}}{1-X / 19.38} & \mathrm{r}^{2}=0.983 \\
\eta=\frac{e^{0.169 X}}{1-X / 35.73} & \mathrm{r}^{2}=0.997
\end{array}
$$

The fit for yield stress was very good while that for consistency was excellent. The yield stress limiting wt \% IS value of 19.38 is of similar magnitude to that of the Test 3 results. Figure 3-20 and Figure 3-21 compare the model curve to the simulant data and also to the actual radioactive sample data. Additional data in the region of rapid increase in both yield stress and in consistency would be useful to better confirm the depicted curves. The Test 4 simulant does not appear to be an effective physical simulant based on the limited actual waste data available. 


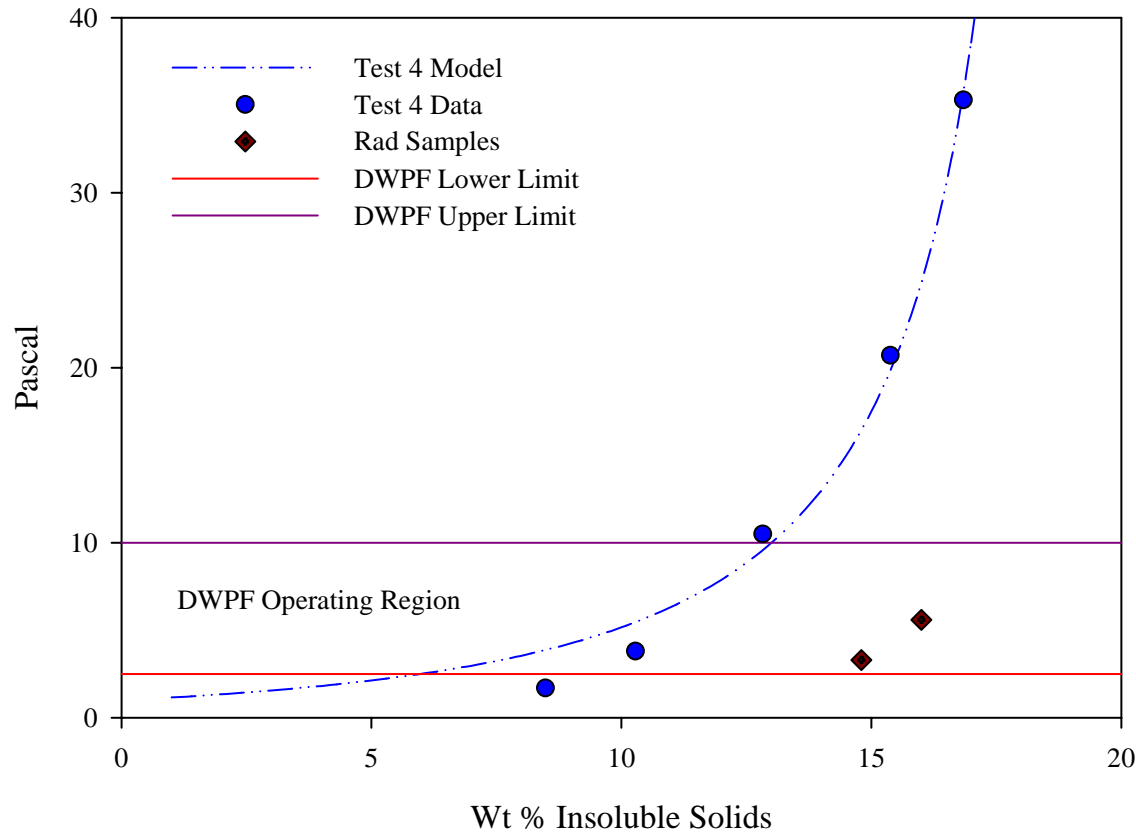

Figure 3-20 Test 4 Yield Stress as a Function of Insoluble Solids

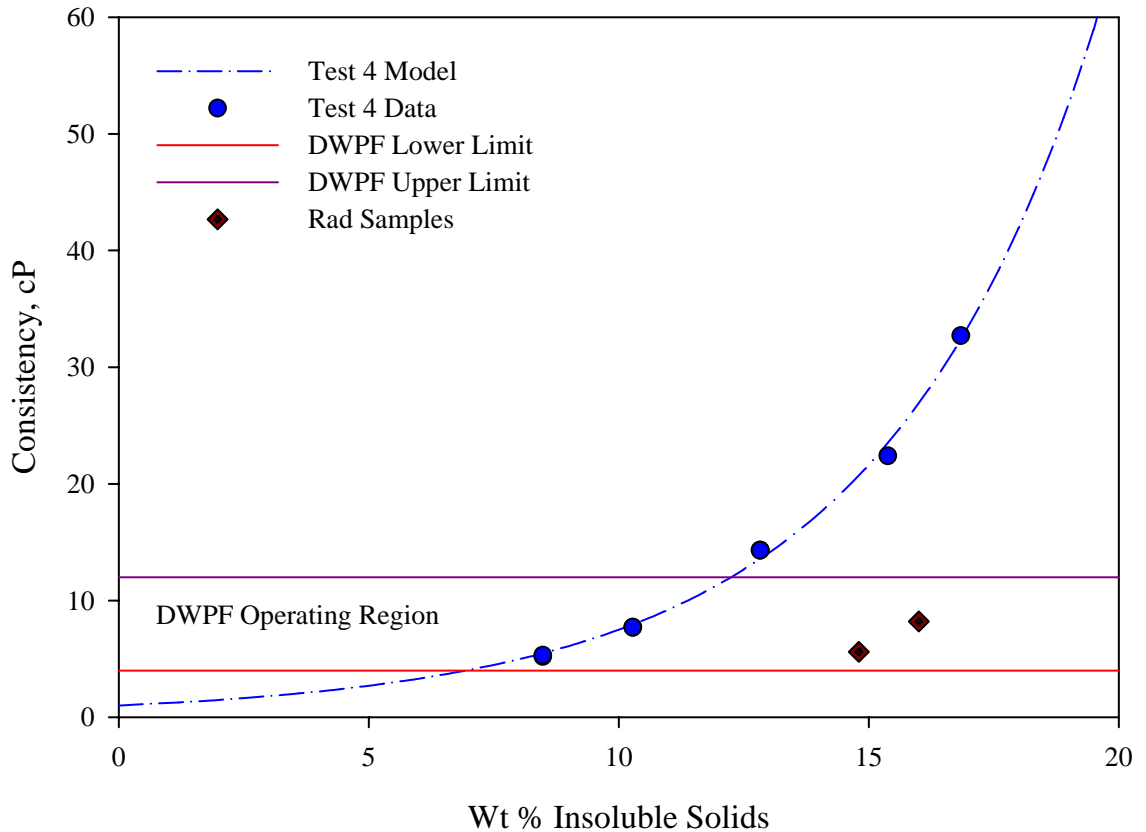

Figure 3-21 Test 4 Consistency and Insoluble Solids

\subsection{Test 5 Heat Treatment after Washing Method}

Test 5 also tested heat treatment as a means of modifying the physical properties of the sludge simulant. The Test 5 simulant was prepared by the same process as Test 1 until step I in section 3.3 was complete. At this point, the simulant was processed through a heat treatment cycle of 8 hours at $98{ }^{\circ} \mathrm{C}$. After the heat treatment was completed, the sludge was cooled overnight and the rest of the steps in section 3.3 
were completed. The difference in the heat treatment between the Test 4 and Test 5 simulant is that in Test 5 simulant, the heat treatment takes place in a supernate that is very low in ionic strength (less than 0.16 molar in $\mathrm{NaNO}_{3}$ ). This suggests that the potential for reprecipitation of smaller particles is less likely with this test mixture.

The particle size results are shown in Figure 3-22, Figure 3-23, and in Table 3-15. The curve labeled as "Initial" is the result for the initially precipitated sludge while the "Final" is the distribution cuve for the final simulant (after heat treatment). These results show only a minor shift to slightly smaller particles as a result of the heat treatment process.

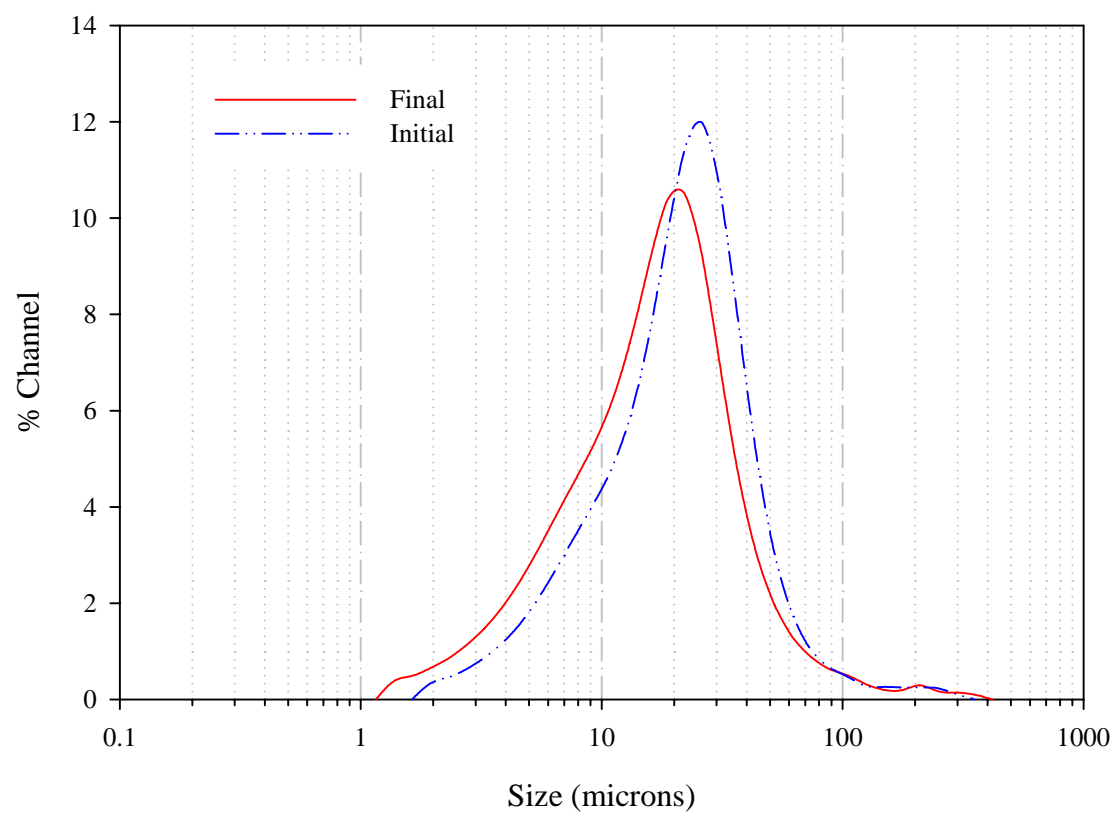

Figure 3-22 Test 5 Particle Size Distribution Volume Basis 


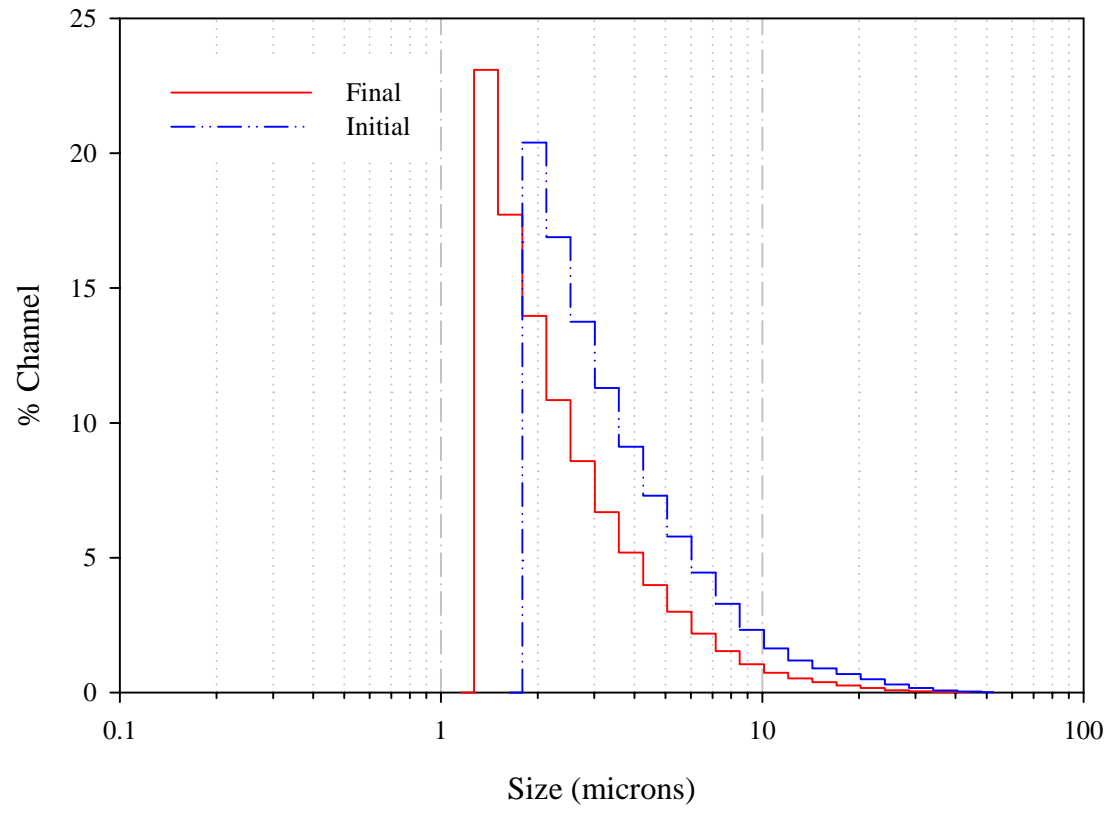

Figure 3-23 Test 5 Particle Size Distribution on a Number Basis

Table 3-15 Summary of Particle Size Results for Test 5

\begin{tabular}{|c|c|c|c|c|c|c|}
\hline Measurement & Units & $\begin{array}{c}\text { Initial } \\
\text { Precipitated } \\
\text { Sludge }\end{array}$ & $\begin{array}{c}\text { After } \\
\text { Second } \\
\text { Wash }\end{array}$ & $\begin{array}{c}\text { After } \\
\text { Third } \\
\text { Wash }\end{array}$ & $\begin{array}{c}\text { After Heat } \\
\text { Treatment }\end{array}$ & $\begin{array}{c}\text { Final } \\
\text { Completed } \\
\text { Simulant }\end{array}$ \\
\hline $\begin{array}{c}\text { Mean - } \\
\text { Volume }\end{array}$ & microns & 24.2 & 20.6 & 20.7 & 20.8 & 20.9 \\
\hline $\begin{array}{c}\text { Mean - } \\
\text { Number }\end{array}$ & microns & 3.6 & 4.5 & 3.8 & 3.1 & 2.6 \\
\hline Mean - Area & microns & 13.5 & 13.3 & 12.4 & 11.3 & 10.1 \\
\hline CSSA & $\mathrm{m}^{2} / \mathrm{cm}^{3}$ & 0.4 & 0.5 & 0.5 & 0.5 & 0.6 \\
\hline
\end{tabular}

The rheology results for the Test 5 simulant are shown in Table 3-16. The simulant having the lowest solids loading was nearly Newtonian with only a small yield stress value of $0.8-0.8 \mathrm{~Pa}\left(8-9\right.$ dynes/cm ${ }^{2}$ ). However, as the solids loading in the simulant increased the yield stress and consistency climbed rapidly. It was possible to concentrate the Test 5 insoluble solids by use of the centrifuge to nearly the highest level of solids of any of the sludge preparation methods. 
WSRC-TR-2004-00578

Revision 0

Table 3-16 Test 5 Rheology Results

\begin{tabular}{|c|c|c|c|}
\hline $\begin{array}{c}\text { Insoluble } \\
\text { Solids } \\
\text { (wt \%) }\end{array}$ & $\begin{array}{c}\text { Total } \\
\text { Solids } \\
\text { (wt \%) }\end{array}$ & $\begin{array}{c}\text { Bingham Yield Stress } \\
\text { (Pascal) }\end{array}$ & $\begin{array}{c}\text { Bingham Consistency } \\
\text { (cP) }\end{array}$ \\
\hline 7.25 & 14.85 & 0.9 & 3.8 \\
\hline 7.25 & 14.85 & 0.8 & 3.7 \\
\hline 10.23 & 17.53 & 4.1 & 6.6 \\
\hline 10.23 & 17.53 & 4.1 & 6.5 \\
\hline 12.96 & 19.93 & 11.7 & 11.7 \\
\hline 12.96 & 19.93 & 11.6 & 23.7 \\
\hline 15.44 & 22.26 & 29.0 & 27.9 \\
\hline 18.31 & 24.89 & 58.5 & \\
\hline
\end{tabular}

The increase in both yield stress and consistency as a function of either IS or TS again fits an exponential function. Applying equation (6) to the rheology data using the wt \% IS, gave the following Test 5 model equations:

$$
\begin{array}{ll}
\tau=\frac{e^{0.1335 X}}{1-X / 22.74} & \mathrm{r}^{2}=0.979 \\
\eta=\frac{e^{0.176 X}}{1-X / 100} & \mathrm{r}^{2}=0.94
\end{array}
$$

The fit for yield stress was very good while the fit for consistency was not quite as good. Additional measurements at the higher IS concentrations might improve the consistency fit. Figure 3-24 and Figure 3-25 compare the model curve to the simulant data and also to the actual radioactive sample data.

Additional data in the region of rapid increase in both yield stress and in consistency would be useful to better confirm the depicted curves. Test 5 does not appear to be an effective physical simulant based on the actual waste data currently available. 
WSRC-TR-2004-00578

Revision 0

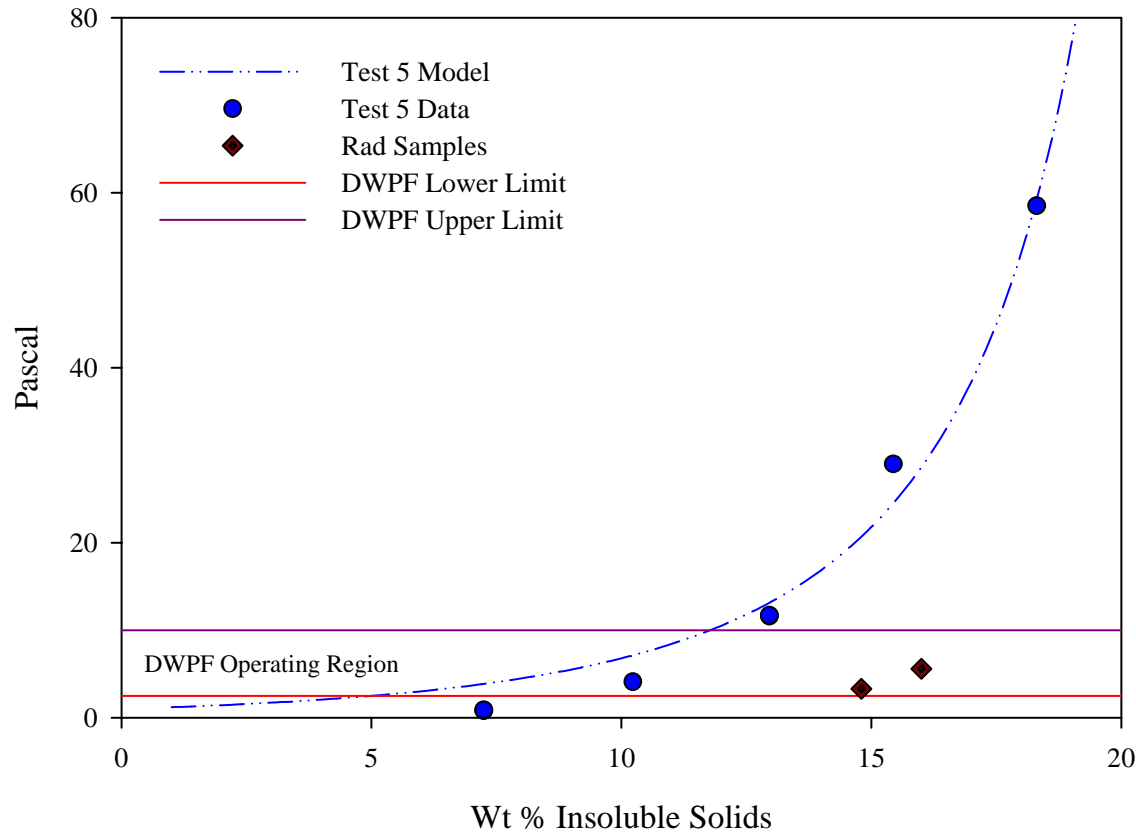

Figure 3-24 Test 5 Yield Stress and Insoluble Solids

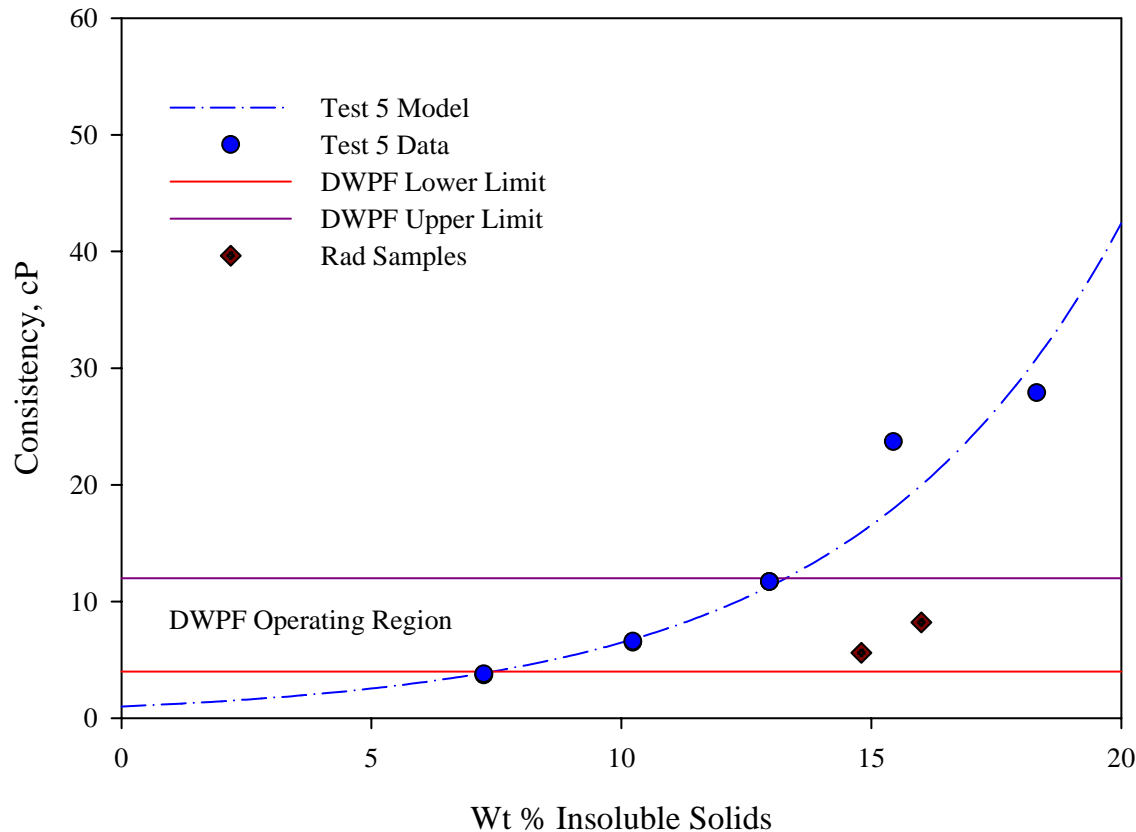

Figure 3-25 Test 5 Consistency and Insoluble Solids 


\subsection{Test 6 Modified $\mathrm{MnO}_{2}$ Generation Method}

Test 6 was the first of the sludge preparation methods that modified the sequence of chemical additions. All of the amounts of chemicals added are the same as in Tests 1, 2, 4 and 5 (test 3 increased the batch size by a factor of 5). The new sequence of steps to produce the sludge is given below:

6-A. Combine the following metal nitrates and dissolve: Fe, Ni, Zr, Ce, Gd, La, Ba, Ca, Cd, $\mathrm{Cr}, \mathrm{Cu}, \mathrm{Mg}, \mathrm{Pb}, \mathrm{Sr}, \mathrm{Zn}$, and $\mathrm{Ag}$.

6-B. Add potassium permanganate to the solution from 6-A and mix to dissolve. While mixing, add manganous nitrate solution to precipitate $\mathrm{MnO}_{2}$.

6-C. Precipitate the metals by addition of an 8 molar or greater $\mathrm{NaOH}$ solution while maintaining good mixing. The $\mathrm{pH}$ target for the precipitated slurry is between $\mathrm{pH} 10$ and $\mathrm{pH} 11$ using caustic addition.

6-D. Add 0.4 liters of a 0.6 molar sodium carbonate solution per liter of precipitated sludge to convert moderately-soluble hydroxides into less soluble carbonates.

6-E. $\quad$ Stop mixing and allow the sludge to settle for 24-48 hours before decanting and disposing of the clear supernate (high in sodium nitrate solution).

6-F. $\quad$ Wash the settled sludge by addition 3 volumes of $\mathrm{pH} 11$ inhibited water (0.001 molar NaNO2 and 0.001 molar $\mathrm{NaOH}$ ) per volume of settled sludge. Settle overnight and decant the clear spent wash water.

6-G. $\quad$ Repeat step 6-F two more times.

6-H. Confirm that the nitrate anion concentration in the supernate is $1000 \mathrm{mg} / \mathrm{L}$ or less. If not repeat step 6-F and analyze the nitrate anion concentration..

6-I. Add the following base-reactive insoluble solids: $\mathrm{Al}_{2} \mathrm{O}_{3}, \mathrm{SiO}_{2}, \mathrm{SnO}_{2}, \mathrm{TiO}_{2}$.

6-J. $\quad$ Determine the volume of sludge produced. This can be done by measuring the sludge mass and the density of the sludge and calculating the volume.

6-K. Add the salts necessary to match the supernate concentrations for the soluble species.

The production of the hydrated $\mathrm{MnO}_{2}$ in the presence of metal ions is a better simulation of the process by which the $\mathrm{MnO}_{2}$ in the actual waste was produced. It also allows the metal ions to play a role in the generation of the $\mathrm{MnO}_{2}$ precipitate by either absorption or as a coagulant. Both mechanisms have been reported to take place in studies of $\mathrm{MnO}_{2}$ chemistry. ${ }^{11,12}$

Particle size data only showed a minor shift to smaller particles as the Test 6 simulant was produced. The results are shown in Figure 3-26, Figure 3-27 and in Table 3-17. 


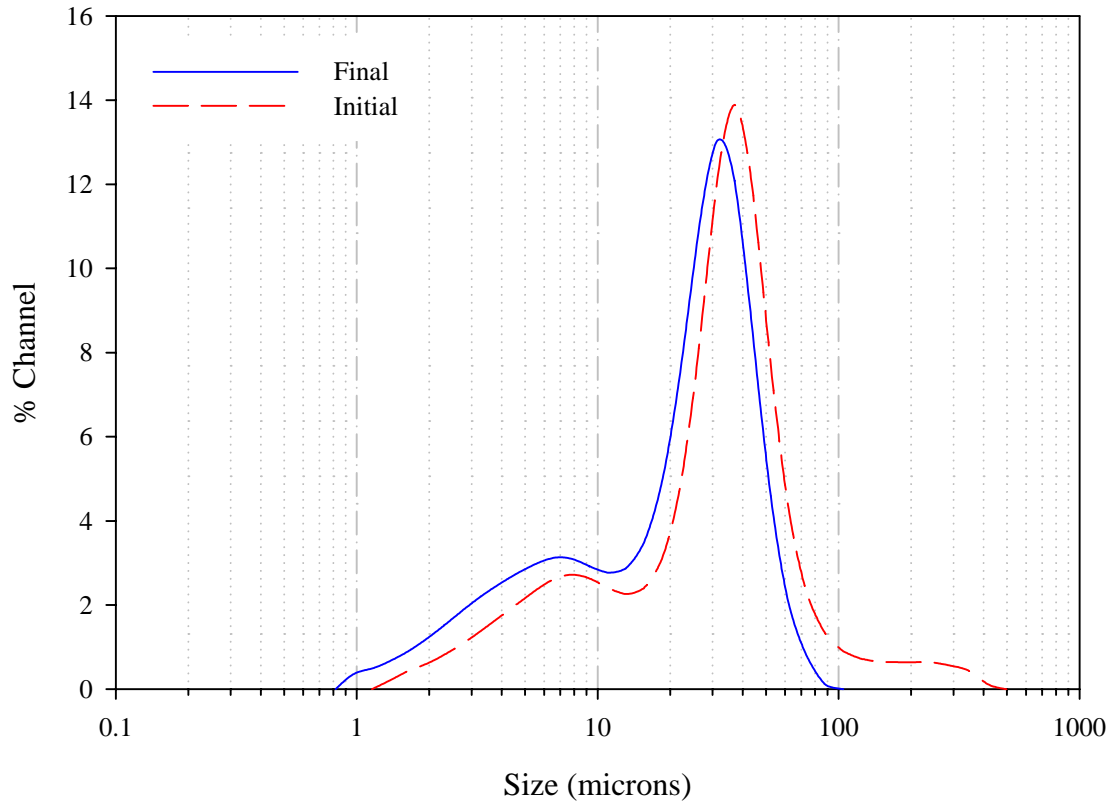

Figure 3-26 Test 6 Particle Size Distribution on a Volume Basis

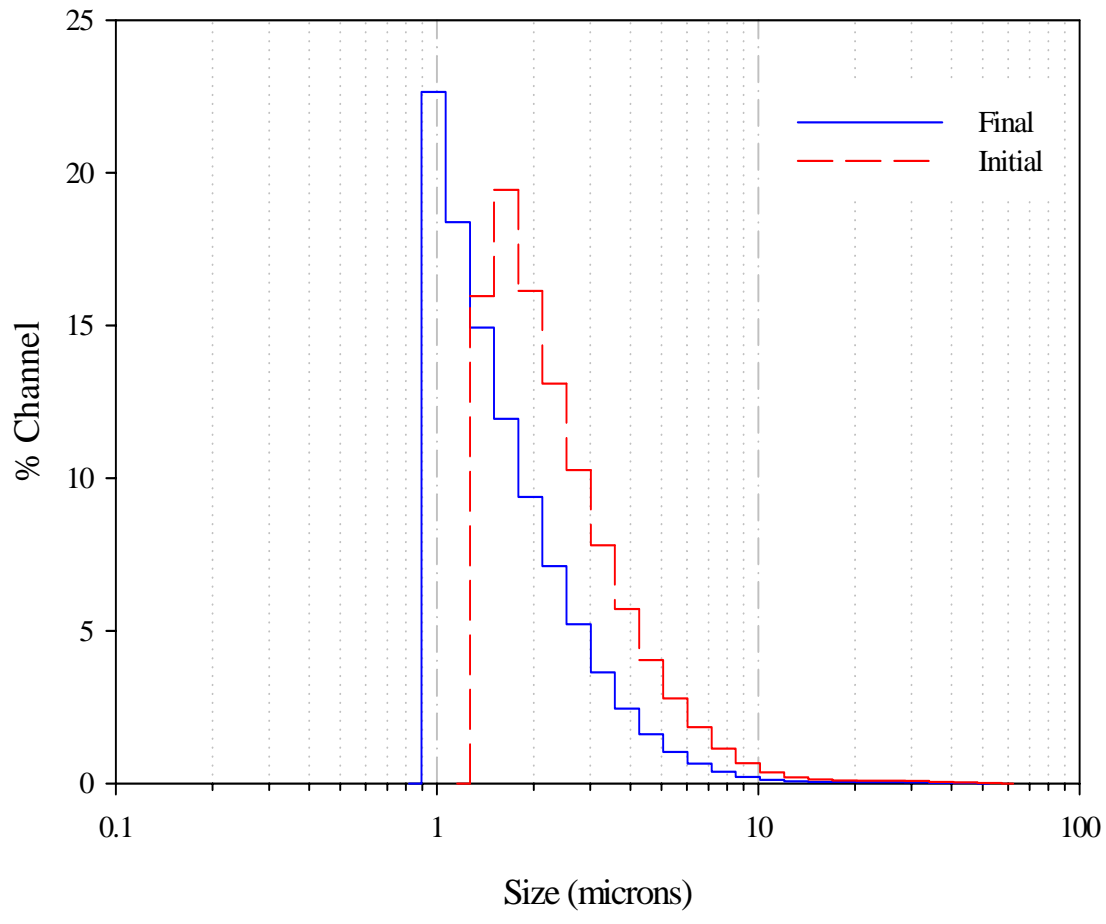

Figure 3-27 Test 6 Particle Size Distribution on a Number Basis 
WSRC-TR-2004-00578

Revision 0

Table 3-17 Summary of Particle Size Results for Test 6

\begin{tabular}{|c|c|c|c|}
\hline Measurement & Units & Initial & Final \\
\hline $\begin{array}{c}\text { Mean - } \\
\text { Volume }\end{array}$ & microns & 33.3 & 22.4 \\
\hline $\begin{array}{c}\text { Mean - } \\
\text { Number }\end{array}$ & microns & 2.5 & 1.7 \\
\hline Mean - Area & microns & 13.2 & 9.0 \\
\hline CSSA & $\mathrm{m}^{2} / \mathrm{cm}^{3}$ & 0.5 & 0.7 \\
\hline
\end{tabular}

The rheology results for the Test 6 simulant are summarized in Table 3-18.

Table 3-18 Test 6 Rheology Results

\begin{tabular}{|c|c|c|c|}
\hline $\begin{array}{c}\text { Insoluble } \\
\text { Solids } \\
\text { (wt \%) }\end{array}$ & $\begin{array}{c}\text { Total } \\
\text { Solids } \\
\text { (wt \%) }\end{array}$ & $\begin{array}{c}\text { Bingham Yield Stress } \\
\text { (Pascal) }\end{array}$ & $\begin{array}{c}\text { Bingham Consistency } \\
\text { (cP) }\end{array}$ \\
\hline 7.26 & 15.07 & 2.3 & 4.5 \\
\hline 7.26 & 15.07 & 2.3 & 4.6 \\
\hline 10.44 & 17.84 & 7.9 & 10.7 \\
\hline 10.44 & 17.84 & 7.7 & 21.3 \\
\hline 13.2 & 20.34 & 20.1 & 21.4 \\
\hline 13.2 & 20.34 & 20.2 & 32.6 \\
\hline 14.49 & 21.54 & 32.6 & 49 \\
\hline 15.74 & 22.68 & 51.2 & \\
\hline
\end{tabular}

The rise in yield stress and consistency as a function of IS or TS is exponential. Applying equation (6) to the rheology results using the insoluble solids data as X, gave the following Test 6 model equations:

$$
\begin{array}{cc}
\tau=\frac{e^{0.1344 X}}{1-X / 18.74} & \mathrm{r}^{2}=0.993 \\
\eta=\frac{e^{0.157 X}}{1-X / 20.78} & \mathrm{r}^{2}=0.999
\end{array}
$$

The fits for yield stress and consistency were excellent. The yield stress fit indicate that the simulant will approach a solid material at 18.74 wt \% IS. Figure 3-28 and Figure 3-29 compare the model curve to the simulant data and to the actual radioactive sample data and show the excellent fit to the model equations. Additional data in the region of rapid increase in both yield stress and in consistency would be useful to better confirm the depicted curves. The Test 6 simulant does not appear to be a good physical simulant based on the actual waste data available. 
WSRC-TR-2004-00578

Revision 0

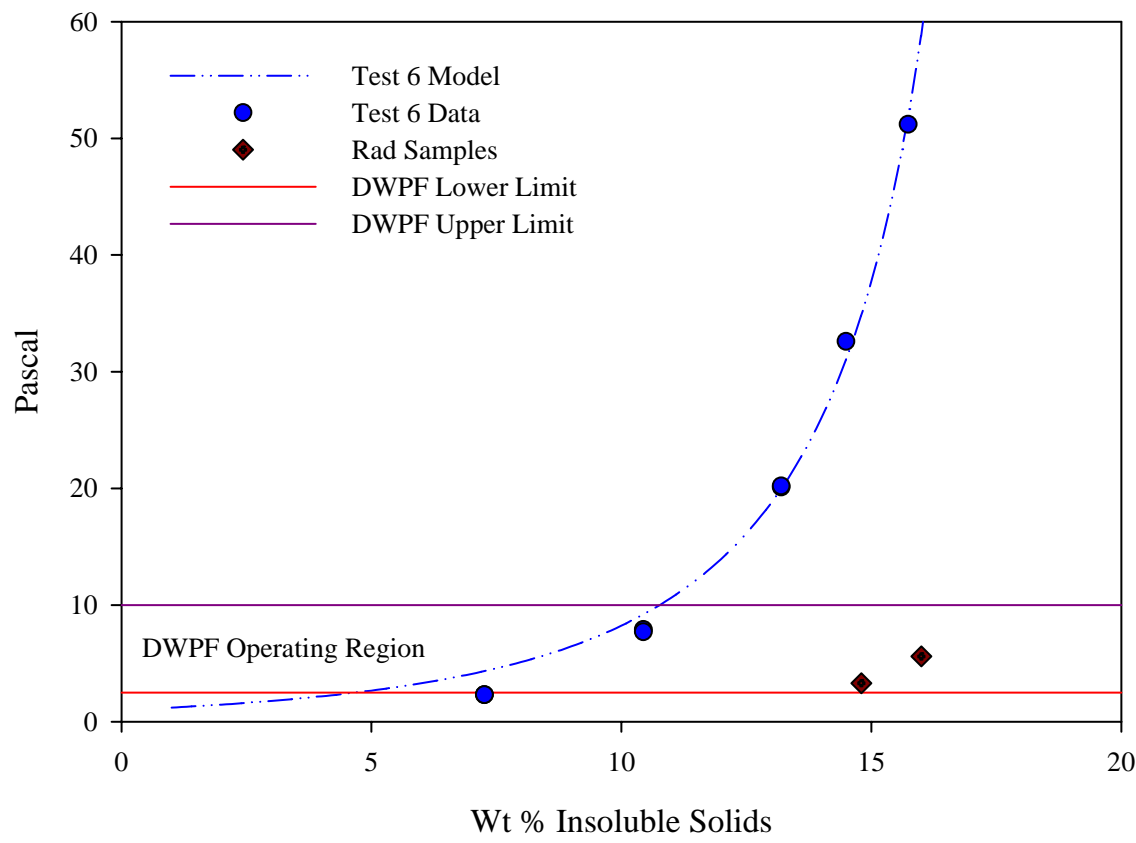

Figure 3-28 Test 6 Yield Stress versus Insoluble Solids

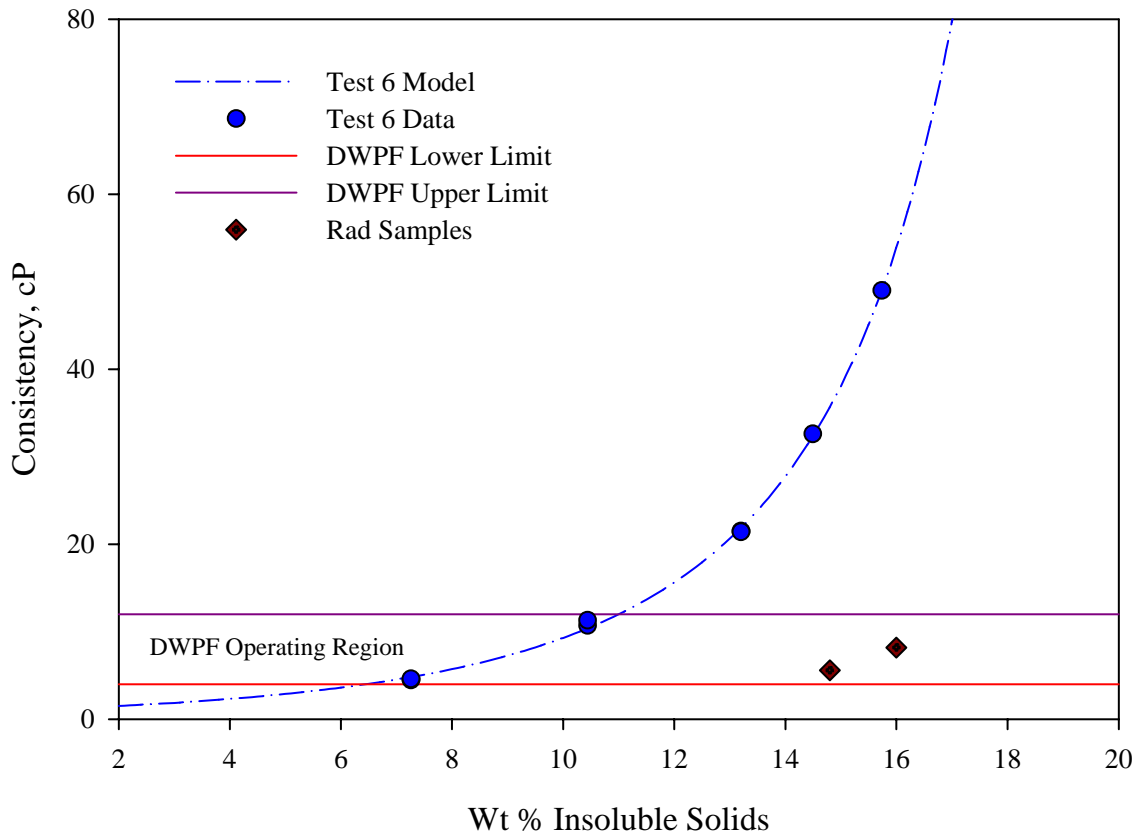

Figure 3-29 Test 6 Consistency Results

\subsection{Test 7 Coprecipitation of Aluminum Method}

Test 7 was developed to be the most complete representation of the manner in which DWPF sludge was produced at the Savannah River Site without using a heat treatment step. The change made to the sludge preparation method was to include aluminum in the metals precipitate in step 6-C in section 3.8. The Test 
7 simulant was produced by following the same steps as the Test 6 simulant with the modification of including aluminum in the initial mixture. The $\mathrm{pH}$ target on step 6-C was also adjusted to 9-10 instead of 10-11 to prevent redissolution of the precipitated aluminum (aluminum solubility increases rapidly above $\mathrm{pH}$ 10). The final change was to add only $\mathrm{SiO}_{2}, \mathrm{SnO}_{2}$ and $\mathrm{TiO}_{2}$ in step 6-I.

The particle size results for the Test 7 sludge are shown in Figure 3-30, Figure 3-31 and in

Table 3-19. The only change observed during Test 7 production was a small shift to smaller particles similar to that seen in some of the other test mixtures.

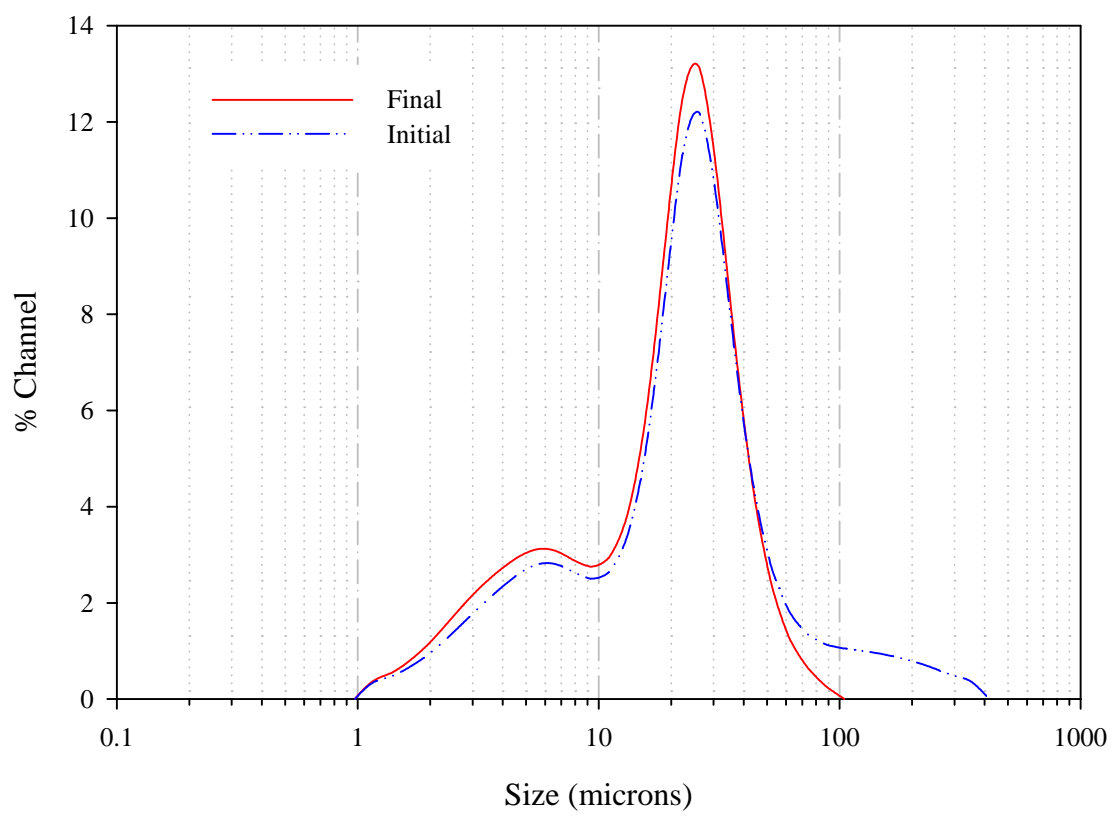

Figure 3-30 Test 7 Particle Size Distribution on a Volume Basis 
WSRC-TR-2004-00578

Revision 0

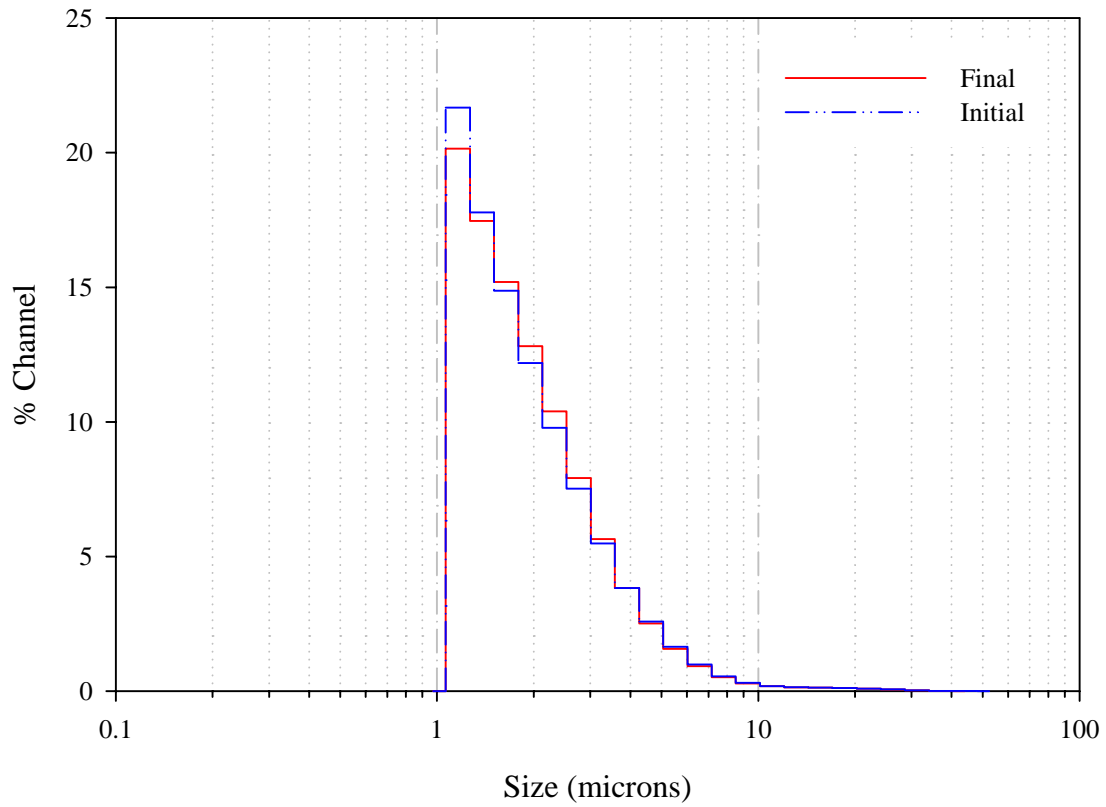

Figure 3-31 Test 7 Particle Size Number Distribution

Table 3-19 Summary of Particle Size Results for Test 7

\begin{tabular}{|c|c|c|c|}
\hline Measurement & Units & Initial & Final \\
\hline $\begin{array}{c}\text { Mean - } \\
\text { Volume }\end{array}$ & microns & 29.2 & 19.7 \\
\hline $\begin{array}{c}\text { Mean - } \\
\text { Number }\end{array}$ & microns & 2.0 & 2.0 \\
\hline Mean - Area & microns & 10.2 & 9.1 \\
\hline CSSA & $\mathrm{m}^{2} / \mathrm{cm}^{3}$ & 0.6 & 0.7 \\
\hline
\end{tabular}

The rheology results for the Test 7 simulant as a function of solids is summarized in Table 3-20. Test 7 simulant was a thinner, less viscous sludge than any of the initial 6 simulants tested based on the measured values and on the observations of the sludge. The difference between the Test 7 simulant the others reported so far is that the Test 7 simulant yield stress is much smaller for a given wt \% IS as compared to the other simulants. 
WSRC-TR-2004-00578

Revision 0

Table 3-20 Test 7 Rheology Results

\begin{tabular}{|c|c|c|c|}
\hline $\begin{array}{c}\text { Insoluble } \\
\text { Solids } \\
\mathbf{( w t} \%)\end{array}$ & $\begin{array}{c}\text { Total } \\
\text { Solids } \\
\mathbf{( w t ~ \% )} \\
7.26\end{array}$ & $\begin{array}{c}\text { Bingham Yield Stress } \\
\text { (Pascal) }\end{array}$ & $\begin{array}{c}\text { Bingham Consistency } \\
\text { (cP) }\end{array}$ \\
\hline 7.26 & 15.08 & 0.37 & 3.4 \\
\hline 10.33 & 15.08 & 0.54 & 4.0 \\
\hline 10.33 & 17.8 & 2.38 & 7.0 \\
\hline 12.84 & 20.12 & 2.4 & 7.1 \\
\hline 12.84 & 20.12 & 7.0 & 16.1 \\
\hline 15.02 & 22.11 & 7.5 & 16.1 \\
\hline 15.02 & 22.11 & 7.35 & 44.2 \\
\hline 18.31 & 25.12 & 7.6 & 45.6 \\
\hline & & 11.4 & 76.8 \\
\hline
\end{tabular}

The rise in both yield stress and consistency as a function of either IS or TS can be represented by an exponential function. Applying equation (6) to the rheology data using the wt \% insoluble solids data as $\mathrm{X}$, gave the following Test 7 model equations:

$$
\begin{array}{ll}
\tau=\frac{e^{0.099 X}}{1-X / 37.99} & \mathrm{r}^{2}=0.85 \\
\eta=\frac{e^{0.228 X}}{1-X / 99.87} & \mathrm{r}^{2}=0.953
\end{array}
$$

The fit for the yield stress is not very good due to a lot of scatter in the data and similar values for the 12.8 and $15.0 \mathrm{wt} \%$ IS data. Note that the fit includes the requirement that a solution without solids will not have a measurable yield stress (however the exponential function returns a value of one at zero wt \% IS). The fit for consistency was definitely better. Figure 3-32 and Figure 3-33 compare the fitted data (equations (19 and (20)) to the simulant data and to the actual radioactive sample data. Additional data for this simulant in the region of rapid increase in both yield stress and in consistency would be useful to better confirm the depicted curves. The Test 7 simulant is a more representative physical simulant based on measurements of the yield stress of the actual waste. The comparison between the Test 7 simulant consistency and actual waste consistency measurements remains poor. 
WSRC-TR-2004-00578

Revision 0

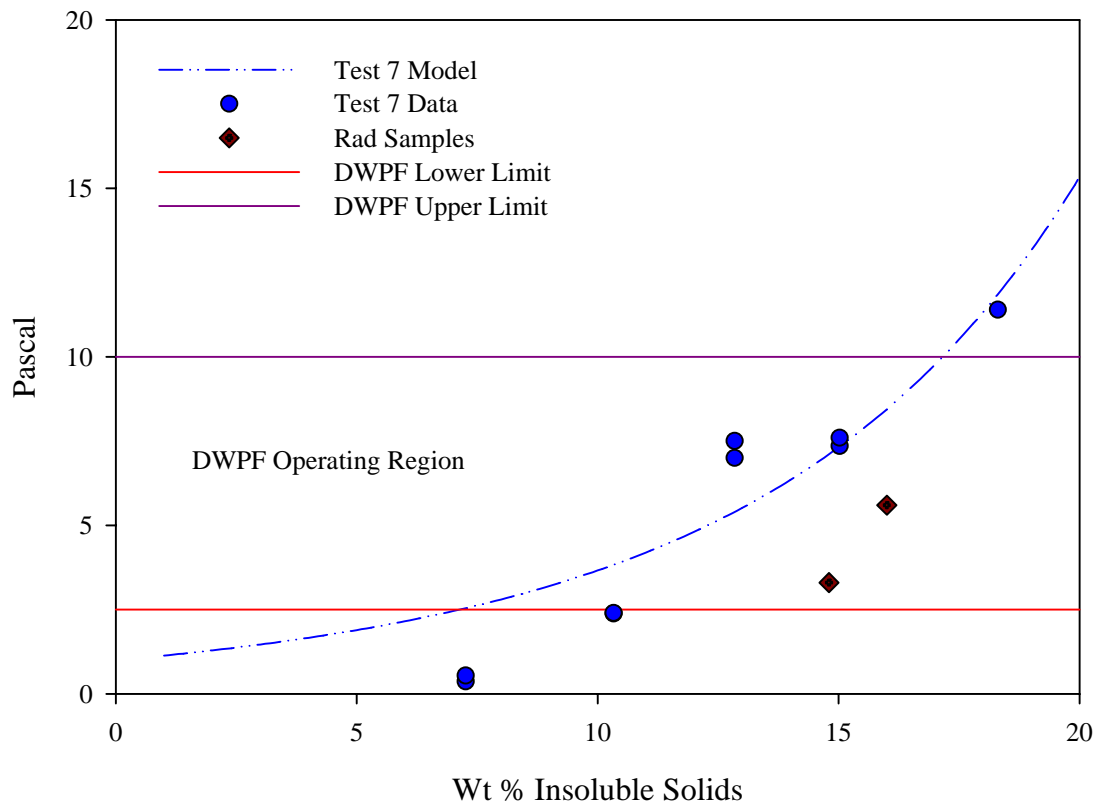

Figure 3-32 Test 7 Yield Stress Results

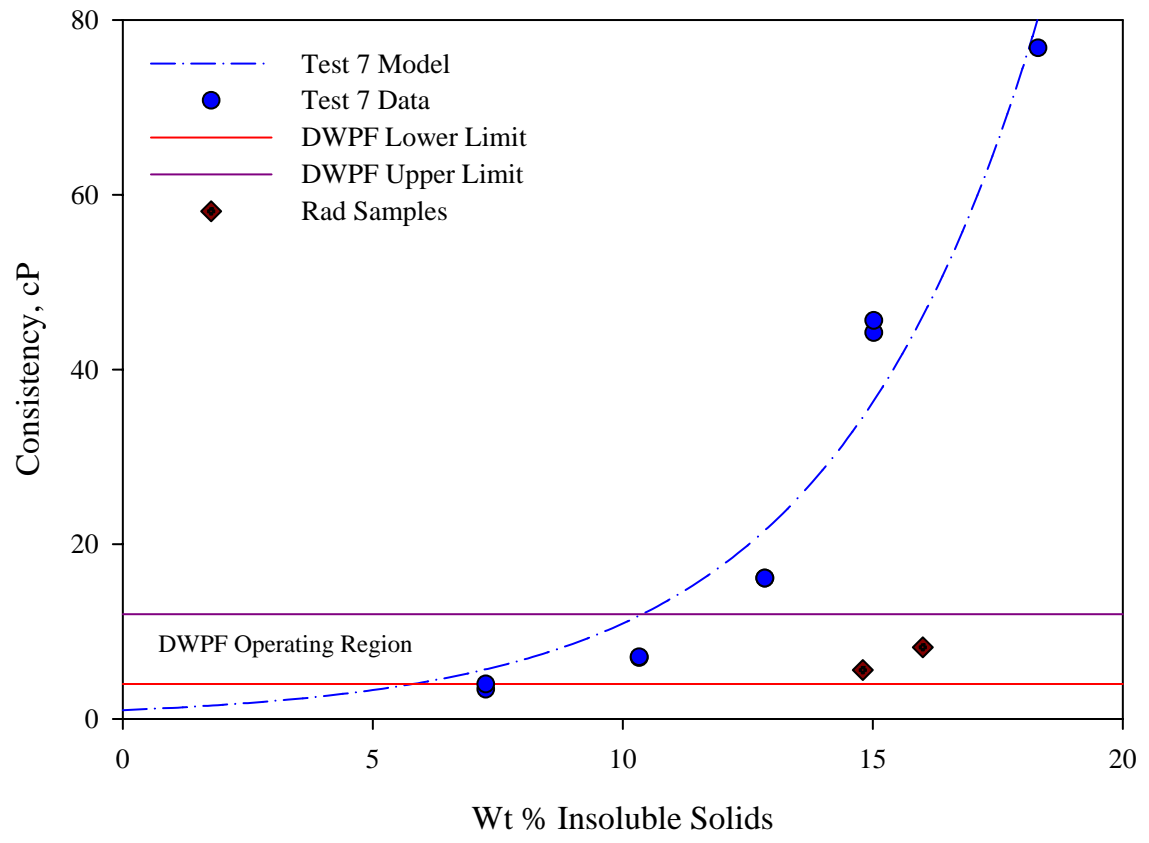

Figure 3-33 Test 7 Consistency Results

\subsection{Test 8 Heat Treatment Combined with Coprecipitation of Aluminum Method}

Test 8 combined the Test 7 method of sludge production with the Test 5 heat treatment step to give a sludge simulant that has nearly all species precipitated and a sludge that has a thermal history. The Test 8 simulant was prepared by the same process as the test 7 simulant, but with the addition of 8 hours of $98^{\circ}$ C heating after the base-reactive insoluble solids addition (step 6-I, section 3.8). 
The density was measured for all five wt \% insoluble solids concentrations of the Test 8 simulant and is plotted in Figure 3-34 along with the density of the supernate phase (wt $\%$ IS $=0$ ). The comparison with the actual density measured for the radioactive sludge sample that served as a basis for these simulants shows an excellent agreement. ${ }^{3}$

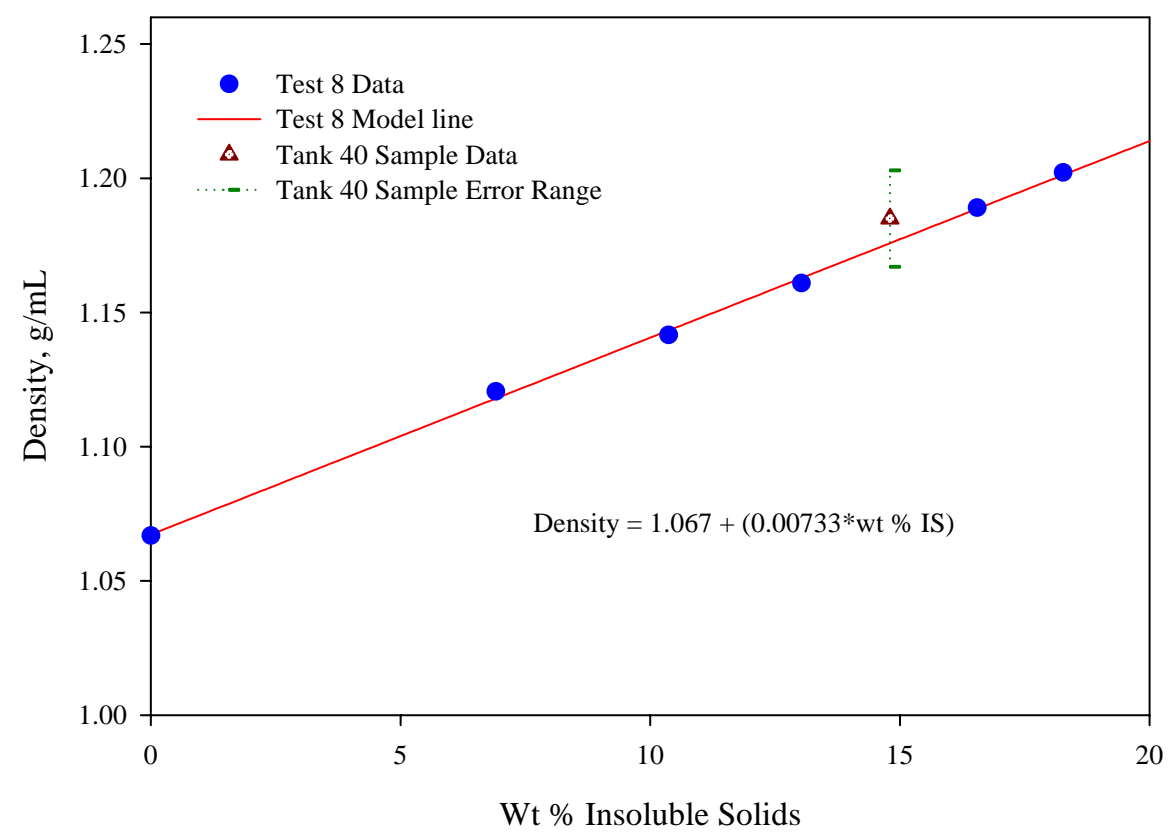

Figure 3-34 Test 8 Simulant Density as a Function of Insoluble Solids

The results for the particle size distribution for Test 8 simulant was similar to that obtained for the Test 7 simulant. The results are shown in Figure 3-35, Figure 3-36 and are tabulated in Table 3-21. 


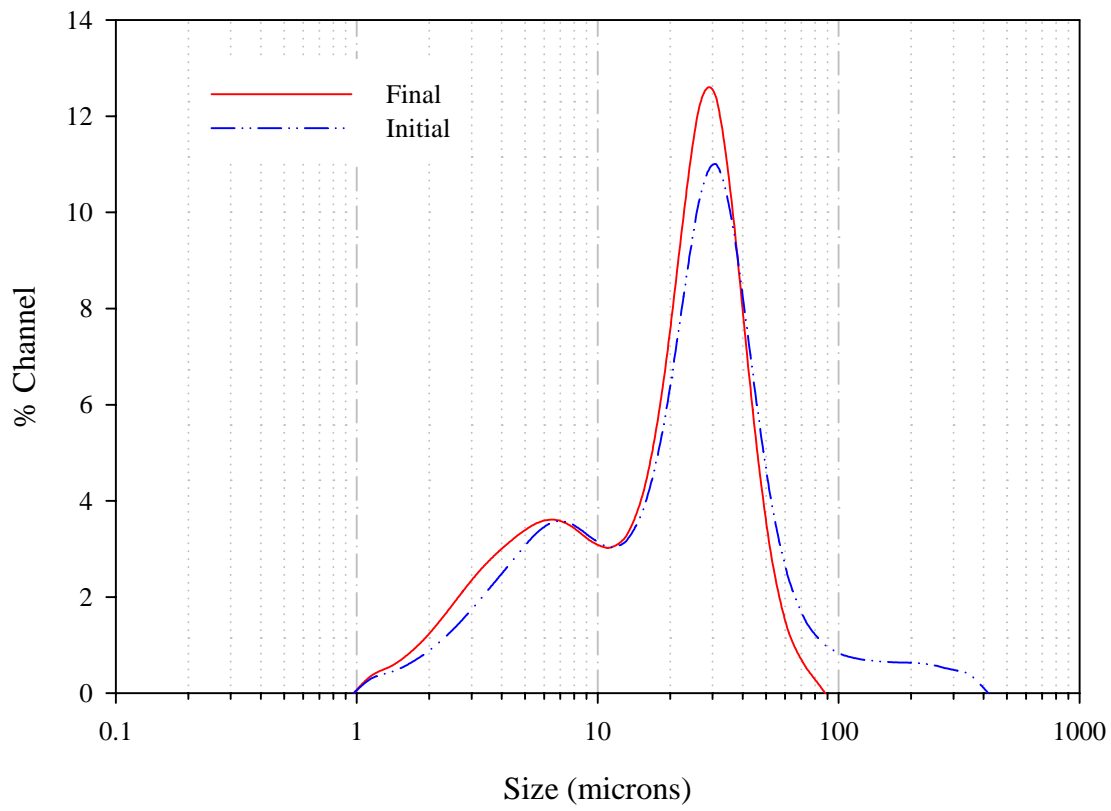

Figure 3-35 Test 8 Particle Size Volume Distribution

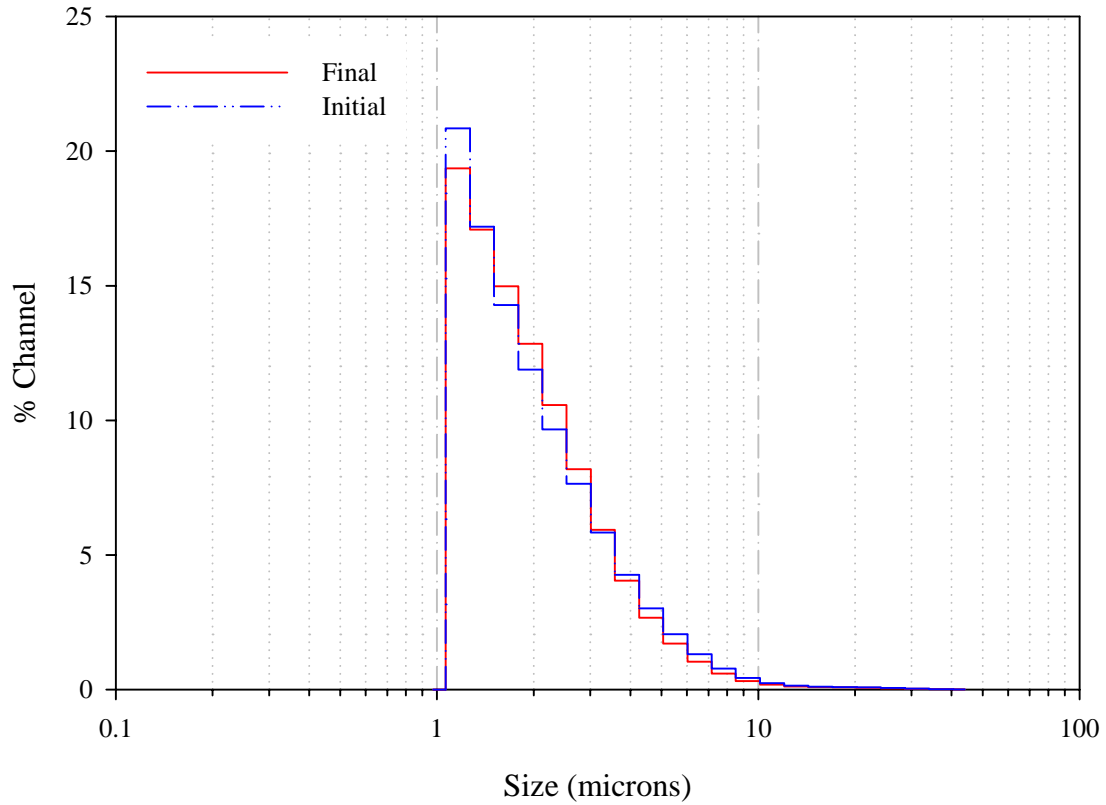

Figure 3-36 Test 8 Particle Size Number Distribution 
WSRC-TR-2004-00578

Revision 0

Table 3-21 Summary of Particle Size Results for Test 8

\begin{tabular}{|c|c|c|c|c|c|}
\hline Measurement & Units & Initial & $\begin{array}{c}\text { After } \\
\text { Washing }\end{array}$ & $\begin{array}{c}\text { After } \\
\text { Heating }\end{array}$ & Final \\
\hline $\begin{array}{c}\text { Mean - } \\
\text { Volume }\end{array}$ & microns & 30.1 & 28.9 & 25.4 & 20.1 \\
\hline $\begin{array}{c}\text { Mean - } \\
\text { Number }\end{array}$ & microns & 2.1 & 2 & 2 & 2.1 \\
\hline Mean - Area & microns & 10.2 & 9.9 & 9.3 & 8.8 \\
\hline CSSA & $\mathrm{m}^{2} / \mathrm{cm}^{3}$ & 0.6 & 0.6 & 0.6 & 0.7 \\
\hline
\end{tabular}

The rheology results for the Test 8 simulants listed in Table 3-22 show that the sludge was the least viscous material produced. The variability in the measured values (especially for the yield stress) is high and additional data would be useful.

Table 3-22 Test 8 Rheology Results

\begin{tabular}{|c|c|c|c|}
\hline $\begin{array}{c}\text { Insoluble } \\
\text { Solids } \\
\text { (wt \%) }\end{array}$ & $\begin{array}{c}\text { Total } \\
\text { Solids } \\
\text { (wt \%) }\end{array}$ & $\begin{array}{c}\text { Bingham Yield Stress } \\
\text { (Pascal) }\end{array}$ & $\begin{array}{c}\text { Bingham Consistency } \\
\text { (cP) }\end{array}$ \\
\hline 6.91 & 14.65 & 0.58 & 4.0 \\
\hline 6.91 & 14.65 & 0.58 & 4.0 \\
\hline 10.37 & 17.95 & 3.89 & 8.5 \\
\hline 10.37 & 17.95 & 3.88 & 8.5 \\
\hline 13.03 & 20.38 & 8.75 & 25.5 \\
\hline 13.03 & 20.38 & 8.47 & 25.4 \\
\hline 16.55 & 23.61 & 5.74 & 36.6 \\
\hline 18.27 & 25.18 & 8.29 & 43.1 \\
\hline
\end{tabular}

Applying equation (6) to the rheology results using the wt \% IS data as X, gave the following Test 8 model equations:

$$
\begin{array}{cc}
\tau=\frac{e^{0.112 X}}{1-X / 100} & \mathrm{r}^{2}=0.61 \\
\eta=\frac{e^{0.2 X}}{1-X / 100} & \mathrm{r}^{2}=0.89
\end{array}
$$

The fit for yield stress is very poor and has the same issues noted for the Test 7 simulant. Note that the fit includes a data point for zero insoluble solids producing no measurable yield stress. The fit for consistency was to some extent better but also includes the viscosity value for water(representing no solids). Figure 3-37 and Figure 3-38 compare the fitted data (equations (21) and (22)) to the simulant data and the actual radioactive sample data. Additional data for this simulant in both yield stress and in consistency would be useful to better confirm the current fitted curves or determine curves that are more 
representative. The Test 8 simulant is the closest to being a representative physical simulant based on the yield stress of the actual waste data. The comparison between the Test 8 simulant consistency and actual waste consistency measurements is poor.

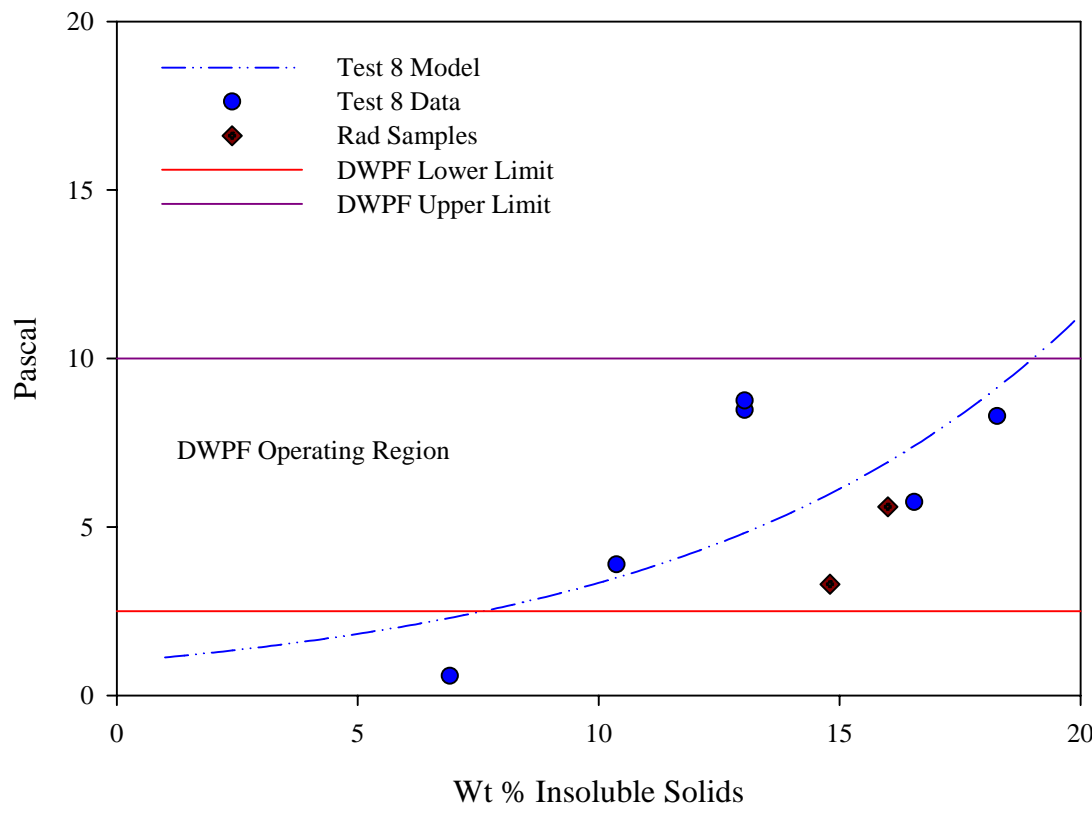

Figure 3-37 Test 8 Yield Stress as a Function of Insoluble Solids

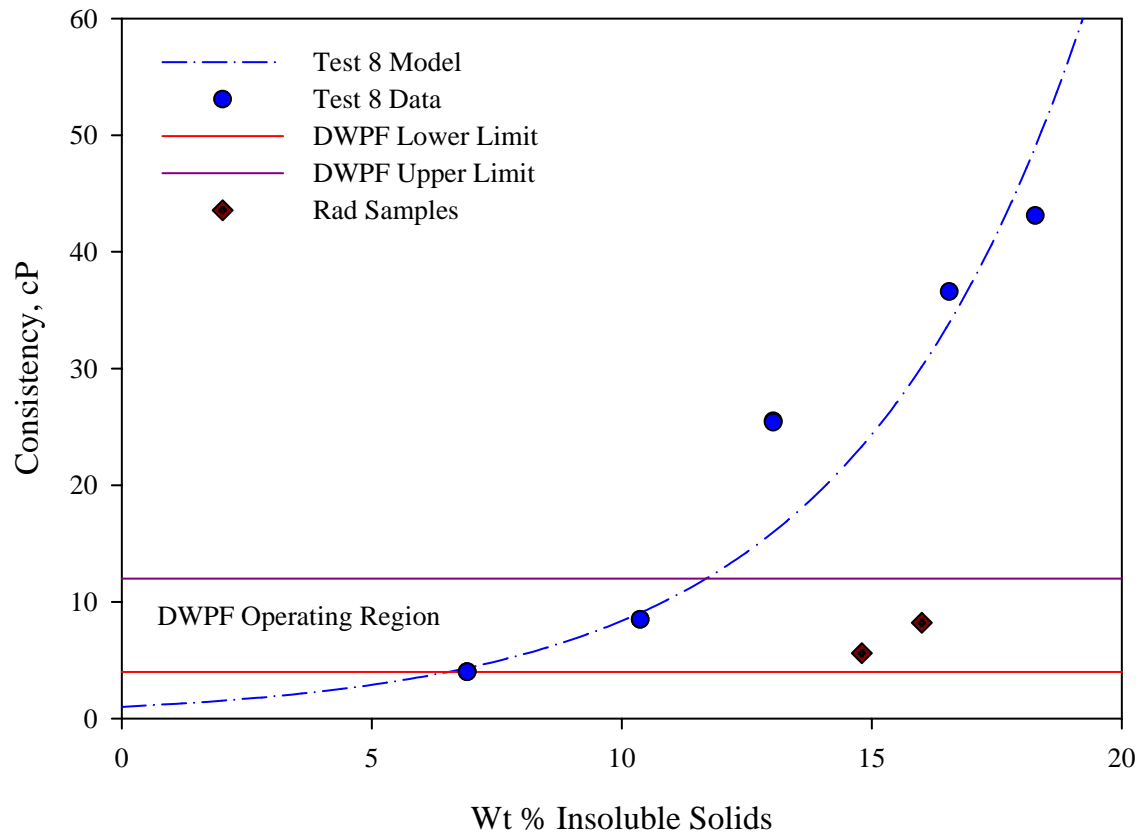

Figure 3-38 Test 8 Consistency Results 


\subsection{Impact of the Sequence of Metal Species Addition}

Tests 6, 7 and 8 tested alternative sequences of metal additions and can be compared to the baseline (Test 1) method to determine the impact of addition sequence. A comparison of particle size distributions for Test 6 and Test 1 simulants show that the impact of including other metal ions during the precipitation of $\mathrm{MnO}_{2}$ leads to a narrowing the particle size distribution. Figure 3-39 and Figure 3-40 show that the both the volume and the number distributions for the final Test 6 simulant tighten which may be an indication that the presence of the other metal ions does promote coagulation of the solids.

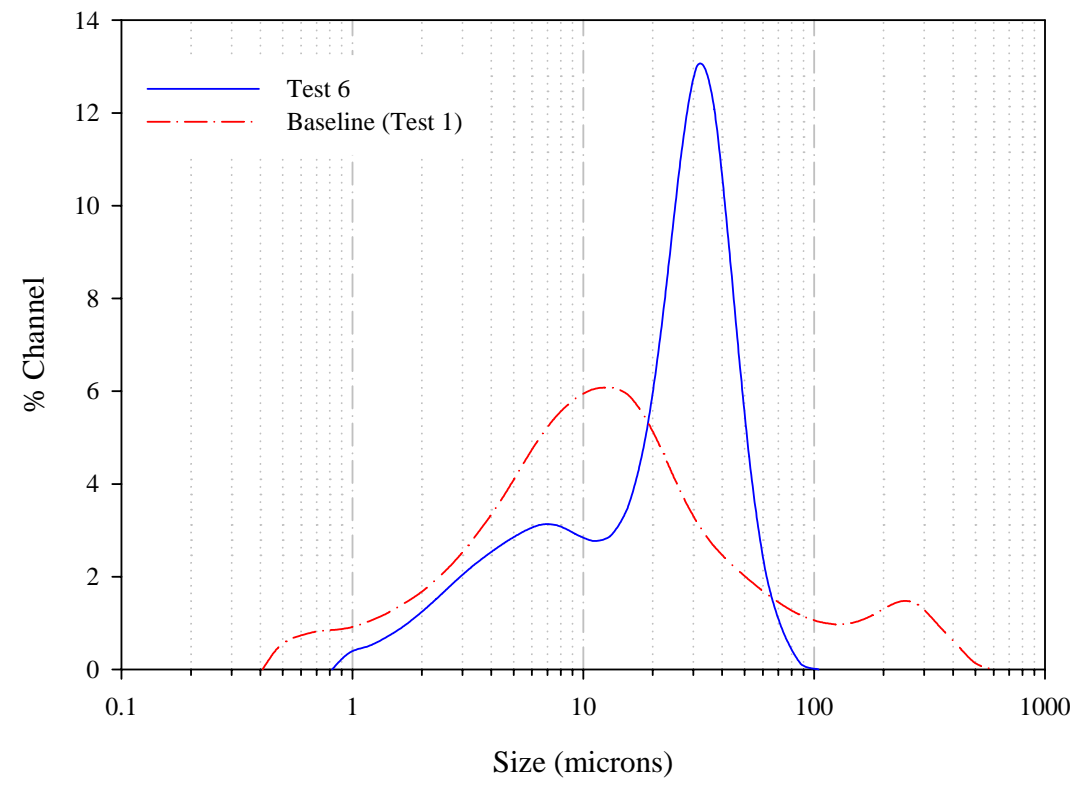

Figure 3-39 Comparison of the Particle Size Distribution by Volume for the Modified $\mathrm{MnO}_{2}$ Method (Test 6) to the Baseline Method (Test 1) 
WSRC-TR-2004-00578

Revision 0

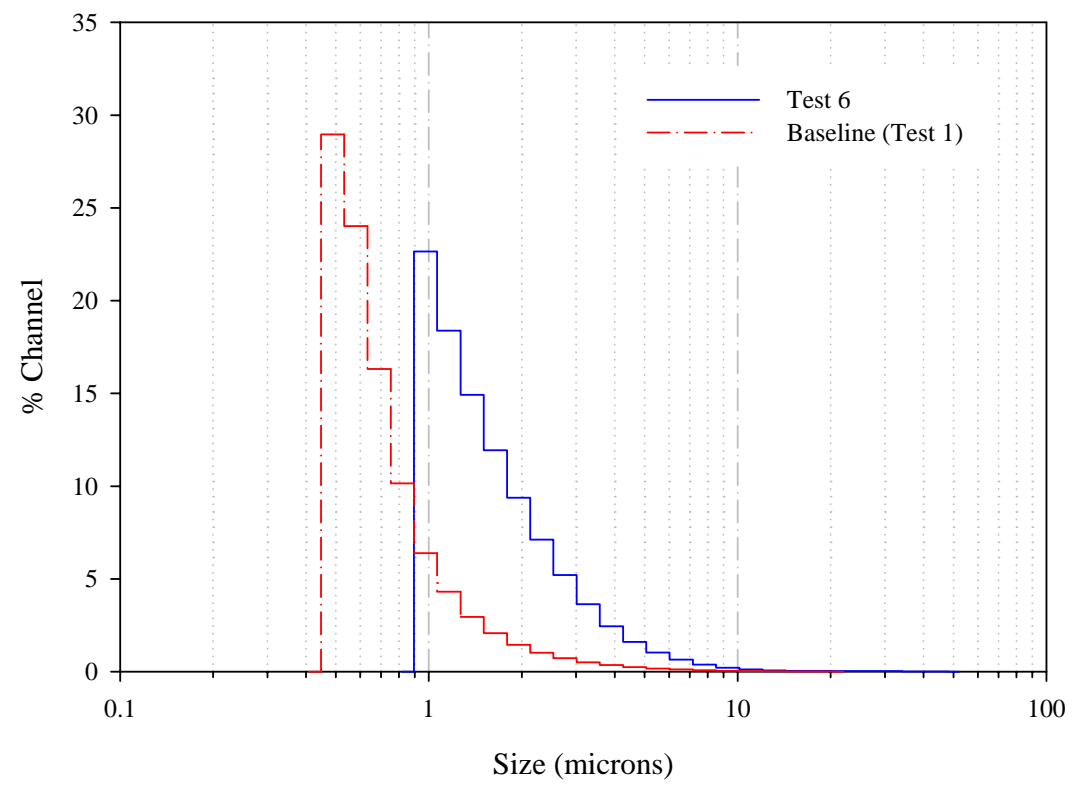

Figure 3-40 Comparison of the Particle Size Distribution by Number for the Modified $\mathrm{MnO}_{2}$ Method (Test 6) to the Baseline Method (Test 1)

A comparison of the rheology curves in Figure 3-41 and Figure 3-42 also shows that the modified $\mathrm{MnO}_{2}$ preparation method generated a more viscous sludge. This could also be due to the narrower particle size distribution or it might be an indication of more interparticle interactions due to other ions on the surface of the hydrated manganese dioxide particles. 
WSRC-TR-2004-00578

Revision 0

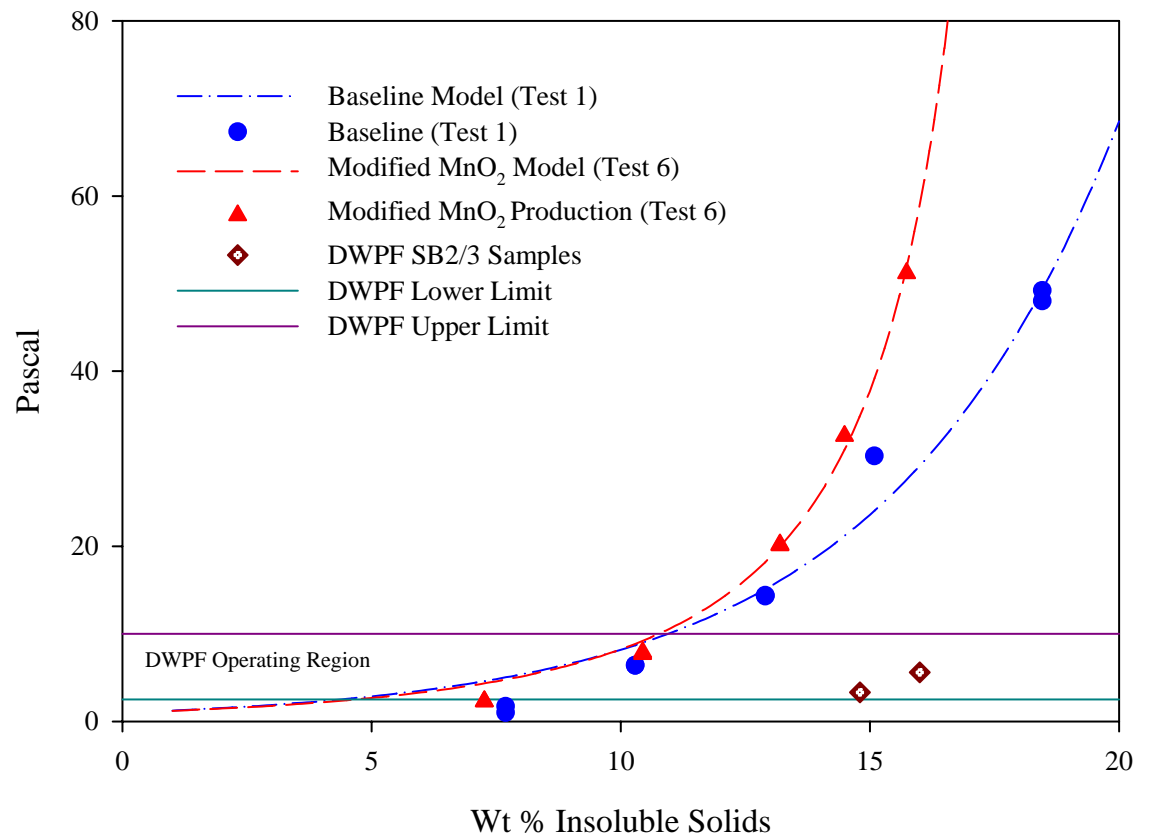

Figure 3-41 Comparison of Test 6 Yield Stress Result with the Baseline (Test 1) and Actual Sludge Batch 3 Rheology

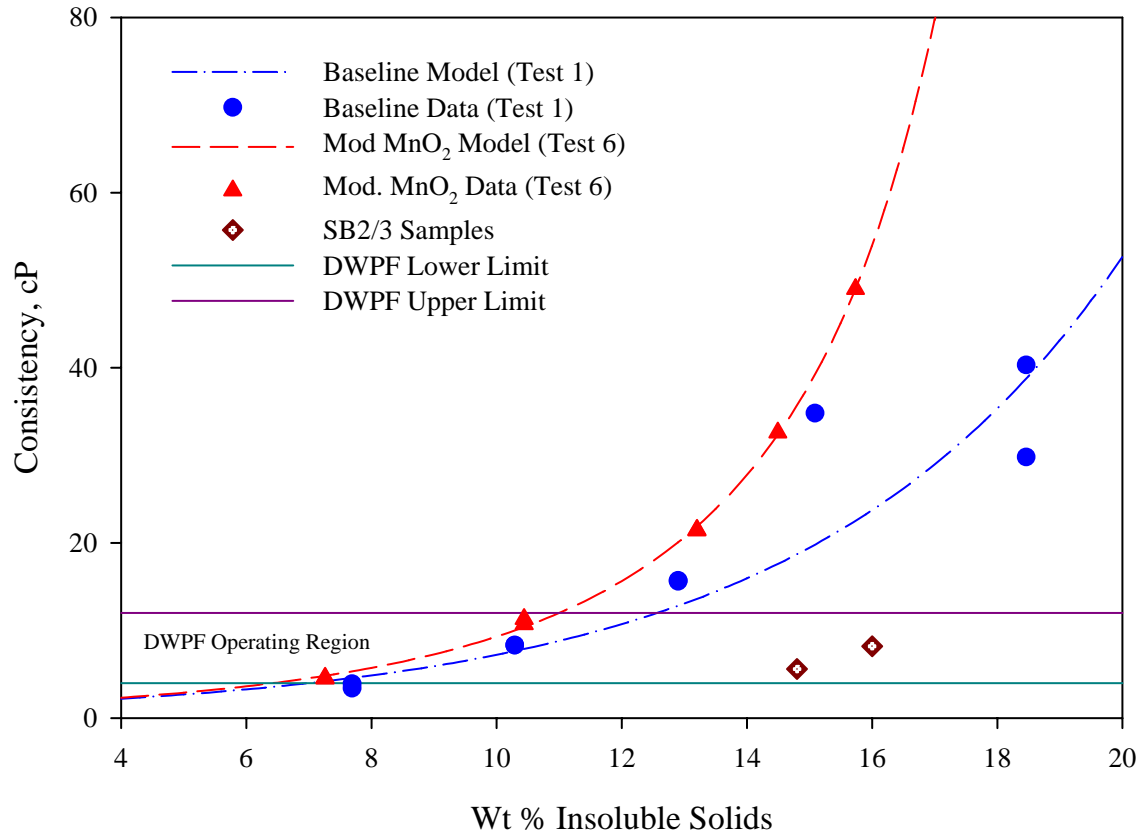

Figure 3-42 Comparison of Test 6 Consistency with Test 1 and Actual Sludge Batch 3 Consistency

Particle size data comparisons for the all metals precipitated sludge (Test 7) also show a narrowing of the distribution similar to that observed with the modified $\mathrm{MnO}_{2}$ method (Test 6). Figure 3-43 and Figure 3-44 compare the distributions for volume and number respectively for Test 7 with those for the baseline method (Test 1) of sludge production. Comparing the locations of the modes for tests 6, 7 and 1 (as 
shown in Table 3-23) also suggest that both of the modified sequence of additions methods have produced simulants that are similar based on particle size.

Table 3-23 Particle Size Comparisons

\begin{tabular}{|c|c|c|c|c|}
\hline \multirow{2}{*}{ Method } & $\begin{array}{c}\text { Average } \\
\text { Size }\end{array}$ & $\begin{array}{c}\text { Average } \\
\text { Size }\end{array}$ & Mode 1 & Mode 2 \\
\cline { 2 - 5 } & Volume & Number & Maxima & Maxima \\
\hline Test 1 & 33.8 & 0.75 & 12 & 370 \\
\hline Test 6 & 22.4 & 1.7 & 7 & 31 \\
\hline Test 7 & 20 & 2 & 6 & 25 \\
\hline
\end{tabular}

All units are in microns

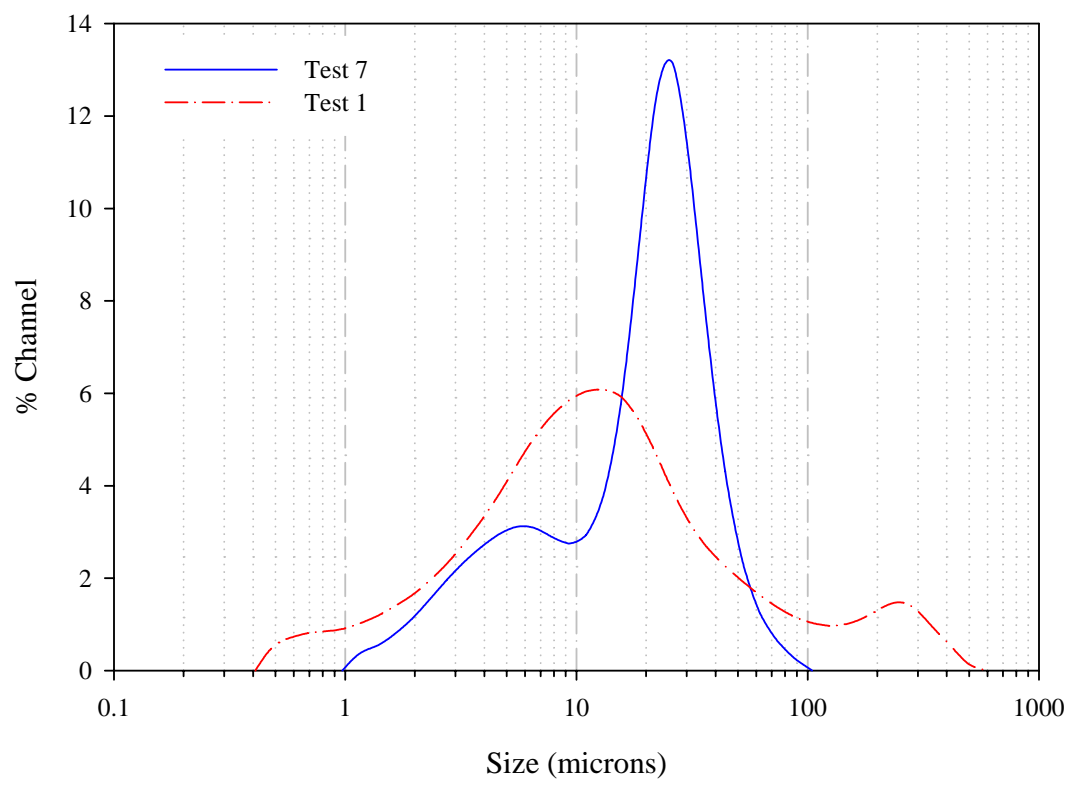

Figure 3-43 All Metals Precipitated Method Impact on Particle Size Volume Distribution 
WSRC-TR-2004-00578

Revision 0

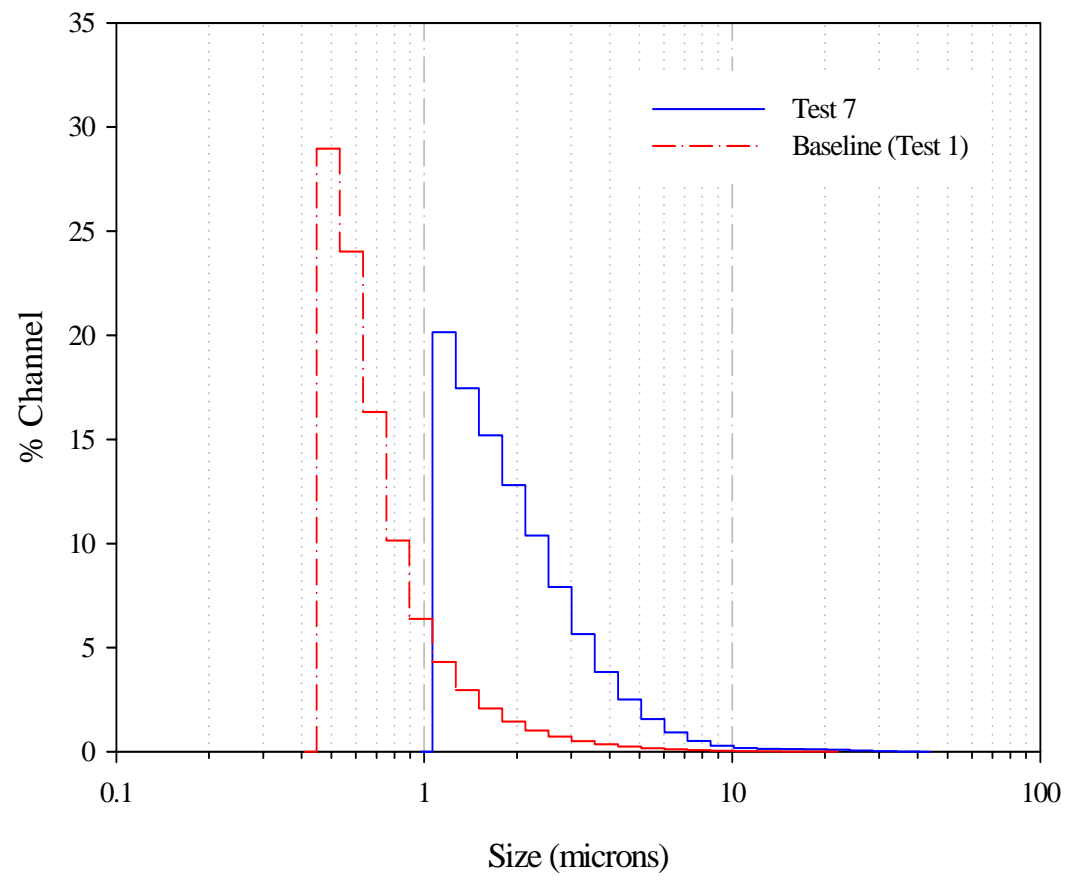

Figure 3-44 All Metals Precipitated Method (Test 7) Impact on Particle Size Number Distribution

The particle size data suggests that the rheology of Test 7 simulant should be similar to that of Test 6 simulant if the primary factor is the width of the particle size distribution. Therefore, Test 7 should be more viscous than Test 1 if this conclusion is correct.

The comparison of rheology results for the all metals precipitated sludge (Test 7) with the baseline sludge (Test 1 ) does not support the conclusion that the narrowing of the particle size distribution will lead to a more viscous sludge for this composition of waste. Figure 3-45 and Figure 3-46 show the relationship between yield stress or consistency and weight percent insoluble solids for Test 1 and Test 7 simulants. The Test 7 simulant has a lower rheology response for yield stress than the baseline sludge and reasonably matches that of the actual waste. 
WSRC-TR-2004-00578

Revision 0

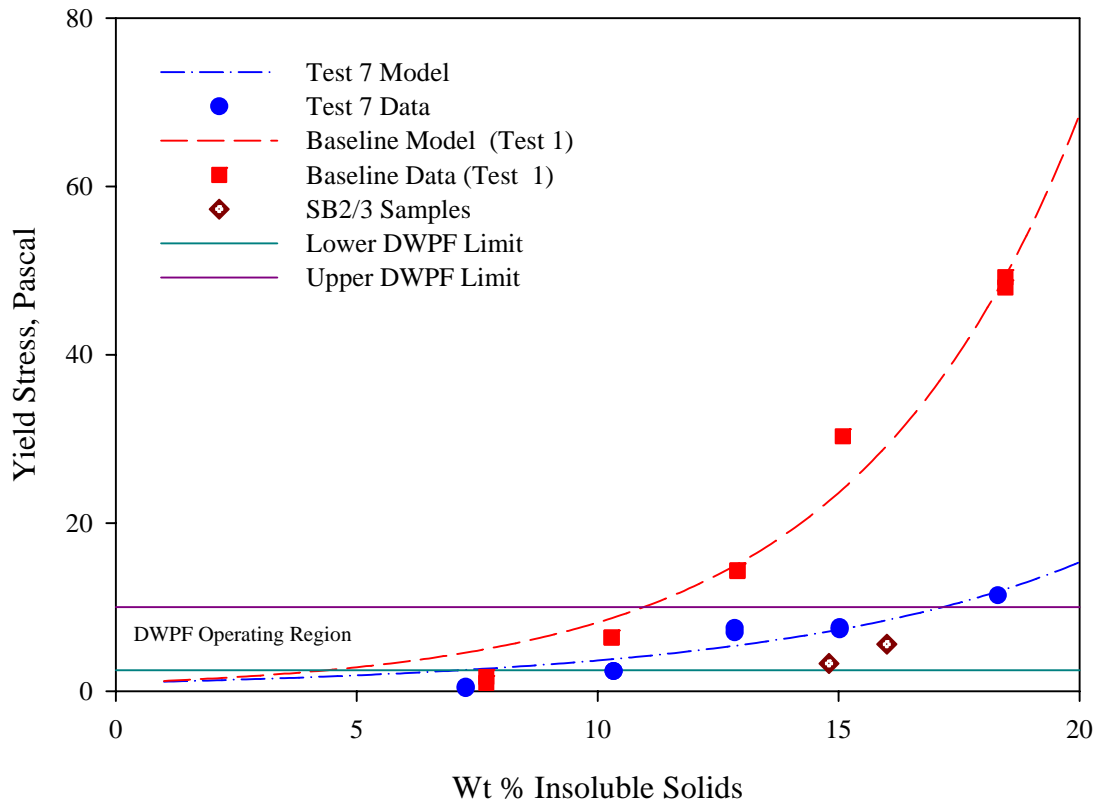

Figure 3-45 Impact of Precipitating All Metals on Yield Stress by Comparison of Test 1 and Test 7 Simulants

The consistency data for the all metals precipitated simulant (Test 7) indicates that the rate of change of the apparent viscosity as a function of shear is greater than that observed for the baseline sludge. The consistencies of all of the test simulants are much greater than that measured for the actual waste. These results suggest that the composition or surface characteristics of the sludge particles have a greater influence on the simulant rheology than the relative narrowness of the particle size distribution. In the all metals precipitated case it appears that the addition of aluminum to the precipitating mixture dilutes the impact of yield stress as a function of insoluble solids and more nearly matches the rheology properties of the actual waste. One conclusion of the sequence of addition tests is that compositional impacts are probably most significant in the interaction between waste particles and that future tests should try to determine which waste species are the most important in terms of their impact on waste rheology. 
WSRC-TR-2004-00578

Revision 0

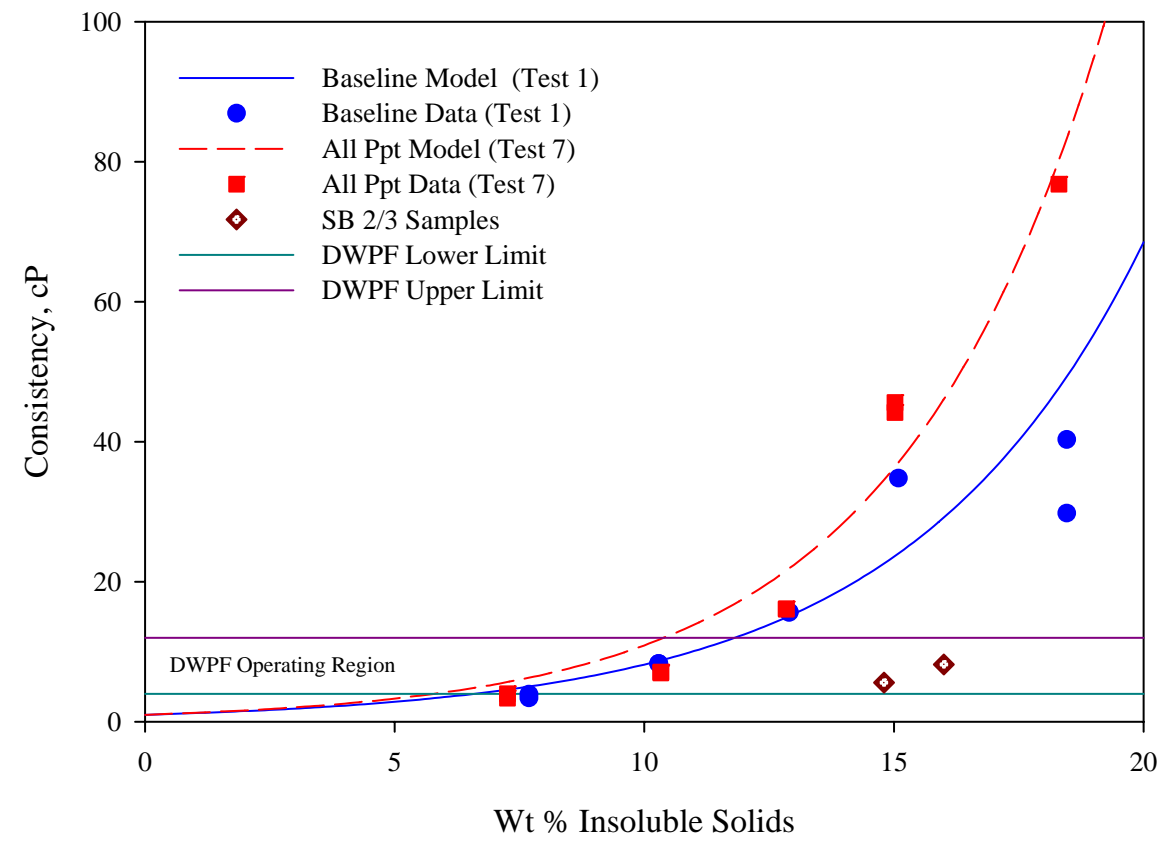

Figure 3-46 Impact of Precipitating All Metals on Consistency by Comparing Test 7 and Test 1 Simulants

\subsection{Impact of the Heat Treatment}

The application of a heat treatment step in the production of a sludge simulant directly modifies the insoluble particles in the sludge. A comparison of when to apply heat treatment based on the results of the particle size volume distribution (Figure 3-47) indicates that the heat treatment before washing (Test 4) produces the smaller particle size simulant. 
WSRC-TR-2004-00578

Revision 0

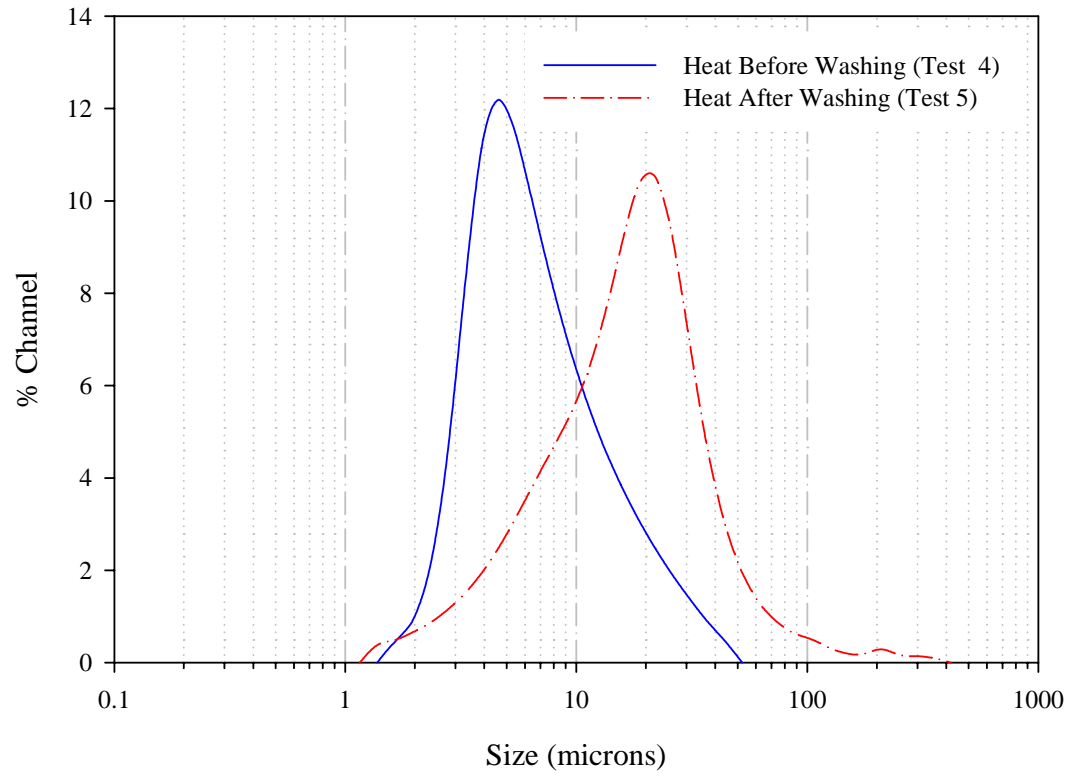

Figure 3-47 Heat Treatment (Before or After Washing) and Particle Size Volume Distribution

The particle size number distribution comparison gives a different perspective on the impact of heat treating before washing the precipitate. Figure 3-48 shows that heat treating after washing produces a distribution based on the number of particles that is weighted toward the smallest particle and this distribution is typical of a precipitated sludge. The number distribution for the simulant that was heat treated before washing shows a completely different pattern of particle sizes. Instead of being weighted by a large number of the smallest particles, it indicates that the most numerous particles are those nearest the average particle size. If actual waste particle size distribution information were available then a decision could be made between the two methods for best matching the actual waste.

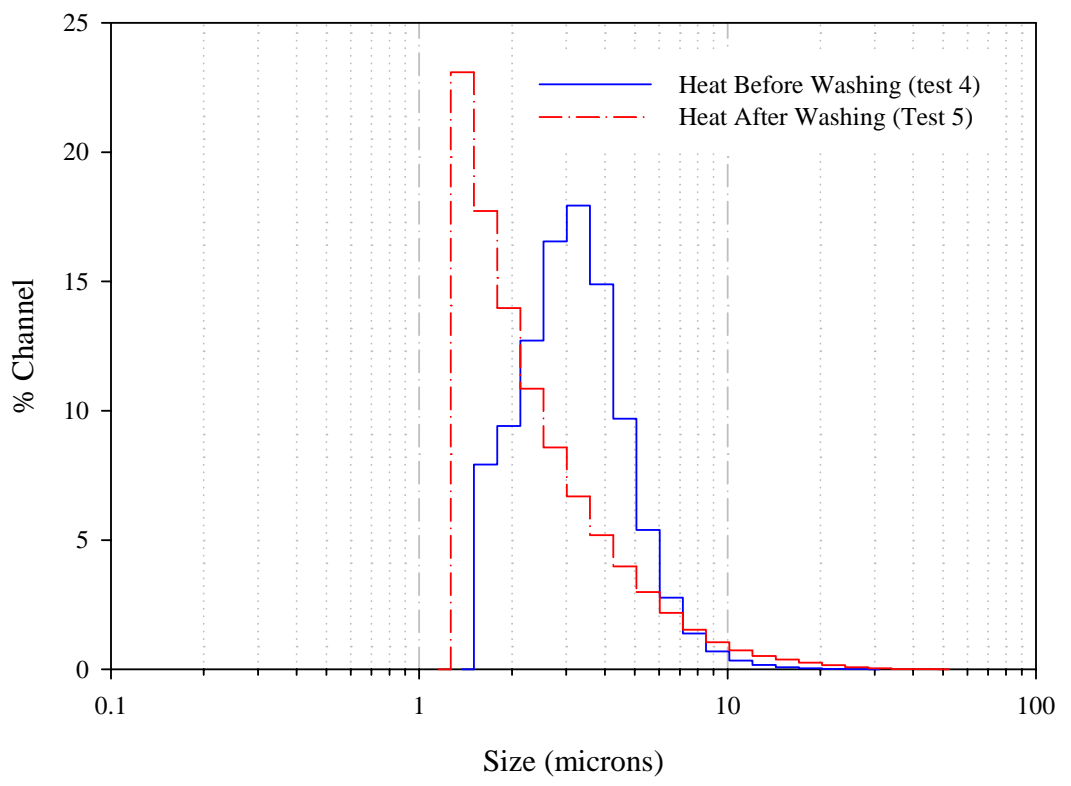

Figure 3-48 Heat Treatment (Before or After Washing) and Particle Size Number Distribution 
The rheology comparisons between the two methods of heat treatment do not show much difference between the methods. Figure 3-49 and Figure 3-50 compare the yield stress versus wt \% IS relationship and the consistency versus wt \% IS relationship for both methods and the baseline method of producing the Sludge Batch 3 simulant. There is no significant difference in the yield stress and the possible differences seen in the consistency curve is due to a single data point at the highest wt \% IS. The heat treatment steps performed for these tests (4 and 5) did not significantly modify the rheology properties of these simulants. This lack of rheology impact could be due to the limited time of heat treatment compared to the much longer times experienced in the Tank Farm (hours versus years).

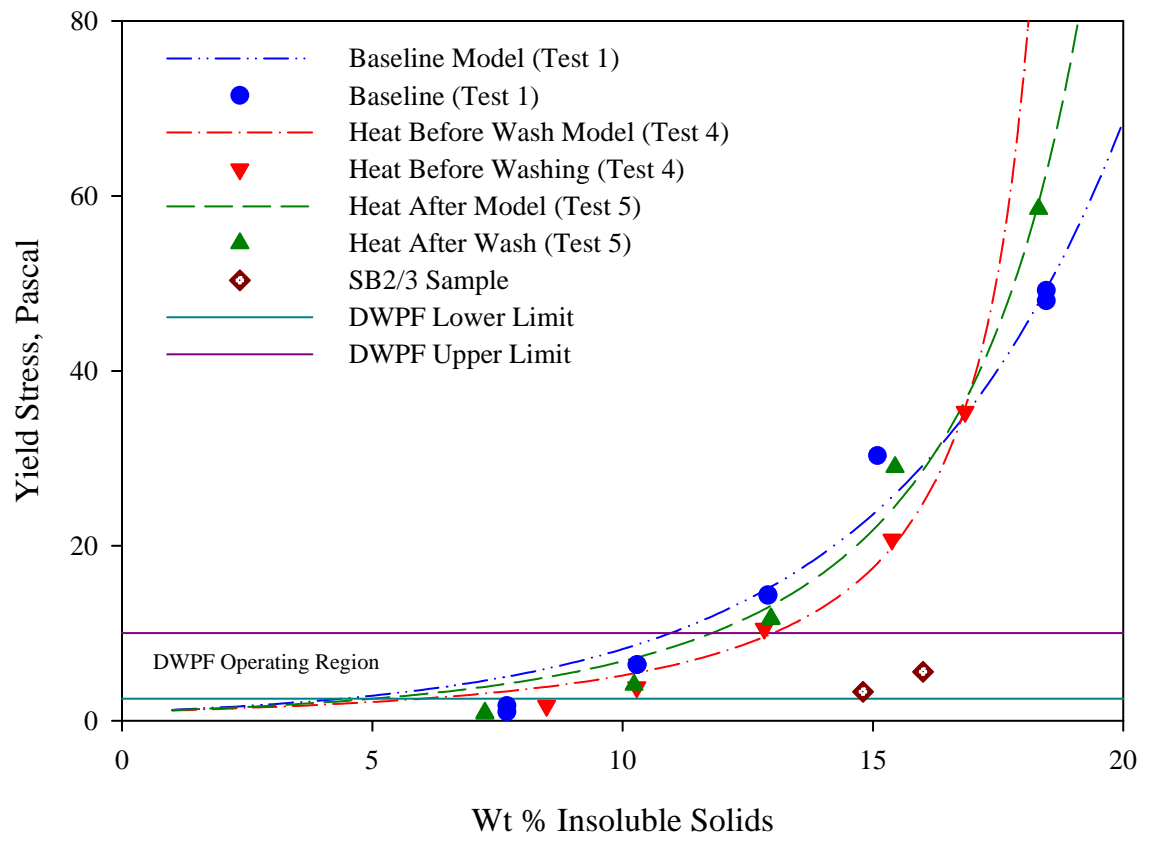

Figure 3-49 Heat Treatment and Yield Stress 
WSRC-TR-2004-00578

Revision 0

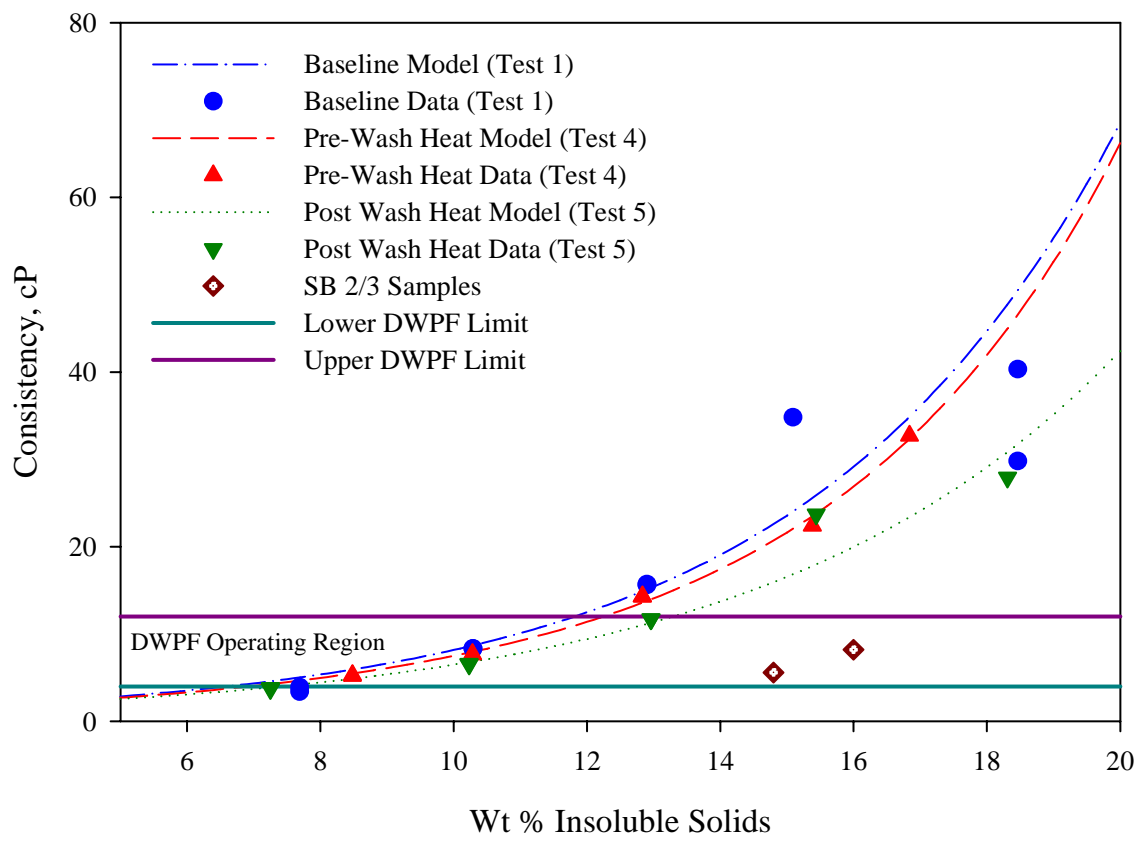

Figure 3-50 Consistency and Heat Treatment Methods

Test 8 combined the heat treatment after washing procedure with the all metals precipitated procedure to see if there was an improvement in the simulant rheological properties. Figure 3-51 shows a slight shift in the yield stress relationship toward the actual waste data. Since the data shows some scatter, this shift may not be significant. Figure 3-52 shows a more significant change in the consistency versus wt \% IS relationship that is a definite improvement toward the actual waste consistency data. In general, the combination of all metals precipitated and heat treatment after washing produced a simulant that is the closest to reproducing the rheology of the actual waste. 


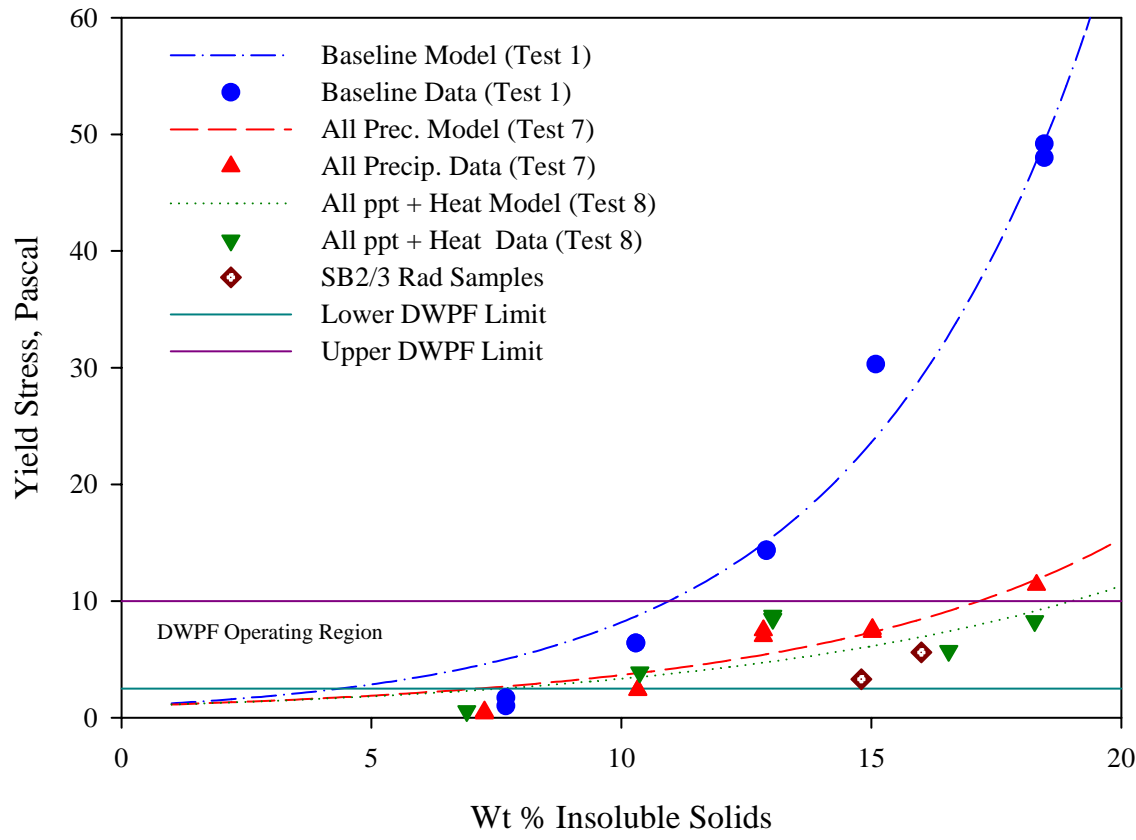

Figure 3-51 Combining Heat Treatment and All Metals Precipitated Versus Yield Stress

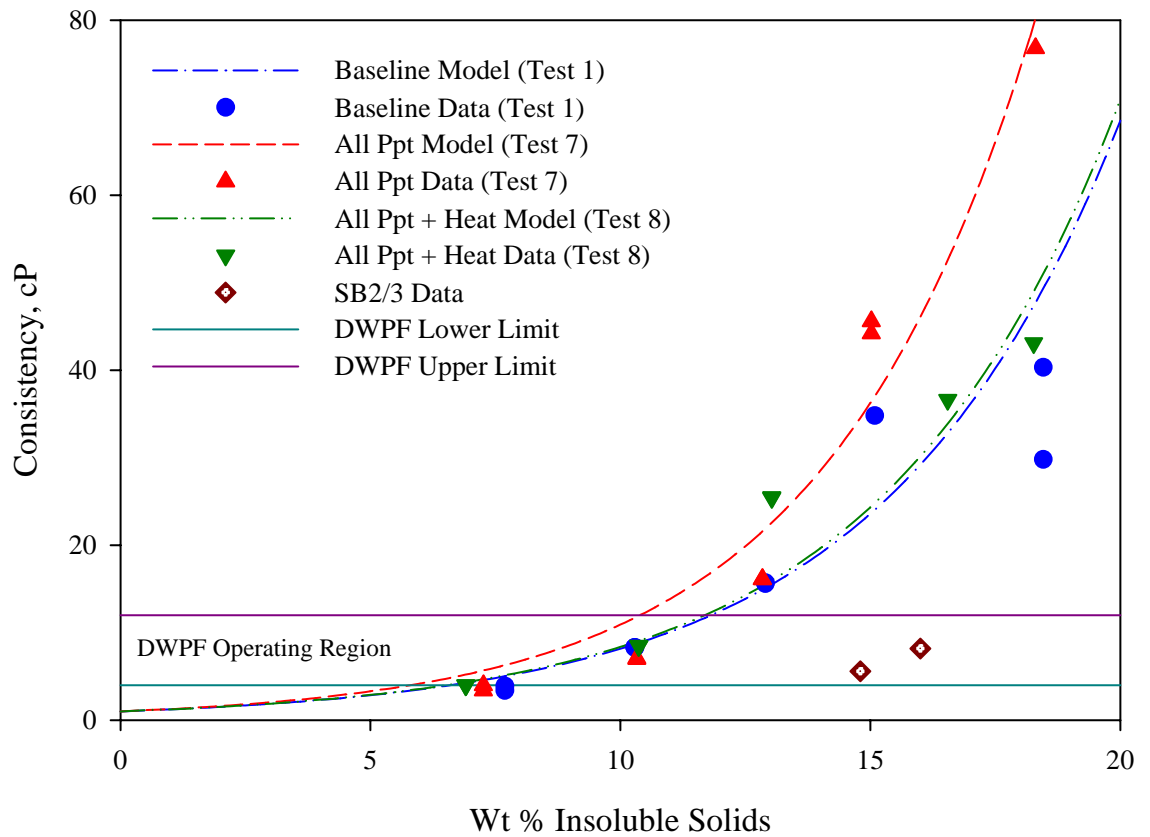

Figure 3-52 All Metals Precipitated Plus Heat Treated and Consistency

\subsection{The Impact of Shear}

The impact of increased shear during simulant preparation was expected to produce simulants with smaller particle sizes. Based upon experience with shearing existing simulants, addition of higher levels 
of shear was also expected to produce sludge simulants that were more viscous. The impact of shear on the average particle size is summarized in Table 3-24. The size based on volume distribution shows a significant reduction and is reflected in the graph of the particle size volume distribution (Figure 3-53). The number distribution value indicates only a small reduction as is seen in Figure 3-54. The average size based on area provides the best basis for ranking the tests.

Table 3-24 Comparison of Average Particle Size Data for the Tests that Examined Shear

\begin{tabular}{|c|c|c|c|c|}
\hline \multirow{2}{*}{ Method } & \multicolumn{3}{|c|}{ Average Size, microns } & \multirow{2}{*}{$\begin{array}{c}\text { CSSA, } \\
\mathbf{m}^{2} / \mathbf{c m}^{\mathbf{3}}\end{array}$} \\
\cline { 2 - 4 } & Volume & Number & Area & 1.2 \\
\hline Test 1 & 33.8 & 0.75 & 5 & 2.3 \\
\hline Test 2 & 13.7 & 0.6 & 2.7 & 5.2 \\
\hline Test 3 & 3.1 & 0.6 & 1.2 & \\
\hline
\end{tabular}

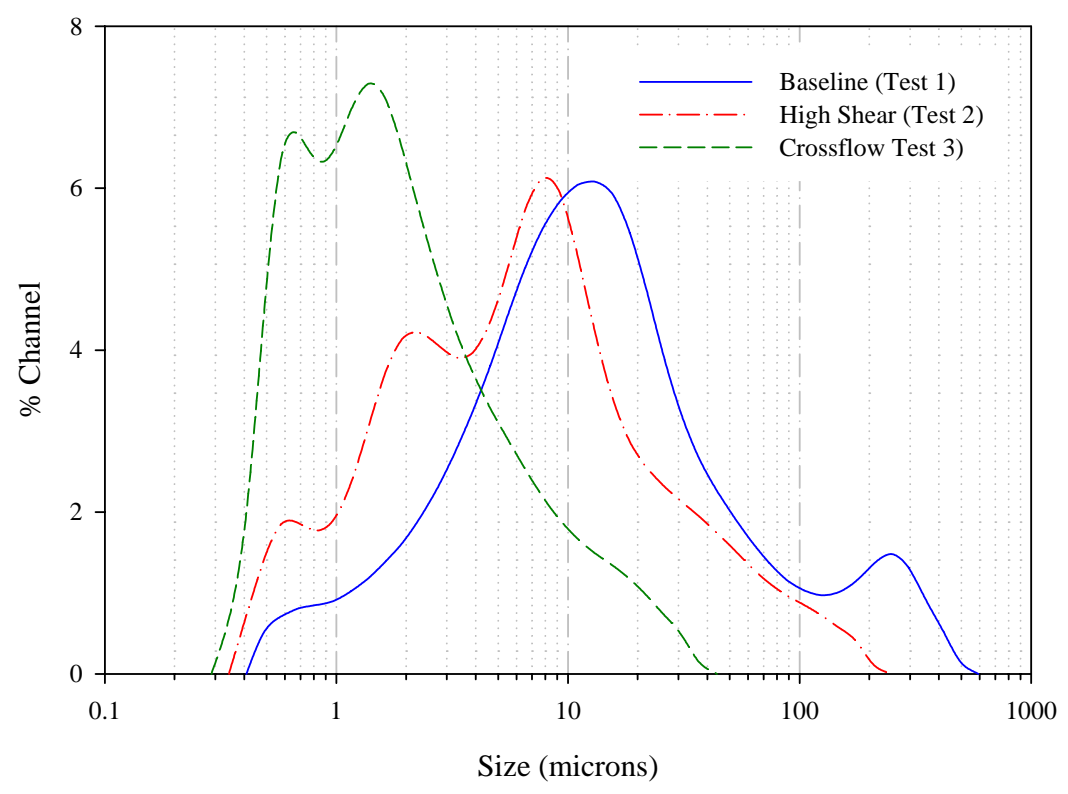

Figure 3-53 Comparison of Shearing Method versus Particle Size Volume Distribution 
WSRC-TR-2004-00578

Revision 0

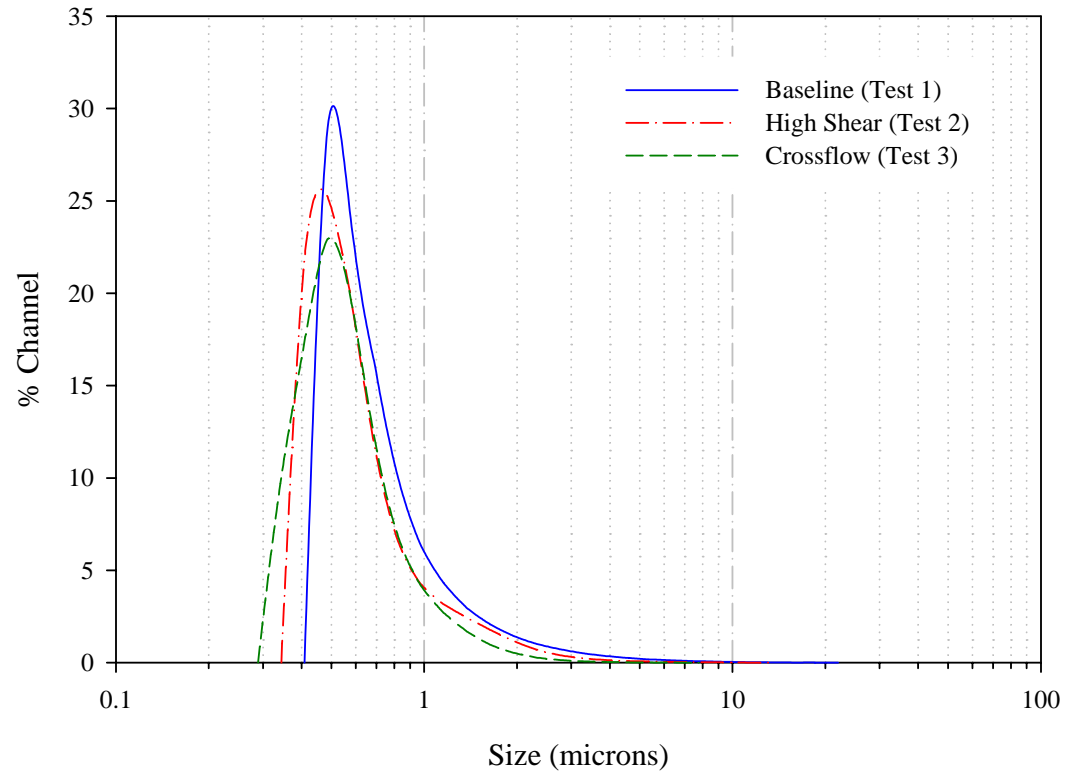

Figure 3-54 Comparison of Shear Method versus Particle Size Number Distribution

The impact of shear during sludge preparation of the product rheology is displayed in Figure 3-55 and Figure 3-56. The sludges that had the smallest particle size because of the application of shear were the thickest simulants produced in this testing. The yield stress versus wt \% insoluble solids curve rises very steeply while consistency is less strongly influenced by the particle size. Attempts were made to evaluate the data as a three dimensional surface but more data would be needed to better define the surface.

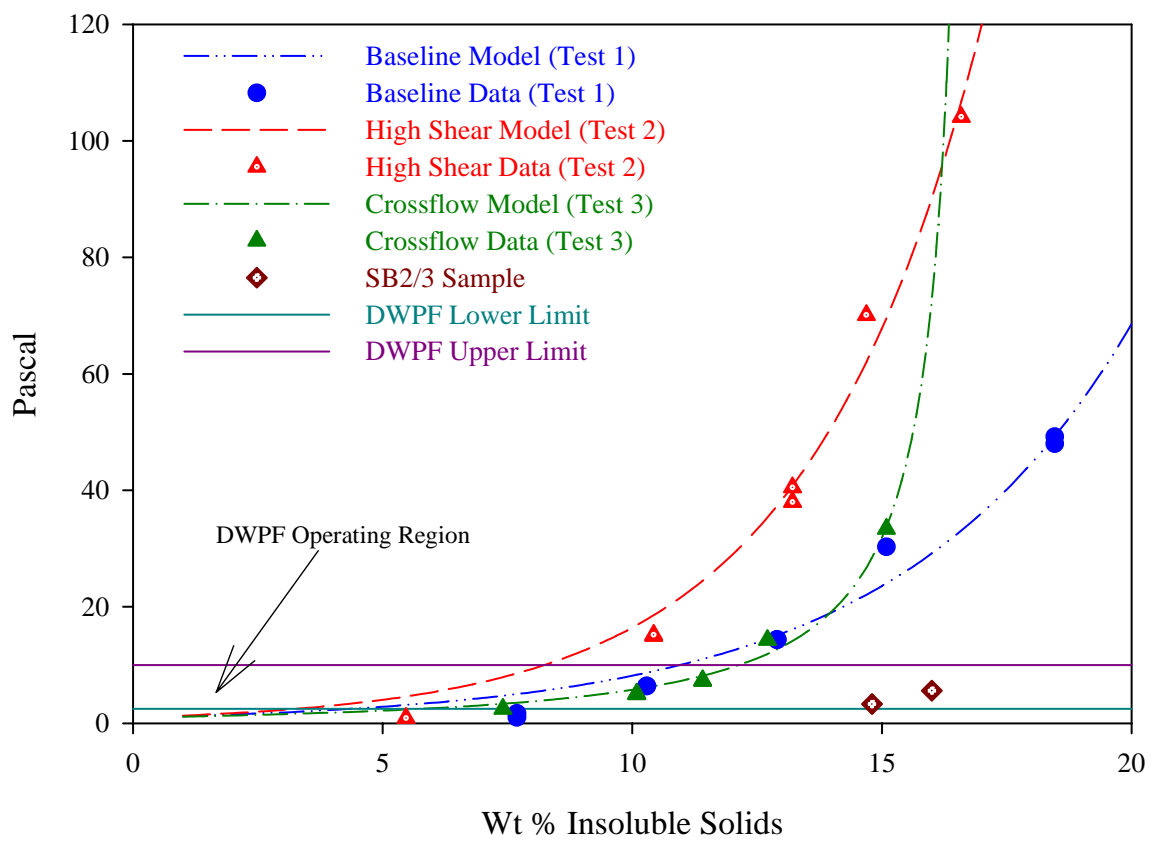

Figure 3-55 Impact of the Shearing Method on Yield Stress 
WSRC-TR-2004-00578

Revision 0

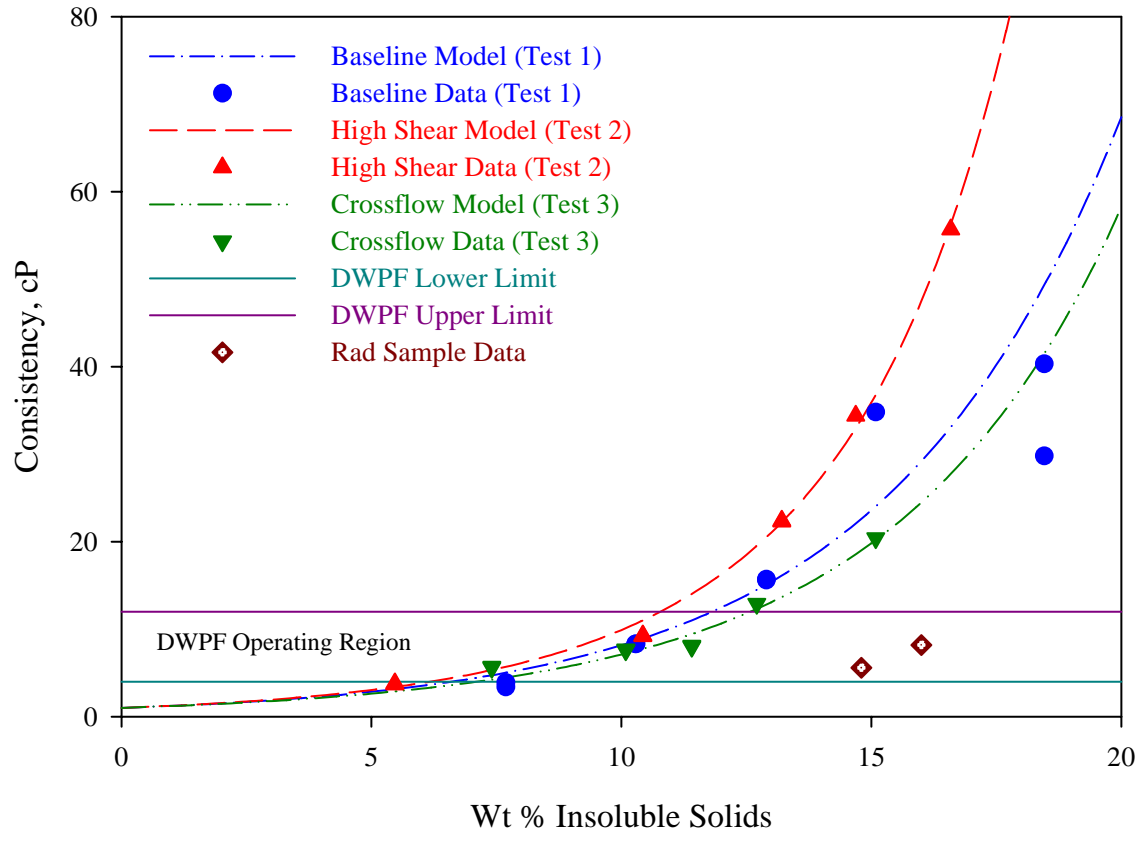

Figure 3-56 Comparison of Shear Methods and Impact on Consistency 


\subsection{CONCLUSIONS}

The limited testing performed as part of this program demonstrated that many factors influence the physical properties of a sludge simulant. Factors such as order of chemical addition, mixing (shear) rates and temperature have been shown to modify the rheology of simulant sludge batches that were compositionally the same. As a result of these tests, the following conclusions were made:

- Precipitating as many species as possible ( $\mathrm{Al}, \mathrm{Fe}, \mathrm{Ca}$, etc.) and heat treating the washed sludge produces a product which nearly matches actual waste yield stress but not consistency. This is the best method for producing a DWPF sludge simulant based upon current testing.

- Inclusion of metals in $\mathrm{MnO}_{2}$ production impacts rheology.

- Precipitation of $\mathrm{Al}$ with the other metals appears to dilute the simulant based on the change in rheology.

- Heat treatment narrows the particle size distribution but has less impact on the rheology of the sludge simulant.

- Heat treatment after precipitation, but before washing, significantly alters the particle size distribution.

- Shear has a large impact on particle size and on rheology.

- Compositional changes may have the strongest impact on sludge rheology.

- All eight simulants prepared in this study were rheologically conservative (yield stress and consistency greater than) compared to actual waste. Previous simulants were not necessarily conservative based upon rheology. ${ }^{14}$

This document also provides insight in helping assist in the development of future simulants, where the actual waste stream rheological properties could be much different that that of the SB3 sludge. 
WSRC-TR-2004-00578

Revision 0

This page intentionally left blank. 


\subsection{RECOMMENDATIONS/PATH FORWARD}

The results of the current sludge preparation study indicate that there are many methods of modifying the physical properties of a DWPF sludge simulant. Additional studies are recommended to improve our understanding of the important properties (chemical and physical) of DWPF sludges.

- Measure the impact of solids concentration on actual DWPF feed rheology to provide a better basis for comparison with potential simulants.

- Actual waste particle size information is needed to guide the application of heat treatment or of shear in preparing sludge simulants.

- Heat treatment time/temperature need to be studied since this study only examined one temperature and one time.

- Test all metals precipitated then heat treated followed by crossflow filter washed.

- Test all metals precipitated then crossflow filter washed followed by heat treatment.

- Vary levels of Fe, Al, Ni, etc. to study compositional impact on physical properties.

- Apply the DWPF chemical processes to the modified simulants to determine if the property changes remain a factor further into the facility.

- Irradiate a sludge simulant to determine if radiation has any impact on the physical properties of the sludge. 
WSRC-TR-2004-00578

Revision 0

This page intentionally left blank. 


\subsection{REFERENCES}

1. Fowler, J. R., Carter, J. T., Landon, L.F., Marek, J. C., and C. L. Pearson. Development of Feed Simulant Specifications for Integrated Cold Runs in the Defense Waste Processing Facility (U). WSRC-RP-89-238, Savannah River Site, Aiken SC 29808 (July 1989).

2. Orr, C. Jr. and J. M. Dallavalle. Fine Particle Measurement Size, Surface and Pore Volume. p. 2, The MacMillan Company, New York, NY Second Edition (1960).

3. Pareizs, J. M., Fellinger, T. L. and D. R. Click. Characterization of the March 2004 Yank 40 (Sludge Batch 3) Dip Samples. WSRC-TR-2004-00208, Savannah River Technology Center, Aiken SC 29808 (May 2004)

4. The Transportation of Solids in Steel Pipelines. Colorado School of Mines Research Foundation, Inc., Golden, CO (1963).

5. Shook, C. A. and M. C. Roco. Slurry Flow Principles and Practice. p. 62, ButterworthHeinemann, Boston, MA (1991).

6. Krieger, I. M., "Rheology of Monodisperse Lattices”. Advances Colloid Interface Science 3, (1972).

7. Marek, J. C., Preliminary Melter Feed Rheology Study (U). WSRC-RP-92-1240, Savannah River Site, Aiken SC 29808 (October 21, 1992).

8. Marek, J. C., Rheology of SME Product from Alternative Sludge-Only Flowsheet with Batch One Sludge Simulant (U). WSRC-TR-96-0179, Savannah River Site, Aiken SC 29808 (June 26, 1996).

9. Bannochie, C. J., Pareizs, J. M. and D. C. Koopman, Sludge Batch 2/3 Blend SRAT Cycle in the SRNL Shielded Cells. WSRC-TR-2004-00097, Rev. 0, Savannah River Site, Aiken SC 29808 (May 2004).

10. Shook, C. A. and M. C. Roco. Slurry Flow Principles and Practice. p. 64, ButterworthHeinemann, Boston, MA (1991).

11. Kennedy, C., Smith, C. S., and L. A. Warren. "Surface chemistry and relative Ni sorptive capacities of synthetic hydrous Mn oxyhydroxides under variable wetting and drying regimes". Geochimica et Cosmochimica Acta 68, pp 443-454 (2004).

12. Perez-Benito, J. F., “Coagulation of colloidal manganese dioxide by divalent cations”. Colloids and Surfaces A: Physicochemical Engineering Aspects 225, pp 143-145 (2003).

13. Technical Data Summary for the Defense Waste Processing Facility Sludge Plant, DPSTD80-38-2, Part 3, Item 400-405 Rev.1, Savannah River Site, Aiken, SC 29808 (September 1982).

14. Koopman, D. C., A Comparison of Rheology Data for Radioactive and Simulant Savannah River Site Waste (U). WSRC-TR-2004-00044, Rev. 0, Savannah River Site, Aiken SC 29808 (March 2004). 


\subsection{ACKNOWLEDGEMENTS}

I would like to acknowledge the assistance of Mark Baich of the Immobilization Technology section in operation of the crossflow filter system, Jon Duvall, Debbie March and Vickie Williams for assistance in preparation and measurement of the properties of the simulants. 
WSRC-TR-2004-00578

Revision 0

APPENDIX A. PARTICLE SIZE DATA FOR INSOLUBLE RAW MATERIALS 
WSRC-TR-2004-00578

Revision 0

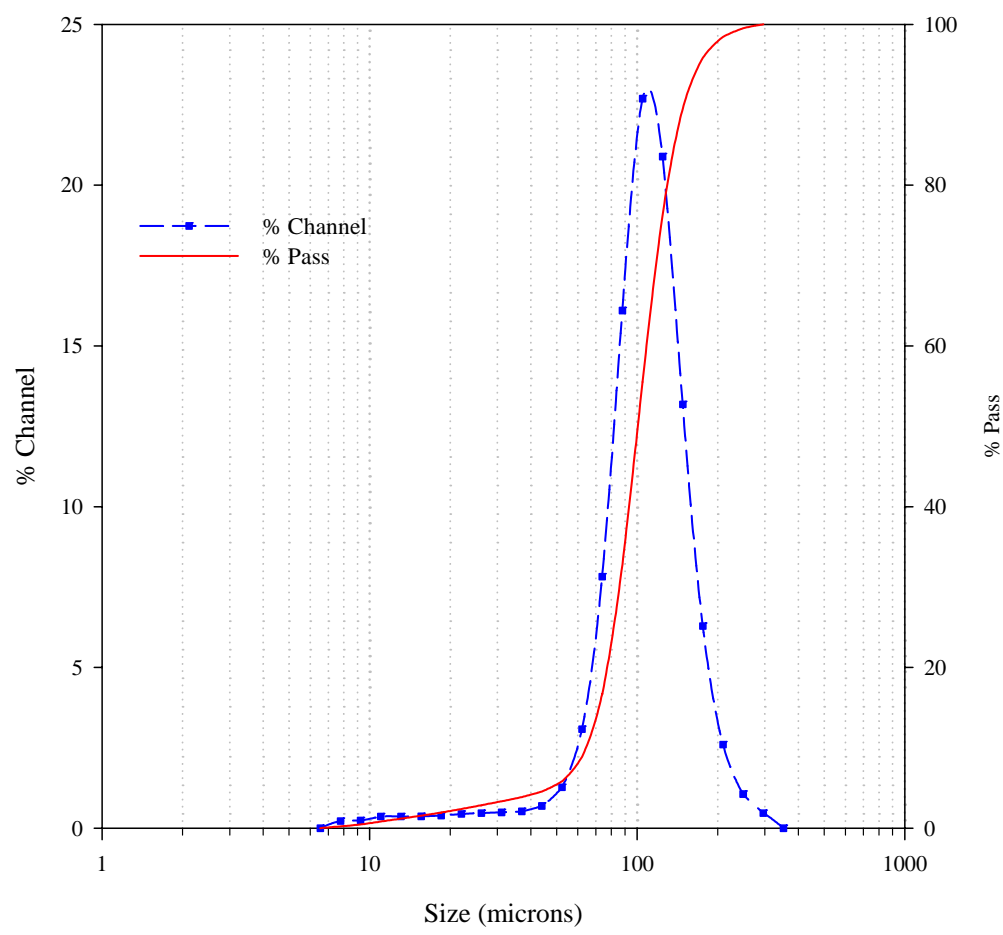

Figure A- 1 Alumina Particle Size Distribution (Volume Basis)

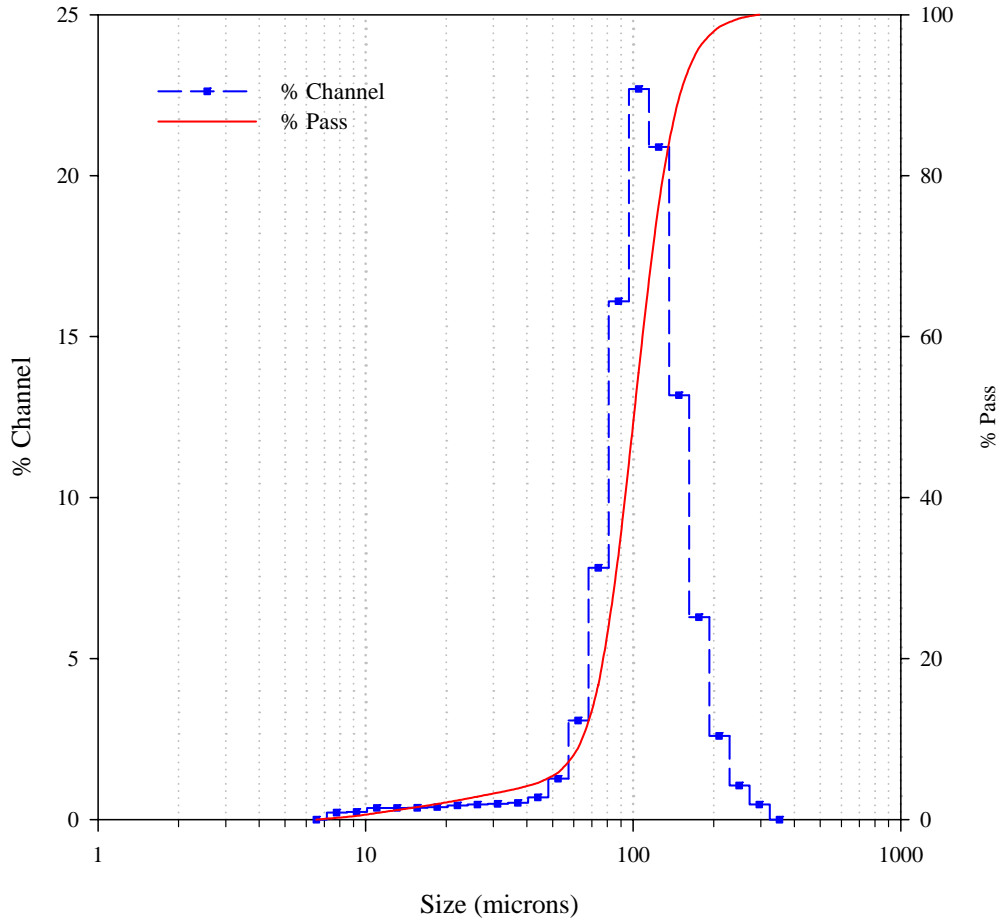

Figure A- 2 Alumina Particle Size Distribution (Number Basis) 
WSRC-TR-2004-00578

Revision 0

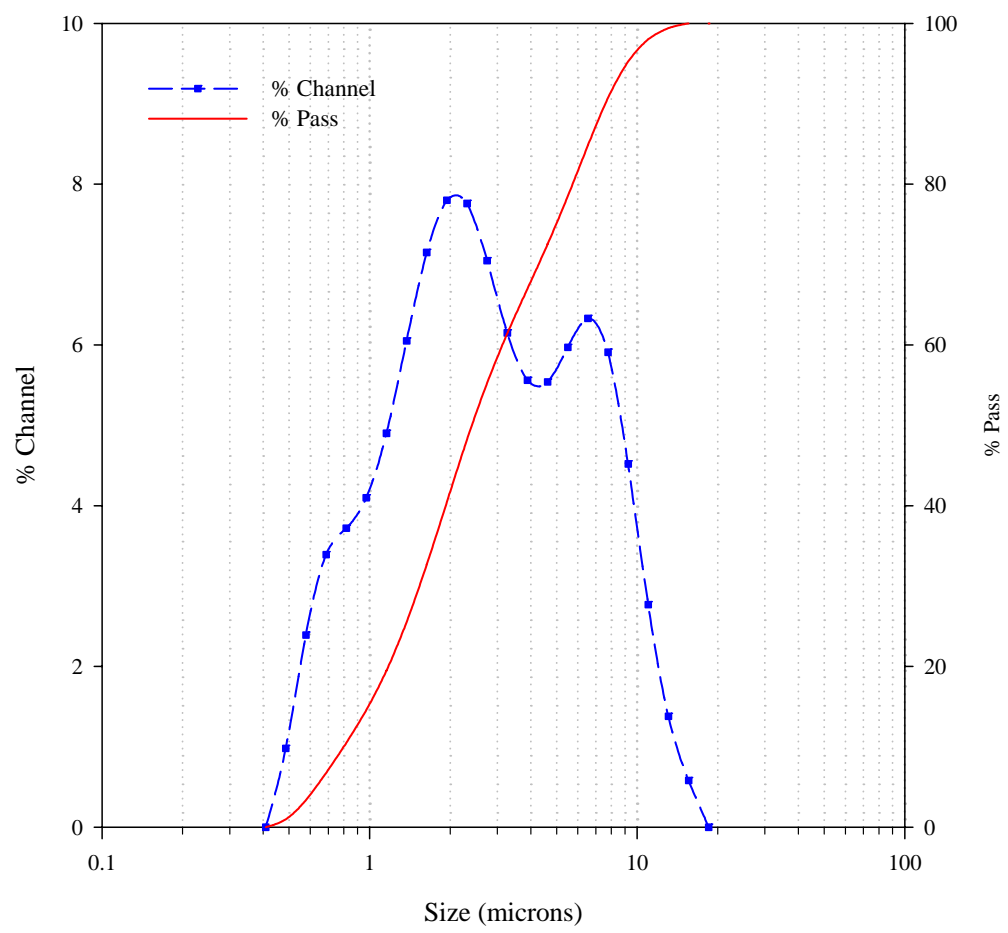

Figure A- 3 Silica Particle Size Distribution (Volume Basis)

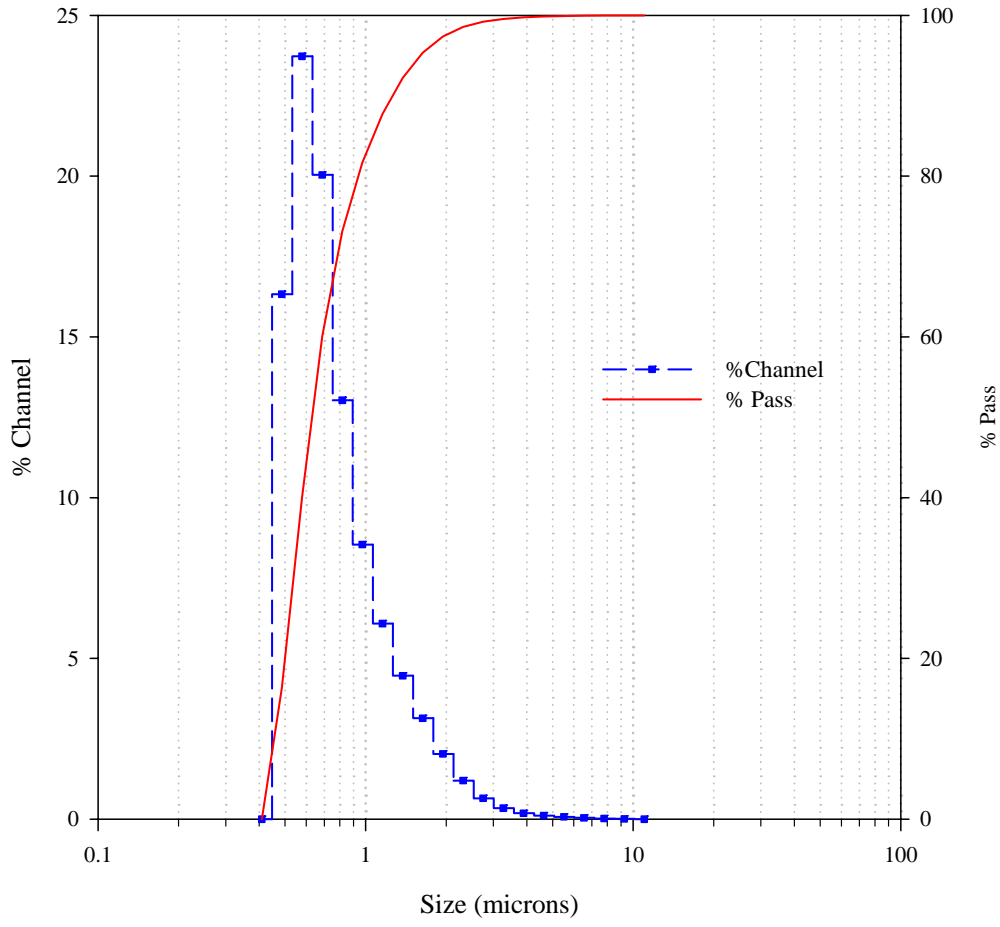

Figure A- 4 Silica Particle Size Data (Number Basis) 
WSRC-TR-2004-00578

Revision 0

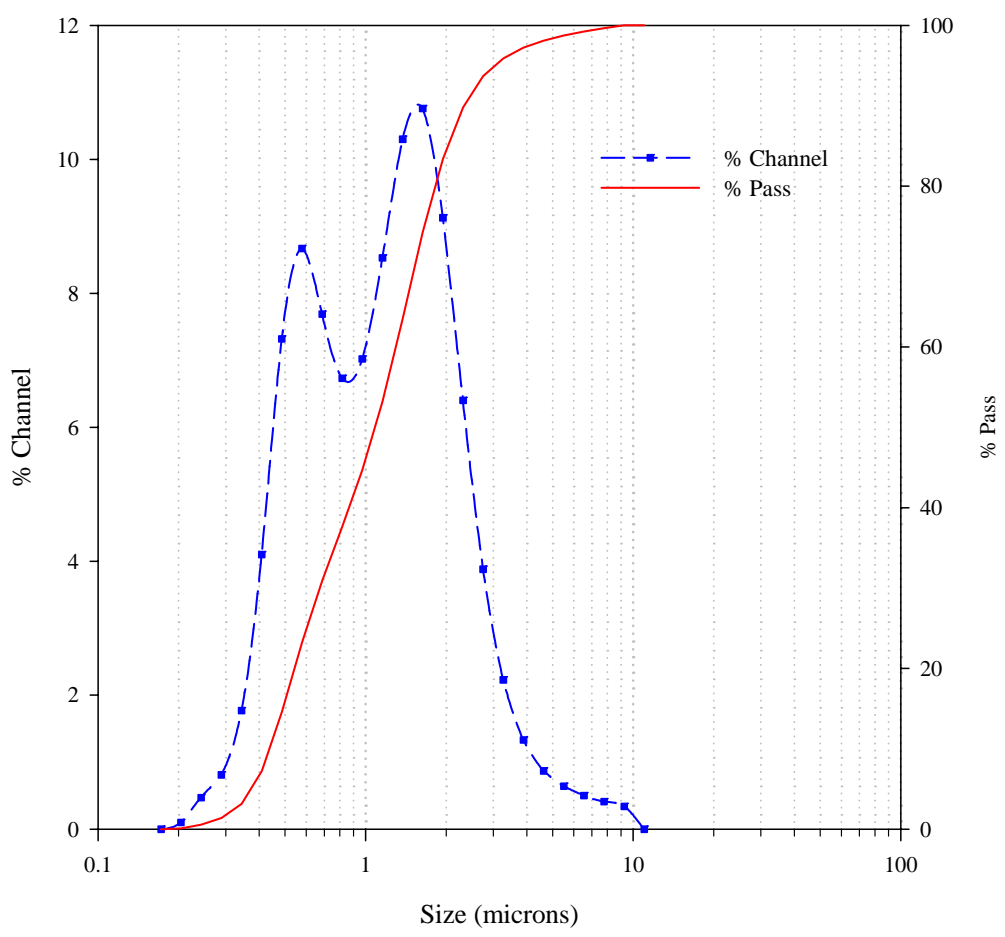

Figure A- 5 Tin Dioxide, $\mathrm{SnO}_{2}$, Particle Size Data (Volume Basis)

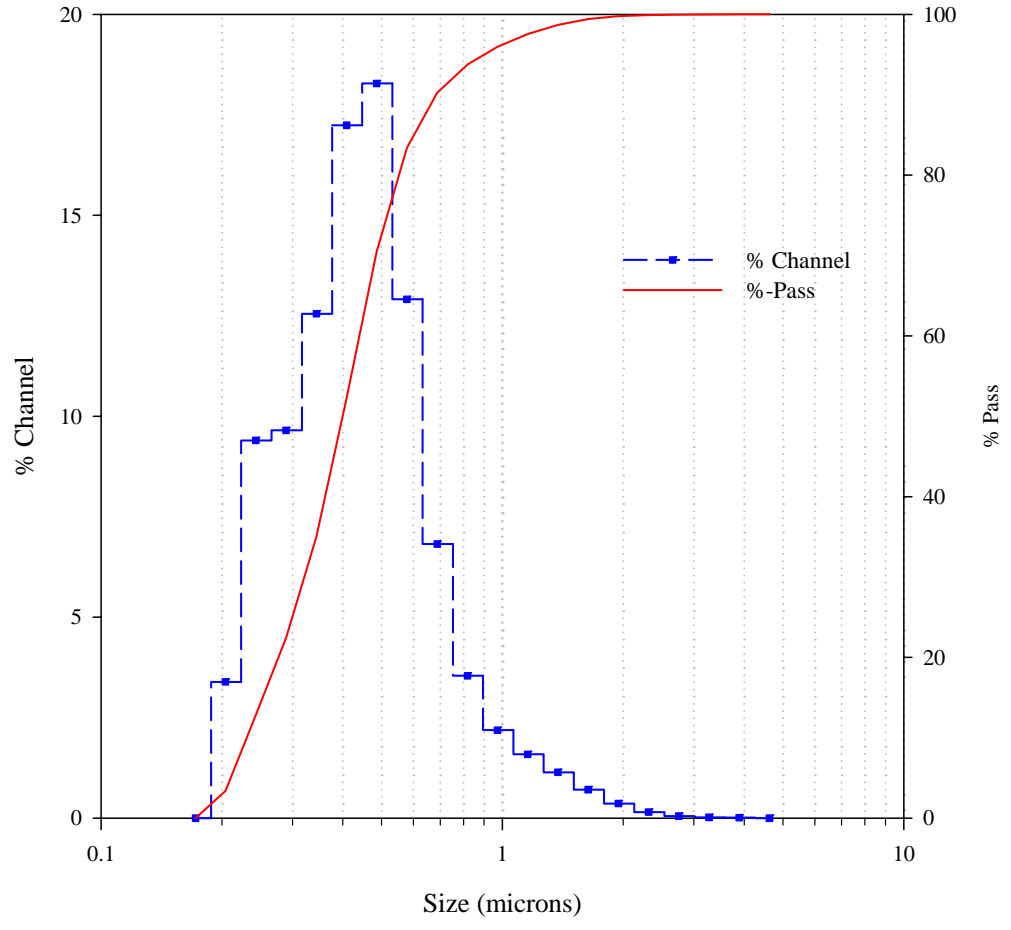

Figure A- 6 Tin Dioxide, $\mathrm{SnO}_{2}$, Particle Size Data (Number Basis) 
WSRC-TR-2004-00578

Revision 0

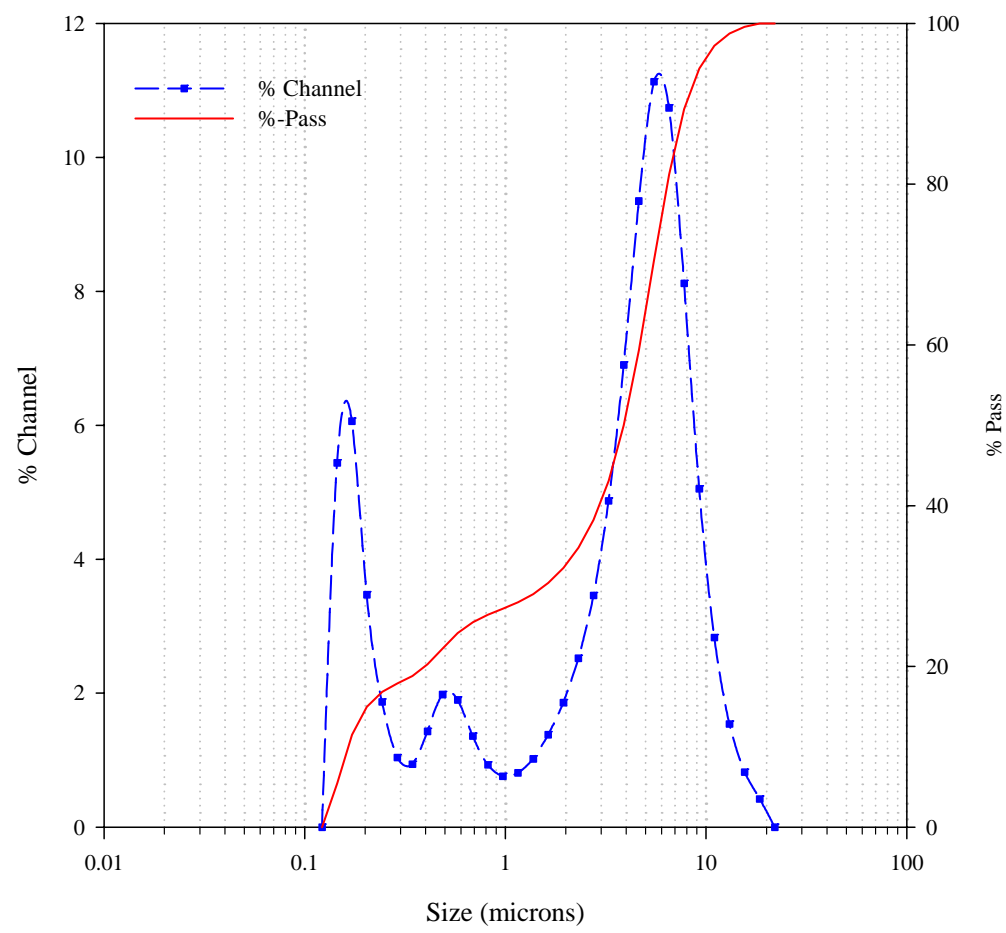

Figure A- 7 Titanium Dioxide, $\mathrm{TiO}_{2}$, Particle Size Data (Volume Basis)

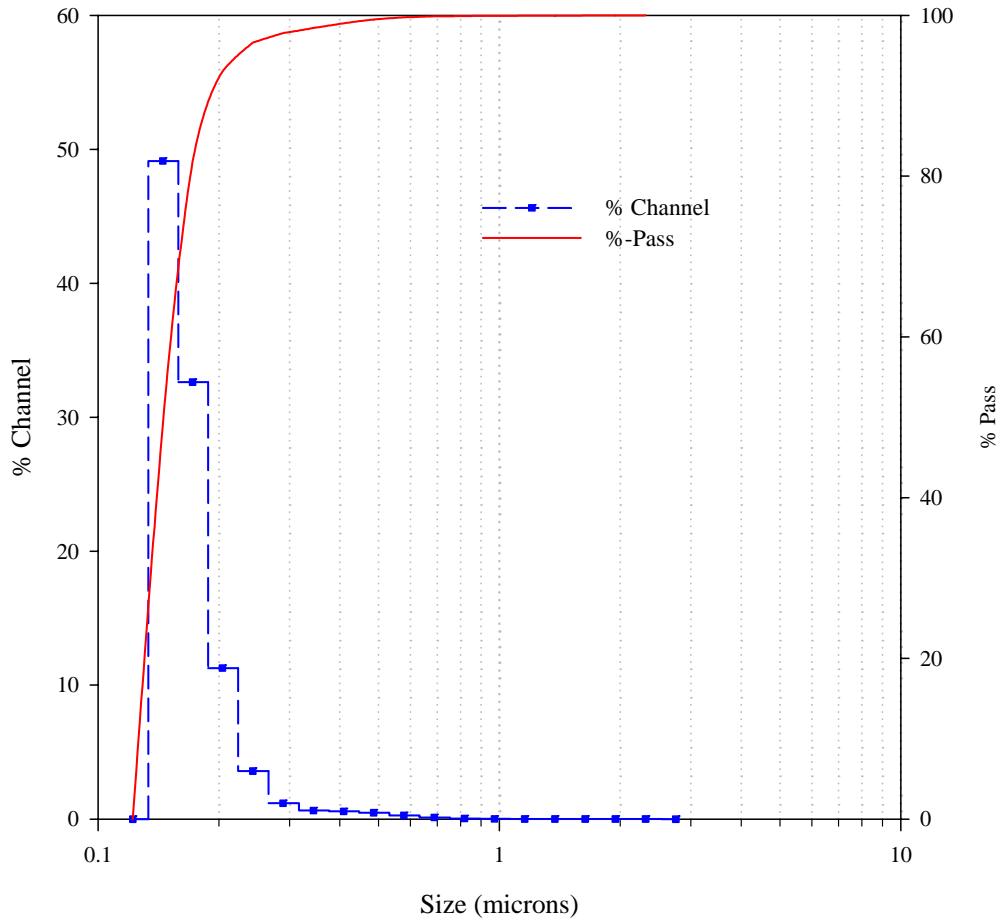

Figure A- 8 Titanium Dioxide, $\mathrm{TiO}_{2}$, Particle Size Data (Number Basis) 